UNIVERSIDADE DE BRASÍLIA INSTITUTO DE BIOLOGIA

PROGRAMA DE PÓS-GRADUAÇÃO

EM NANOCIÊNCIA E NANOBIOTECNOLOGIA

PRODUÇÃO E CARACTERIZAÇÃO DE MONOCRISTAIS DE ÓXIDOS DE FERRO COM MORFOLOGIA DE NANOANÉIS

DISSERTAÇÃO DE MESTRADO

GRAZIELE SILVA PEREIRA

BRASÍLIA - DF 2016 
PROGRAMA DE PÓS-GRADUAÇÃO

EM NANOCIÊNCIA E NANOBIOTECNOLOGIA

\title{
PRODUÇÃO E CARACTERIZAÇÃO DE MONOCRISTAIS DE ÓXIDOS DE FERRO COM MORFOLOGIA DE NANOANÉIS
}

Dissertação de mestrado apresentada ao programa de Pós-Graduação em Nanociência e Nanobiotecnologia, da Universidade de Brasília, como parte dos requisitos para a obtenção do título de Mestre em Nanociência e Nanobiotecnologia.

Autora: Graziele Silva Pereira

Orientador: Prof. Dr. Sebastião William da Silva

Co-orientadora: Prof. Dra. Emília Celma de Oliveira Lima

\author{
BRASÍLIA - DF
}


Dissertação de Mestrado

Graziele Silva Pereira

Título:

\title{
${ }^{66}$ PRODUÇÃO E CARACTERIZAÇÃO DE MONOCRISTAIS DE ÓXIDOS DE FERRO COM MORFOLOGIA DE NANOANÉIS"
}

Comissão Examinadora:

\author{
$200 \ln -\frac{-}{2}$ \\ Prof. Dr. Sebastiao William da Silva \\ Presidente \\ $P P G / N A N O-U n B$
}
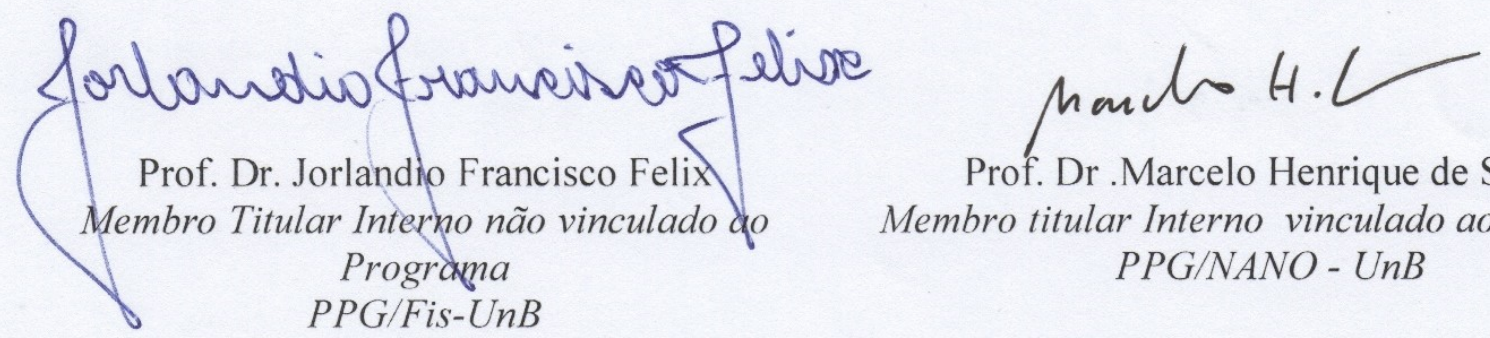

Prof. Dr.Marcelo Henrique de Sousa Membro titular Interno vinculado ao programa $P P G / N A N O-U n B$

PPG/Fis-UnB 
Talvez não tenha conseguido fazer o melhor, mas lutei para que o melhor fosse feito.

Não sou o que deveria ser, mas Graças a Deus, não sou o que era antes". (Marthin Luther King) 
Dedico esse trabalho a toda minha família.

Em especial ao meu marido e companheiro Thiago Lopes,

aos meu pais Luís e Maria José

e as minhas irmãs Olívia e Eliane. 


\section{Agradecimentos}

Agradeço a Deus, pela vida, sabedoria e força que ele me concedeu. A Nossa Senhora por toda a proteção e interseção por toda a minha caminhada.

Agradeço ao meu orientador Prof. Dr. Sebastião William da Silva pela orientação, paciência, por todas as discussões, disposição e ensinamentos que tornaram possível este trabalho.

Ao meu marido, Thiago Lopes, por todo o apoio, paciência, atenção, suporte e por ser essa pessoa maravilhosa em minha vida. Te amo!

Aos meus pais, Luís e Maria José, e minhas irmãs Olívia e Eliane por todo apoio e incentivo durante toda a minha jornada, pois nunca deixaram de me apoiar e incentivar para que assim eu alcançasse meus objetivos. Amo vocês! Aos meus cunhados e meu sobrinho Marcos Antônio, por todos os momentos de descontração.

A Prof. Dra. Emília Celma de Oliveira, pela co-orientação nos auxiliando na produção dos nanoanéis.

A Queila por toda ajuda, paciência e companheirismo. A Lizbet e o Marcos que muito me auxiliaram quando precisei fazer uso do módulo 10 e ao Tiago por toda ajuda nas medidas de DRX.

Aos amigos do laboratório que fazem de lá um ótimo ambiente de trabalho, Ísis, Lucélia, Camila Letti, Antônia, Hermano, Paulo, Manu e Deize.

A todos os membros do LMSC por sempre me oferecerem um local para estudos, bate-papo, troca de ideias. Obrigado por tornar os meus dias bem melhores. 
Ao meu amigo Wagner por todo companheirismo nas disciplinas e por todas as conversas e trocas de ideias. A minha amiga de infância Larizza que mesmo com a distância sempre que possível se faz presente.

Ao professor Marcelo Henrique e o Marcelão por toda disposição e ajuda no laboratório de química, pelas broncas e ensinamentos.

Ao professor Coaquira e John, pelas medidas de magnetização e troca de conhecimentos. Aos professores Aderbal e Garg pelas medidas de Mössbauer.

A CAPES pela concessão da bolsa de estudos. 


\section{Lista de Abreviaturas e Acrônicos}

nm - nanômetro

NP's - Nanopartículas

NA - Nanoanéis

MEV - Microscopia Eletrônica de Varredura

MET - Microscopia Eletrônica de Transmissão

HRTEM - Microscopia Eletrônica de Transmissão de Alta Resolução

DRX - Difração de raios X

$\mathrm{T}_{\mathrm{C}}-$ Temperatura de Curie

$\mu$ - Momento magnético

$\mu_{\text {at }}$ - momento magnético atômico

$\mathrm{N}$ - Número de átomos magnéticos

$\alpha-\mathrm{Fe}_{2} \mathrm{O}_{3}-$ Hematita

$\mathrm{Fe}_{3} \mathrm{O}_{4}$-Magnetita

$\mathrm{Fe}^{3+}$ - Cátion trivalente de ferro

$\mathrm{Fe}^{2+}$ - Cátion bivalente de ferro

$O^{2-}$ - Ânion bivalente do oxigênio

$D_{3 d}^{6}(R \overline{3} c)$ - Grupo de simetria espacial da hematita

$\mathrm{T}_{\mathrm{N}}-$ Temperatura de Néel

$\mathrm{T}_{\mathrm{M}-}$ Transição de Morin

$O_{h}^{7}(F d \overline{3} m)$ - Grupo de simetria espacial da magnetita

$\mathrm{T}_{\mathrm{V}}$ - Transição de Verwey

IS - Desvio isomérico

$\mathrm{Q}$ - Momento de quadrupolo nuclear

M - Magnetização do meio

H - Campo Magnético

$\chi$-Susceptibilidade

B - Indução Magnética

$\mathrm{M}_{\mathrm{R}}$ - Magnetização Remanescente

$\mathrm{H}_{\mathrm{C}}$ - Campo Coercivo

$\mathrm{Na}_{2} \mathrm{SO}_{4}$ - Sulfato de sódio

$\mathrm{NaH}_{2} \mathrm{PO}_{4}-$ Fosfato de sódio mobásico 
$\mathrm{Na}_{2} \mathrm{HPO}_{4} \cdot 7 \mathrm{H}_{2} \mathrm{O}$ - Fosfato de sódio dibásico heptahidratado

$\mathrm{FeCl}_{3} \cdot 6 \mathrm{H}_{2} \mathrm{O}$ - Cloreto férrico hexahidratado

$\mathrm{H}_{2}$ - Gás Hidrogênio

Ar - Argônio

ZFC - zero-field-cooled

FC - field-cooled

GSAS - General StructureAnalysis System

VSM - Magnetômetro de amostra vibrante

$\mathrm{NA}-\left(\alpha-\mathrm{Fe}_{2} \mathrm{O}_{3}\right)$ - Nanoanéis de hematita

$\mathrm{NA}-\left(\mathrm{Fe}_{3} \mathrm{O}_{4}\right)-$ Nanoanéis de magnetita

$\gamma-\mathrm{Fe}_{2} \mathrm{O}_{3}-$ Maghemita

QS - interaçãoquadrupolar elétrica

$\mathrm{HF}$ - campohiperfino

$K_{e f f}$ - constante de anisotropia efetiva

$\chi_{h f}$-susceptibilidade magnética a alto campo

$\chi_{i}$-susceptibilidade magnética a baixo campo

$\kappa_{B}$ - constante de Boltzman

Co - Cobalto 


\section{Resumo}

Nos últimos anos, devido ao grande potencial terapêutico de nanopartículas magnéticas, a busca por materiais com características favoráveis a esse tipo de aplicação se intensificou. Neste contexto, nanopartículas magnéticas de óxido de ferro $(\alpha-$ $\left.\mathrm{Fe}_{2} \mathrm{O}_{3} \mathrm{e} \mathrm{Fe}_{3} \mathrm{O}_{4}\right)$ com morfologia de nanoanéis foram obtidas com sucesso a partir da redução de nanoanéis de hematita, previamente sintetizados pelo processo hidrotermal. As amostras obtidas foram caracterizadas por Microscopias Eletrônica de Varredura (MEV) e Transmissão (MET), Microscopia Eletrônica de Transmissão de Alta Resolução (HRTEM), Difração de raios X (DRX), Espectroscopias Raman e Mössbauer e medidas de Magnetização. As imagens de MEV, MET e HRTEM evidenciaram a presença de monocristais com morfologias de nanoanéis com espessuras, diâmetros externos e internos médios de 95, 140 e 65 nm, respectivamente. Os dados de difração de raios-X e espectroscopia Raman revelaram que as duas fases cristalográficas desejadas $\left(\alpha-\mathrm{Fe}_{2} \mathrm{O}_{3}\right.$ e $\left.\mathrm{Fe}_{3} \mathrm{O}_{4}\right)$ foram alcançadas com sucesso. Contudo, verificou-se a presença de ferro metálico $(\alpha-F e)$ nas amostras de magnetita. Foi encontrado que os parâmetros hiperfinos de ambas as fases cristalográficas são consistentes com os valores obtidos para a hematita e magnetita bulk. As medidas de magnetização evidenciaram que ambas as fases cristalográficas apresentaram comportamento ferromagnético nas temperaturas de 5 e $300 \mathrm{~K}$. Contudo, verificou-se que enquanto o valor de campo coercivo obtido para os nanoanéis de $\alpha-\mathrm{Fe}_{2} \mathrm{O}_{3}$ é muito menor que seu respectivo bulk, os valores de $\mathrm{H}_{\mathrm{C}}$ para os nanoanéis de $\mathrm{Fe}_{3} \mathrm{O}_{4}$ é duas veze maior que a da $\mathrm{Fe}_{3} \mathrm{O}_{4}$ bulk. Estas divergências foram atribuídas à anisotropia magnética dos nanoanéis obtidos.

Palavras Chaves: Nanoanéis magnéticos, Ferritas, Nanopartículas, Óxido de Ferro 


\begin{abstract}
In recent years, due the high therapeutic potential of magnetic nanoparticles, the search for materials with excellent features to this application has been intensified. In this context, magnetic nanoparticles of iron oxide $\left(\alpha-\mathrm{Fe}_{2} \mathrm{O}_{3} \mathrm{eFe}_{3} \mathrm{O}_{4}\right)$ with nanorings morphology were successfully obtained from the reduction of hematite nanorings, these previously synthesized by hydrothermal process. The samples obtained were characterized by Scanning Electron Microscopy (SEM) and Transmission (TEM), High Resolution Transmission Electron Microscopy (HRTEM), X ray diffraction (XRD), Raman and Mössbauer Spectroscopy and Measures of Magnetization. The images obtained by SEM, TEM and HRTEM show the presence of single crystals with nanorings morphologies with thicknesses, external and internal diameters average of 95, 140 and $65 \mathrm{~nm}$, respectively. The diffraction of X-ray data and Raman spectroscopy showed that the two desired crystallographic phases $\left(\alpha-\mathrm{Fe}_{2} \mathrm{O}_{3}\right.$ e $\left.\mathrm{Fe}_{3} \mathrm{O}_{4}\right)$ were successfully obtained.However, it was verified the presence of metallic iron $(\alpha-\mathrm{Fe})$ in magnetite samples. It was noticed that the parameters of both crystallographic phases are consistent with values obtained for the hematite and magnetitebulk. The magnetization measurements provide evidence that both crystallographic faces exhibited ferromagnetic behavior in the two temperatures, $5 \mathrm{~K}$ and $300 \mathrm{~K}$. However, it is noted that while the coercive field values for the nanorings $\alpha-\mathrm{Fe}_{2} \mathrm{O}_{3}$ is much smaller than the respective bulk, the $\mathrm{H}_{\mathrm{C}}$ values for the $\mathrm{Fe}_{3} \mathrm{O}_{4}$ rings is twice that of the $\mathrm{Fe}_{3} \mathrm{O}_{4}$ bulk. These differences were attributed to the magnetic anisotropy of nanoring obtained.
\end{abstract}

Keywords: Magnetic Nanorings, Ferrites, Nanoparticles, Iron Oxide. 


\section{Lista de Figuras}

Figura 2.1 - Estrutura de uma célula da Hematita. As esferas em vermelho e cinza representam os íons de Ferro e Oxigênio, respectivamente.

Figura 2.2 - Estrutura de uma unidade da Hematita. As esferas em vermelho e cinza representam os íons de Ferro e Oxigênio, respectivamente.

Figura 2.3 - Arranjo esquemático da rede magnética da hematita bulk acima (esquerdo) e abaixo da Transição de Morin. Figura retirada da Ref. $\left[{ }^{30}\right]$.

Figura 2.4 - Estrutura cristalina de uma unidade de magnetita. As esferas em vermelho e cinza representam os íons de Ferro e oxigênios, respectivamente. 13

Figura 2.5 - Estrutura cristalina de uma célula de magnetita. As esferas em vermelho e cinza representam os íons de Ferro e oxigênios, respectivamente.

Figura 2.6 Representação dos momentos magnéticos em uma configuração de vórtice com destaque para seu núcleo. momentos ${ }^{37}$.

Figura 2.7 Representação da histerese medida ao longo da direção y e a distribuição dos momentos magnéticos correspondentes a diferentes regiões da histerese. ${ }^{38}$. 16

Figura 3.1 - Sinais resultantes da interação do feixe de elétrons primários com a amostra. $^{41}$

Figura 3.2 - Esquema da coluna do MEV. ${ }^{49}$ 20

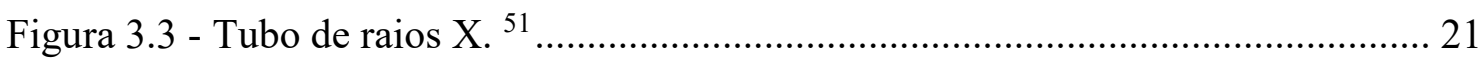

Figura 3.4 - Representação da difração de raios-X por um cristal. ${ }^{54}$............................... 22

Figura 3.5- Representação do Espalhamento da radiação no Raman............................. 23

Figura 3.6 - Representação do decaimento radioativo do ${ }^{57}$ Co. .................................... 25

Figura 3.7- (a) Espectro com desvio isomérico e (b) esquema do deslocamento dos níveis de energia do núcleo. ${ }^{62}$

Figura 3.8 - (a) Espectro com desdobramento quadrupolar e (b) esquema do desdobramento quadrupolar. ${ }^{62}$

Figura 3.9 - (a) Espectro com desdobramento magnético e (b) esquema do desdobramento magnético. ${ }^{62}$ 28

Figura 3.10 - Curva de histerese. ${ }^{67}$

Figura 5.1 - Micrografias de MEV (a, b), MET (c, d) eHRTEM (e, f) da amostra NA- $(\alpha-$ $\left.\mathrm{Fe}_{2} \mathrm{O}_{3}\right)$. 
Figura 5.2 - Micrografias de $\operatorname{MEV}(a, b), \operatorname{MET}(c, d)$ e $\operatorname{HRTEM}(e, f)$ da amostraNA$\left(\mathrm{Fe}_{3} \mathrm{O}_{4}\right)$

Figura 5.3 - Histogramas obtidas a partir das imagens de MET das amostras NA- $(\alpha-$ $\left.\mathrm{Fe}_{2} \mathrm{O}_{3}\right)$ e NA- $\left(\mathrm{Fe}_{3} \mathrm{O}_{4}\right)$. Nos painéis (a), (b) e (c) são mostrados os dados referentes aos valores dos diâmetros externos e internos e da espessura dos nanoanéis da amostra NA$\left(\alpha-\mathrm{Fe}_{2} \mathrm{O}_{3}\right)$, enquanto os painéis (d), (e) e (f) mostram os mesmos dados para a amostra $\mathrm{NA}-\left(\mathrm{Fe}_{3} \mathrm{O}_{4}\right)$

Figura 5.4 - Refinamento Rietveld dos padrões de DRX das amostras NA- $\left(\alpha-\mathrm{Fe}_{2} \mathrm{O}_{3}\right)$ (i) e NA-( $\left(\mathrm{Fe}_{3} \mathrm{O}_{4}\right)$ (ii). Em (iii) é mostrado um padrão de DRX de uma amostra de magnetita bulk.

Figura 5.5- Gráficos de Williamson-Hall obtidos para as amostras NA-( $\alpha$-Fe2O3) (a) e NA-(Fe3O4) (b). No painel (a) são mostrados os dados das fases $\alpha-\mathrm{Fe} 2 \mathrm{O} 3$ (triângulos abertos) e $\alpha-\mathrm{Fe}$ (triângulos fechados), provenientes da amostra NA-( $\alpha-\mathrm{Fe} 2 \mathrm{O} 3)$. Em (b) são mostrados os dados referentes a fase $\mathrm{Fe} 3 \mathrm{O} 4$ da amostra NA-(Fe3O4) (círculos abertos) e da magnetita bulk (círculos fechados).

Figura 5.6 - Espectros Raman das amostras NA- $\left(\mathrm{Fe}_{3} \mathrm{O}_{4}\right)$ (a) e NA- $\left(\alpha-\mathrm{Fe}_{2} \mathrm{O}_{3}\right)(b)$. 45

Figura 5.7 - Espectros Mössbauer nas temperaturas ambiente (inferior) e a $77 \mathrm{~K}$ (superior) das amostras NA- $\left(\alpha-\mathrm{Fe}_{2} \mathrm{O}_{3}\right)$ (a) e NA- $\left(\mathrm{Fe}_{3} \mathrm{O}_{4}\right)$ (b)

Figura 5.8 - Curvas de histerese, magnetização vs campo magnético aplicado, nas temperaturas de 300 (a) e $5 \mathrm{~K}$ (b), para a amostras $\mathrm{NA}-\left(\alpha-\mathrm{Fe}_{2} \mathrm{O}_{3}\right)$.

Figura 5.9 - Curvas de histerese, magnetização vs campo magnético aplicado obtido para a amostra NA-( $\left.\mathrm{Fe}_{3} \mathrm{O}_{4}\right)$ (símbolos em preto) nas temperaturas de $300 \mathrm{~K}$ (a) e $5 \mathrm{~K}$ (b). As curvas em vermelho mostram $\mathrm{M}$ contra $\mathrm{H}$ obtido para uma amostra $\mathrm{Fe}_{3} \mathrm{O}_{4}-$ bulk.

Figura 5.10 - Curvas de magnetização zero-field-cooled (ZFC) (símbolos pretos) e fieldcooled (FC) (símbolo vermelho) da amostra NA- $\left(\alpha-\mathrm{Fe}_{2} \mathrm{O}_{3}\right)$.

Figura 5.11 - Curvas de magnetização zero-field-cooled (ZFC) (símbolos pretos) e fieldcooled (FC) (símbolo vermelho) da amostraNA-( $\left.\mathrm{Fe}_{3} \mathrm{O}_{4}\right)$. 56

Figura 5.12 - Ajuste da curva de M vsH usando a lei de aproximação à saturação (Eq. 5.1) para as amostras NA-( $\left.\mathrm{Fe}_{3} \mathrm{O}_{4}\right)$ e $\mathrm{Fe}_{3} \mathrm{O}_{4}-$ bulk. 


\section{Lista de Tabelas}

Tabela 2.1 -Nomenclatura dos óxidos e hidróxidos de ferro. ${ }^{21}$ 9

Tabela 5.1 - Parâmetros obtidos dos ajustes dos espectros Mössbauer a 300 e 77 K, das amostras NA- $\left(\alpha-\mathrm{Fe}_{2} \mathrm{O}_{3}\right)$ e NA- $\left(\mathrm{Fe}_{3} \mathrm{O}_{4}\right)$.

Tabela 5.2- Parâmetros Magnéticos obtidos para as amostras NA- $\left(\alpha-\mathrm{Fe}_{2} \mathrm{O}_{3}\right)$ e NA $\mathrm{Fe}_{3} \mathrm{O}_{4}$. Para comparação também são mostrados dados referentes a amostras de $\alpha-\mathrm{Fe}_{2} \mathrm{O}_{3}$ - bulk* (ref. ${ }^{30}$ ) e $\mathrm{Fe}_{3} \mathrm{O}_{4}$ bulk (deste trabalho). 50 


\section{Sumário}

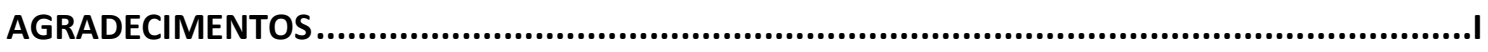

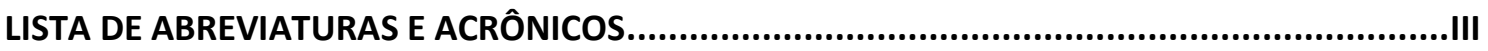

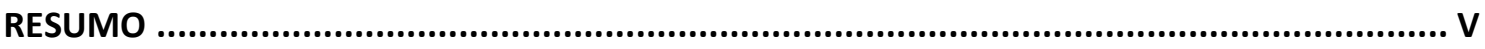

ABSTRACT

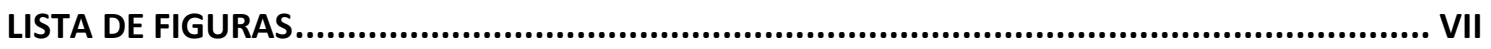

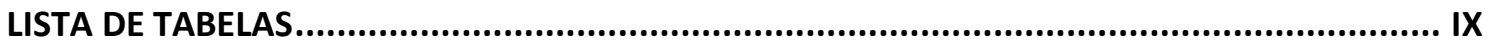

SUMÁRIO

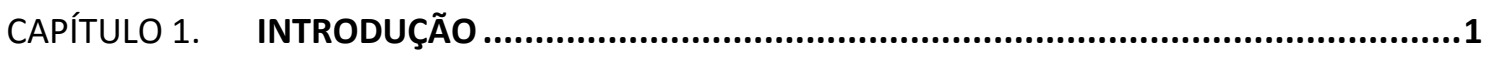

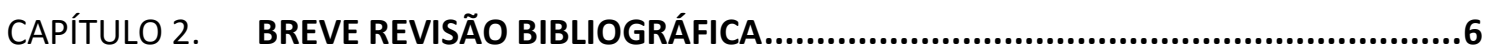

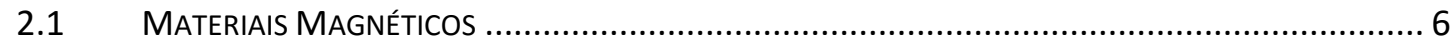

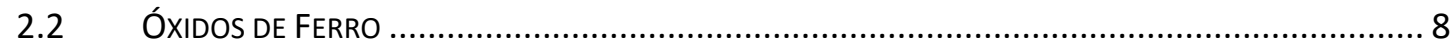

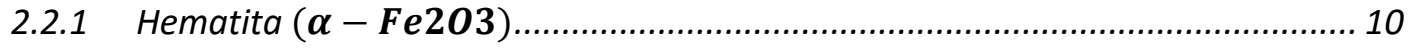

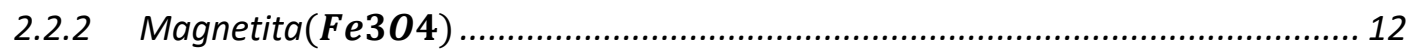

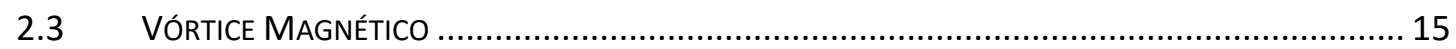

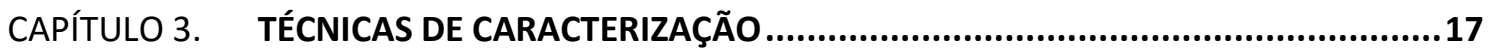

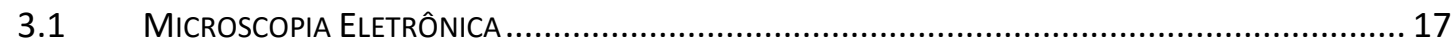

3.1.1 Microscopia Eletrônica de Transmissão (MET)................................................. 18

3.1.2 - Microscopia Eletrônica de Varredura (MEV) ....................................................... 19

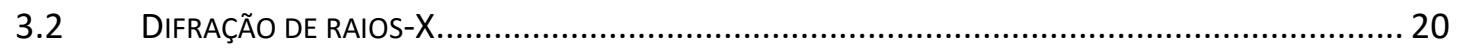

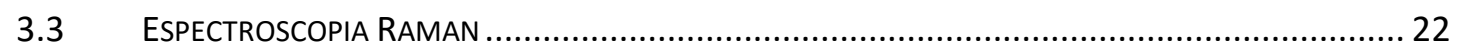

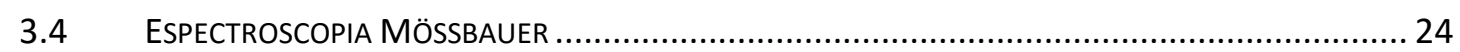

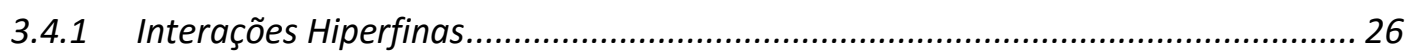

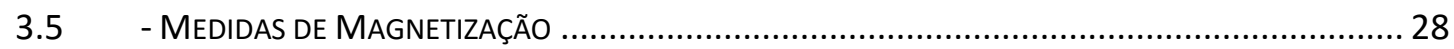

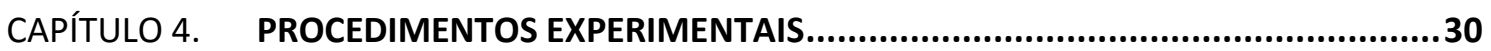

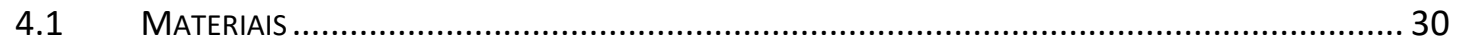

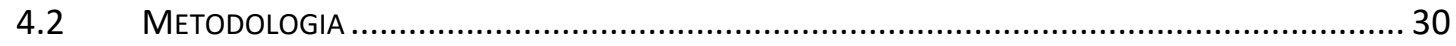

4.2.1 Síntese das Nanopartículas ............................................................................... 31

4.2.2 Caracterização dos Materiais .......................................................................... 32

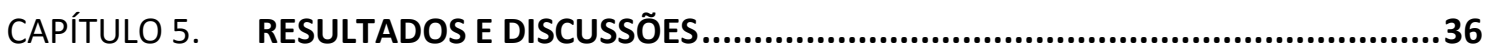




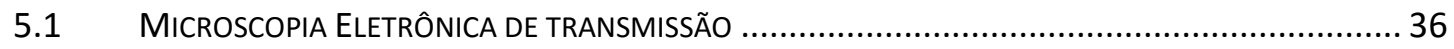

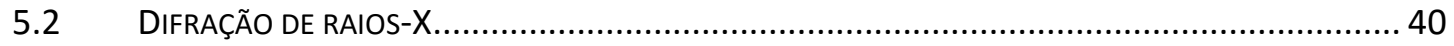

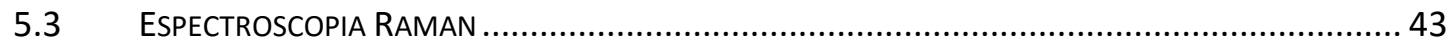

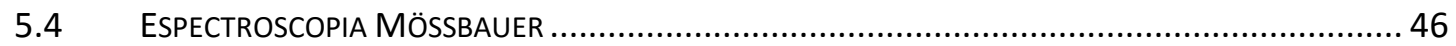

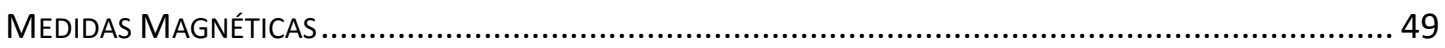

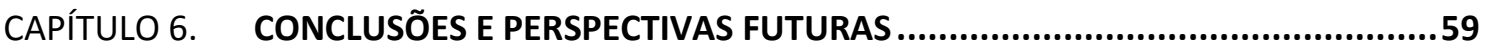

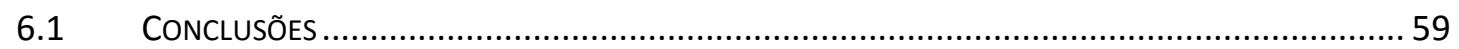

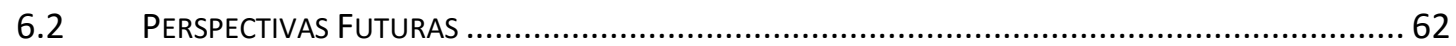

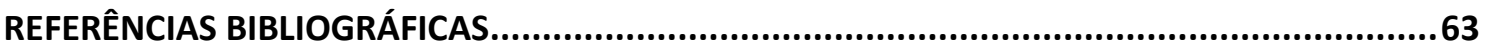




\section{Capítulo 1. Introdução}

A Nanociência é uma área de pesquisa que visa manipular a matéria em escala nanométrica, isto é, na ordem de $10^{-9}$ metros. Vários pesquisadores de diversas áreas, tais como, Química, Física, Biologia e Engenharia estão estudando compostos nanométricos, pois materiais desse tipo, nanoestruturados, já trazem grandes melhorias na qualidade de vida e na preservação do meio ambiente. ${ }^{1}$

Nanotecnologia relaciona-se ao entendimento, controle e exploração de materiais e sistemas cujas estruturas e componentes apresentam propriedades e fenômenos físicos, químicos e biológicos que são significativamente novos e/ou modificados devido à sua escala nanométrica $(1-100 \mathrm{~nm}){ }^{2}$

Termos como nanociência, nanotecnologia e nanomateriais remetem a investigações que visam controlar a estrutura fundamental e o comportamento da matéria com tamanho nanométrico. Isso é de fundamental importância, pois dessa forma é possível compreender novas propriedades físicas e químicas de materiais a um nível microscópico, tais como propriedades da matéria que são muito influenciadas pela superfície, esses efeitos podem ser iguais ou maiores do que o efeito de volume. ${ }^{3}$

Materiais, formados por nanopartículas, têm sido desenvolvidos com um árduo trabalho, tanto de pesquisa básica, que envolve sua síntese e caracterização, como pela pesquisa tecnológica por meio de projetos, construção e testes de dispositivos. Esses novos materiais estão se mostrando úteis em diversas áreas, tais como, saúde, meio ambiente e industrial, dentre outros. ${ }^{4}$

$\mathrm{Na}$ área de saúde, a Magnetohipertemia se destaca pois, em conjunto com outras técnicas, possui grande potencial de aplicação no tratamento de câncer. De forma genérica, magnetohipertermia é um procedimento terapêutico, baseado em 
nanopartículas magnéticas, utilizado para elevar a temperatura de uma região específica do corpo que esteja afetada por uma neoplasia (tumor) com objetivo de causar lise (quebra) das células tumorais. ${ }^{5}$ Sua eficácia é baseada no fato que as células tumorais são menos resistentes ao aumento de temperatura. Enquanto células sadias podem resistir a temperaturas relativamente altas, por volta $44^{\circ} \mathrm{C}$, as células tumorais sofrem apoptose ao terem sua temperatura elevada para cerca de $41-43^{\circ} \mathrm{C} .^{6}$ A elevação da temperatura na região desejada (tumor) é obtida geralmente utilizando-se nanopartículas magnéticas biocompatíveis, que têm suas superfícies modificadas com moléculas bioativas que reconhecem células tumorais. Assim, quando administradas ao paciente, as nanopartículas ficarão concentradas, após algum tempo, na região contendo o tumor. Após a concentração sobre o tumor, as nanopartículas são submetidas a um campo eletromagnético variável. Esse campo alternado leva a uma rotação nos domínios magnéticos das nanopartículas, causando um aumento de energia que gera calor.

Nos últimos anos, o potencial terapêutico da Magnetohipertemia provocou uma imensa busca por materiais magnéticos para este tipo de aplicação ${ }^{7,8}$. A maioria destes estudos é focada no desenvolvimento de nanopartículas cada vez mais eficientes e que possibilitem um controle fino da quantidade de calor gerado.

Como resultado potencial terapêutico da Magnetohipertemia, uma intensa busca de materiais magnéticos para este tipo de aplicação vem ocorrendo nos últimos anos ${ }^{7,8}$. A maioria destes estudos é focada no desenvolvimento de nanopartículas cada vez mais eficientes e que possibilitem um controle fino da quantidade de calor gerado. Quantitativamente, a grandeza que expressa a eficiência da nanopartícula é o SAR (SpecificAbsorption Rate), e dado pela expressão a baixo:

$$
S A R=\frac{W}{m}=\frac{1}{m}\left(\frac{d Q}{d t}\right)=C \frac{m^{\prime}}{m}\left(\frac{d T}{d t}\right)
$$


onde, $\mathrm{C}$ é a capacidade calorífica $\left(\mathrm{Jg}^{-1} \mathrm{~K}^{-1}\right)$ do fluído (solvente + nanopartícula), $m^{\prime}$ é a massa deste mesmo fluído e é a taxa de variação da temperatura em função do tempo e m é a massa de nanopartículas. Ou seja, o SAR quantifica o calor gerado no tecido, de modo que quanto maior esta taxa de absorção específica, menor a dose administrada ao paciente. Sumarizando, um material ideal para ser utilizado em aplicação de hipertermia magnética deve contemplar características tais como: Biocompatibilidade, baixa remanência magnética, baixo campo magnético de saturação, alta magnetização de saturação e perdas histeréticas dinâmicas elevadas. ${ }^{9}$.O sistema que mais se enquadra nestas especificações é o sistema denominado SPION's (superparamagnetic iron oxide nanoparticles). Contudo, devido à sua natureza superparamagnético e aos pequenos valores de magnetização de saturação, campos magnéticos elevados são necessários para detectar ou manipular estas partículas. Por outro lado, se partículas altamente magnéticas são fabricadas (isto é, partículas com maiores domínios individuais), a aglomeração pode ocorrer mesmo em campos magnéticos relativamente baixos. Além disso, os superparamagnetos apresentam baixo SAR, quando comparada a materiais magnéticos convencionais como os ferromagnéticos. Isto decorre do fato de que dos três processos que levam ao aquecimento local (relaxação de Nèel, relaxação de Brown e perdas histeréticas), apenas os dois primeiros estão presentes quando nanopartículas superparamagnéticos estão envolvidas ${ }^{10}$.

No caso dos materiais que apresentam multidomínios o mecanismo de aquecimento por perdas histeréticas passa a ter um papel preponderante sob o SAR. Este mecanismo está associado aos deslocamentos não reversíveis das paredes de domínios, os quais são fortemente afetados pela frequência do campo magnético. De modo que o SAR passa a ser diretamente proporcional a frequência do campo magnético aplicado. 
Isso impõe sérias restrições ao uso de materiais multidomínios para aplicações em hipertermia em condições usuais de laboratório.

Para contornar estas limitações tem-se proposto a utilização de partículas cujas dimensões sejam intermediárias entre o limite de um estado de monodomínio e o de multidomínio $^{8}$, de modo que suas dimensões tendem à largura típica de uma parede de domínio. Neste caso, a minimização da energia magnetostática pode favorecer a formação de vórtices, que se caracteriza por apresentar uma configuração de spin girante, isto é, a magnetização forma círculos concêntricos. Como resultado, nas proximidades do centro do disco, o momento magnético dentro de uma pequena área central do disco se volta para fora do plano. Este comportamento foi denominado de vórtice magnético. ${ }^{11}$

É particularmente interessante estudar a magnetita $\left(\mathrm{Fe}_{3} \mathrm{O}_{4}\right)$, pois além de ser biocompatível, apresenta grande potencial terapêutico por apresentar comportamento superparamagnético, magnetização de saturação e susceptibilidade magnéticas relativamente altas. Porém, devido à atração anisotrópica dipolar, a magnetita nanoparticulada tende a se agregar em grandes "clusters". Dessa forma a partícula perde suas propriedades específicas associadas às estruturas de monodomínio magnético. As dimensões reduzidas aumentam a reatividade destas partículas que podem sofrer rápida degradação em ambientes biológicos. ${ }^{12}$

Dentro deste contexto, este trabalho tem o objetivo de sintetizar e estudar as propriedades estruturais e magnéticas de nanoanéis de óxido de ferro $\left(\alpha-\mathrm{Fe}_{2} \mathrm{O}_{3}, \mathrm{Fe}_{3} \mathrm{O}_{4}\right)$ visando aperfeiçoar suas características para possíveis aplicações em hipertermia magnética. 
As amostras sintetizadas neste trabalho foram caracterizadas pelas técnicas de Microscopia Eletrônica de Varredura (MEV), Microscopia Eletrônica de Transmissão (MET), Microscopia Eletrônica de Transmissão de Alta Resolução (HRTEM), Difração de raios-X (DRX), Espectroscopias Raman e Mössbauer e medidas de Magnetização. A partir dos dados experimentais obtidos foi possível avaliar suas respectivas propriedades físicas e magnéticas.

Esta dissertação está organizada da seguinte forma: o Capítulo 2 é formado por uma breve revisão bibliográfica sobre materiais magnéticos e óxidos de ferro; o Capítulo 3 apresenta as técnicas experimentais empregadas neste trabalho; o Capítulo 4 mostra os detalhes dos procedimentos experimentais empregados na síntese das nanopartículas; o Capítulo 5 apresenta os resultados e discussões acerca do trabalho, finalizando, é apresentado no Capítulo 6 as conclusões e perspectivas futuras para o trabalho. 


\section{Capítulo 2. Breve Revisão Bibliográfica}

\subsection{Materiais Magnéticos}

O magnetismo é uma propriedade dos átomos que tem origem em sua estrutura eletrônica. É resultado da combinação do momento angular orbital e do momento angular de spin eletrônico. A combinação entre esses momentos angulares determina como o material irá se comportar na presença de outro campo magnético. Qualquer substância, independente do seu estado físico mostra alguma característica magnética, em todas as temperaturas. Sendo assim, o magnetismo pode ser considerado uma propriedade básica de qualquer material. ${ }^{13}$

Os materiais magnéticos têm contribuído muito na história das civilizações e no desenvolvimento tecnológico das mesmas. Certos materiais possuem a característica de adquirir um alto e permanente momento magnético, de modo que as aplicações para esses tipos de materiais são as mais variadas e fazem uso de vários aspectos do comportamento magnético.

Os materiais podem ser classificados em diamagnéticos, paramagnéticos, ferromagnéticos, ferrimagnéticos ou antiferromagnéticos de acordo com o seu comportamento diante de um campo magnético externo.

Materiais diamagnéticos quando estão na ausência de um campo magnético externo não apresentam magnetização resultante. Quando esse tipo de material é colocado na presença de um campo magnético ele tem seus momentos magnéticos orientados no sentido contrário ao sentido do campo magnético aplicado. Assim, estabelece-se um campo magnético na substância que possui sentido contrário ao campo aplicado. $^{14}$ 
No paramagnetismo os momentos magnéticos atômicos são desacoplados, dessa forma eles são fracamente atraídos por campos magnéticos. ${ }^{14} \mathrm{Na}$ ausência de campo externo, materiais paramagnéticos possuem seu momento magnético resultante e permanente orientados de forma aleatória, e o momento de dipolo magnético resultante do material é nulo. Porém, se uma amostra do material for colocada em um campo magnético externo, os momentos tendem a se alinhar com o campo, o que dá um momento magnético total não nulo na direção do campo externo. ${ }^{15}$

Os materiais que possuem magnetização espontânea abaixo da Temperatura de Curie $\left(T_{c}\right)$ são denominados de ferromagnéticos. Mesmo na ausência de um campo magnético, esse tipo de material exibe estados magnéticos ordenados. Acima de $T_{c}$ ocorre o desordenamento dos momentos magnéticos devido à alta energia térmica.

Os compostos ferrimagnéticos são constituídos por íons distintos, cuja orientação dos seus momentos magnéticos alinham-se antiparalelamente uns aos outros, mas com magnetização resultante. ${ }^{16} \mathrm{Na}$ presença de um campo magnético externo alinham-se na direção e sentido do campo aplicado. Esse tipo de composto perde sua magnetização acima de $\mathrm{T}_{\mathrm{c}}$, pois a agitação térmica perturba seu ordenamento magnético.

O termo antiferromagnético se refere ao modo com que moléculas individuais alinham seus polos magnéticos. $\mathrm{O}$ antiferromagnetismo, assim como o ferromagnetismo, também é originado pela interação entre os spins, porém eles tendem a alinhar os momentos magnéticos em direções opostas, dessa forma os momentos magnéticos se cancelam mutuamente. ${ }^{17}$ Analogamente ao termo Temperatura de Curie (aplicada à materiais ferro e ferrimagnético), define-se Temperatura de Néel para os casos das substâncias antiferromagnética. Ou seja, é a temperatura na qual desaparece 
os efeitos antiferromagnéticos dos materiais, passando este a comportar-se como materiais paramagnéticos.

O superparamagnetismo, por sua vez, possui uma forte dependência em relação as dimensões dos materiais, pois a medida que o tamanho do material diminui não é mais possível obter uma configuração energética favorável, dessa forma o material é induzido a formar monodomínios. Sendo assim, a nanopartícula passa a apresentar característica magnética bastante distinta do material bulk. ${ }^{14} \mathrm{Em}$ 1950, Bean-Livingston introduziu a teoria do superparamagnetismo. A primeira suposição dessa teoria é considerar que no interior de uma partícula os momentos magnéticos atômicos se movem coerentemente, ou seja, o momento magnético total poderá ser representado por um único vetor clássico de magnitude $\mu=\mu_{a t} N$, onde $\mu_{a t}$ é o momento magnético atômico e $\mathrm{N}$ é o número de átomos magnéticos presentes na partícula. ${ }^{18}$

\section{2 Óxidos de Ferro}

Os óxidos de ferro são substâncias que podem ser encontradas com facilidade na crosta terrestre, e são materiais de ocorrência natural. E devido a facilidade em ser obtidos, tem sido foco de várias pesquisas. ${ }^{19}$ Esses compostos possuem interessantes propriedades magnéticas, morfológicas e físico-químicas. Apresenta baixa toxicidade, baixo custo de síntese e processamento, coloração característica, além de um amplo campo de aplicações, tais como nos campos de equipamentos magnéticos, eletrodos de bateria, catálise, sensores e pigmentos. ${ }^{20}$

São conhecidos como óxidos de ferro os compostos que são formados pelo elemento químico Ferro $(\mathrm{Fe})$ ligado com oxigênio $(\mathrm{O})$ 
, gerando uma grande variedade de compostos. Um amplo espectro de aplicações é possível, pois esses óxidos apresentam diversas variedades alotrópicas, possuindo propriedades únicas. Alguns exemplos desses tipos de compostos se encontra na Tabela $2.1 .^{21}$

Das variações de óxidos citadas na Tabela 2.1 as estruturas $\alpha-\mathrm{FeOOH}, \beta-$ $\mathrm{FeOOH}, \alpha-\mathrm{Fe}_{2} \mathrm{O}_{3}, \gamma-\mathrm{Fe}_{2} \mathrm{O}_{3}$ e $\mathrm{Fe}_{3} \mathrm{O}_{4}\left(\mathrm{Fe}^{2+} \mathrm{Fe}_{2}^{3+} \mathrm{O}_{4}\right)$ são as mais estudadas pela gama de aplicações nos campos de biomedicina, ambiental, catálise, sensores e de energia.

Diante de todas as possibilidades estruturais, a hematita $\left(\alpha-\mathrm{Fe}_{2} \mathrm{O}_{3}\right)$ e a magnetita $\left(\mathrm{Fe}_{3} \mathrm{O}_{4}\right)$ são o foco principal desse trabalho. As mesmas serão apresentadas a seguir.

Tabela 2.1 -Nomenclatura dos óxidos e hidróxidos de ferro. ${ }^{21}$

\begin{tabular}{cc}
\hline Nome do Óxido ou Hidróxido de Ferro & Fórmula molecular \\
\hline Goetita & $\alpha-\mathrm{FeOOH}$ \\
Lepidocrocita & $\gamma-\mathrm{FeOOH}$ \\
Akaganeita & $\beta-\mathrm{FeOOH}$ \\
- & $\delta-\mathrm{FeOOH}$ \\
Feroxita & $\delta^{\prime}-\mathrm{FeOOH}$ \\
Alta Pressão & $\mathrm{FeOOH}$ \\
Bernalita & $\delta-\mathrm{Fe}^{\circ} \mathrm{OH}_{3}$ \\
Hematita & $\alpha-\mathrm{Fe}_{2} \mathrm{O}_{3}$ \\
Magnetita & $\mathrm{Fe}_{3} \mathrm{O}_{4}\left(\mathrm{Fe}^{2+} \mathrm{Fe}_{2}^{3+} \mathrm{O}_{4}\right)$ \\
Maguemita & $\gamma-\mathrm{Fe}_{2} \mathrm{O}_{3}$ \\
- & $\beta-\mathrm{Fe}_{2} \mathrm{O}_{3}$ \\
- & $\epsilon-\mathrm{Fe}_{2} \mathrm{O}_{3}$ \\
Wustita & $\mathrm{FeO}^{2}$ \\
\hline
\end{tabular}




\subsubsection{Hematita $\left(\alpha-\mathrm{Fe}_{2} \mathrm{O}_{3}\right)$}

A Hematita $\left(\alpha-\mathrm{Fe}_{2} \mathrm{O}_{3}\right)$ foi o primeiro óxido de ferro a ser descoberto pelo homem, ele está presente em rochas e no solo. Seu nome se origina do grego (haima= sangue), pois possui coloração avermelhada. ${ }^{22}$ Ela é a fase mais termodinamicamente estável dos óxidos de ferro (III) em temperatura e pressão ambiente. ${ }^{20}$ Se comporta como semicondutor com alta resistência a corrosão e baixo custo. ${ }^{23}$ A hematita e fracamente ferromagnética a temperatura ambiente. A letra $\alpha$ é usada para diferenciá-la da maguemita $\left(\gamma-\mathrm{Fe}_{2} \mathrm{O}_{3}\right)$,que apresenta a mesma fórmula química, mas com estruturas cristalinas diferentes.

A cela unitária da $\alpha-\mathrm{Fe}_{2} \mathrm{O}_{3}$ possui oito átomos de $\mathrm{Fe}^{3+}$ de coordenação octaédrica (estrutura do coríndon) e trinta íons por cela unitária: 12 cátions $F e^{3+}$ e 18 ânions $\mathrm{O}^{2-}$. Os íons de $\mathrm{Fe}^{3+}$ ocupam regularmente os interstícios entre os planos, sendo assim os íons são dispostos a cada dois sítios e o terceiro fica desocupado. ${ }^{24}$ As Figuras 2.1 e 2.2 apresentam a estrutura cristalina da $\alpha-\mathrm{Fe}_{2} \mathrm{O}_{3}$.

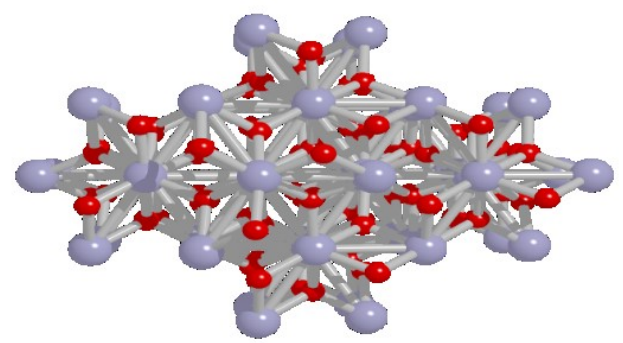

Figura 2.1 - Estrutura de uma célula da Hematita. As esferas em vermelho e cinza representam os ions de Ferro e Oxigênio, respectivamente. 


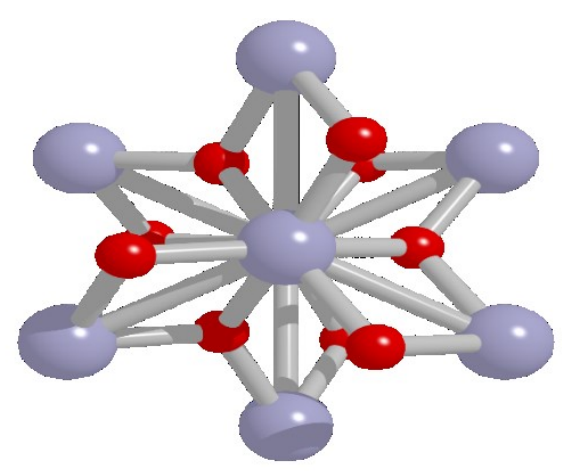

Figura 2.2 - Estrutura de uma unidade da Hematita. As esferas em vermelho e cinza representam os íons de Ferro e Oxigênio, respectivamente.

A hematita possui estrutura do tipo hexagonal formada por pares de $\mathrm{Fe}(\mathrm{O})_{6}$ octaédricos ligados entre si e pertence ao grupo de simetria espacial $D_{3 d}^{6}(R \overline{3} c)$. Sete modos vibracionais são Raman ativos; dois modos $\mathrm{A}_{1 \mathrm{~g}}$ e cinco $\mathrm{E}_{\mathrm{g}}{ }^{25}$, cuja frequências são, respectivamente, 225 e $498 \mathrm{~cm}^{-1}$ para os modos $A_{1 \mathrm{~g}}$ e 247, 293, 299, 412 e $613 \mathrm{~cm}^{-1}$ para os modos $\mathrm{E}_{\mathrm{g}}$. Um sexto modo vibracional, localizado em torno de $660 \mathrm{~cm}^{-1}$, é geralmente observado nos espectros Raman da hematita natural. Não há consenso a respeito da origem deste modo vibracional, enquanto alguns autores atribuem esse modo a possíveis desordem estruturais, ${ }^{26}$ outros autores atribuem este pico à presença de unidades $\mathrm{OH}$ aprisionados nos canais da estrutura da hematita formada (hidrohematita), que leva a um abaixamento da simetria estrutural e um consequente aparecimento de modos vibracionais proibidos. ${ }^{27}$

A hematita bulk quando resfriada abaixo da temperatura de Néel $\left(\mathrm{T}_{\mathrm{N}} \sim 955 \mathrm{~K}\right)$ adota uma estrutura de spins que contem duas sub-redes ferromagnéticas ( $\mathrm{Fe}$ e $\mathrm{Fe}^{\prime}$ ) antiferromagneticamentes acopladas uma com a outra. Os momentos são alinhados aproximadamente perpendiculares ao eixo $c$ com uma pequena inclinação das sub-redes magnéticas em relação uma a outra devido a interação de Dzyaloshinsky-Moriya (DM). ${ }^{28}$ Isto dá ao material um pequeno momento magnético. Se resfriado abaixo de $260 \mathrm{~K}$ o material passa por uma reorientação de spin de primeira ordem, denominada transição de 
Morin $\left(\mathrm{T}_{\mathrm{M}}\right)$, onde os momentos magnéticos alinham-se ao longo do eixo $c$, de modo que momento magnético da rede é perdido (ver Fig. 2.3). ${ }^{29}$
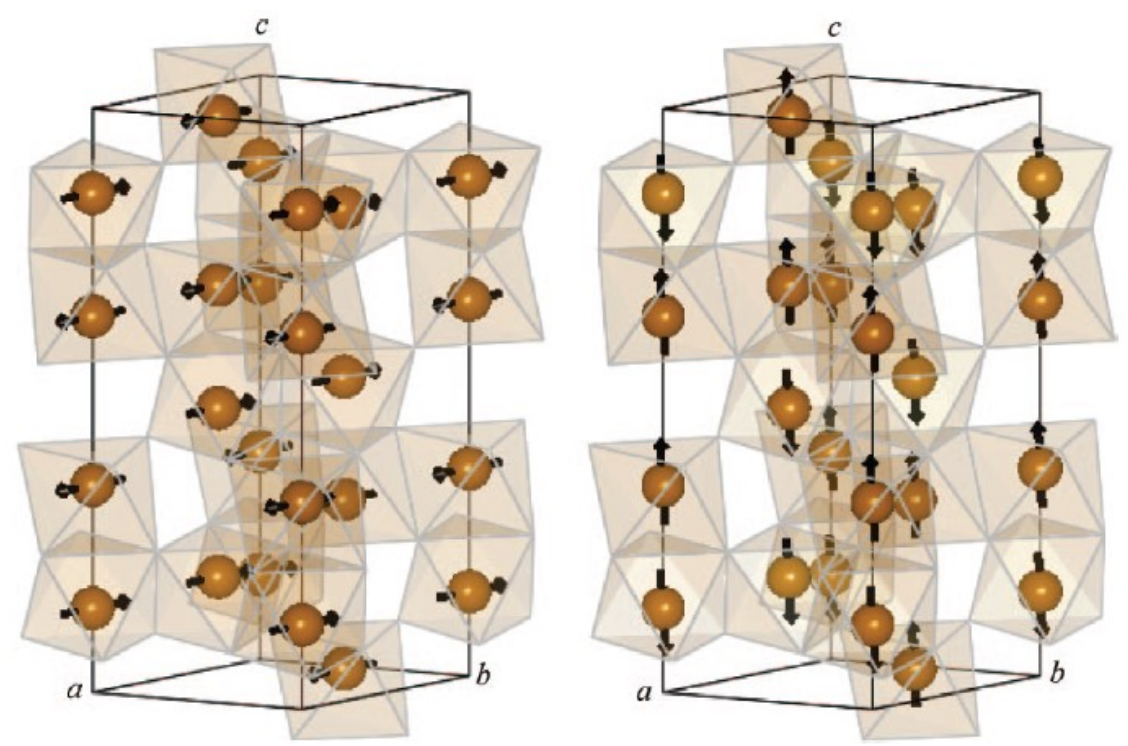

Figura 2.3 - Arranjo esquemático da rede magnética da hematita bulk acima (esquerdo) e abaixo da Transição de Morin. Figura retirada da Ref. $\left[{ }^{30}\right]$.

Acimada temperatura de Néel ( $~ 955 \mathrm{~K})$, a energia térmica do mineral é tão alta que anula qualquer arranjo dos momentos magnético da hematita tornando-a paramagnética.

\subsubsection{Magnetita $\left(\mathrm{Fe}_{3} \mathrm{O}_{4}\right)$}

A magnetita, $\left(\boldsymbol{F e}_{3} \boldsymbol{O}_{4}\right)$, um mineral ferrimagnético, é encontrada em formato de pequenos grãos, constituinte comum de rocha magmática ela também está presente em rochas metamórficas, de metamorfismo de contato ou regional, em meteoritos e também em areias de praia. Sua formação ocorre pela alteração de minerais que contém óxido de ferro em sua composição. ${ }^{31}$

O sistema de cristalização da magnetita é do tipo espinélio invertido formando uma rede cúbica de face centrada (ver Figura 2.4) e pertence ao grupo espacial 
$O_{h}^{7}(F d \overline{3} m) \cdot{ }^{32} \mathrm{Em}$ sua célula unitária, a magnetita possui oito íons $F e^{3+}$ no sítio tetraédrico e no sítio octaédrico há oito íons de cada $\left(\mathrm{Fe}^{2+} e \mathrm{Fe}^{3+}\right)$, (ver Figura 2.4). ${ }^{33}$ Sua fórmula pode então ser escrita da seguinte maneira $\left[\mathrm{Fe}^{3+}{ }_{8}\right]\left\{\mathrm{Fe}^{3+}{ }_{8} \mathrm{Fe}^{2+}{ }_{8}\right\} \mathrm{O}_{32}$, ondeas representações dentro de colchetes simbolizam o sítio tetraédrico, enquanto as chaves o sítio octaédrico.

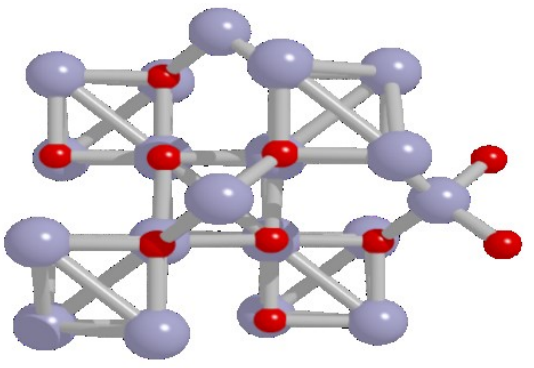

Figura 2.4 - Estrutura cristalina de uma unidade de magnetita. As esferas em vermelho e cinza representam os ions de Ferro e oxigênios, respectivamente.

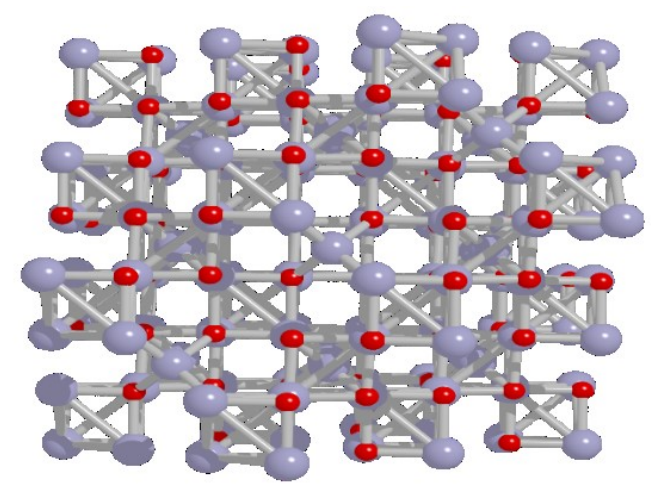

Figura 2.5 - Estrutura cristalina de uma célula de magnetita. As esferas em vermelho e cinza representam os ions de Ferro e oxigênios, respectivamente.

Deve-se ressaltar que a simetria do cristal é cúbica, mas a célula primitiva é romboédrica com dois íons no sítio tetraédrico, o qual apresentam simetria $\mathrm{T}_{\mathrm{d}}$, quatro íons no sítio octaédrico, com simetria $\mathrm{D}_{3 \mathrm{~d}}$, e oito oxigênios, com simetria $\mathrm{C}_{3 \mathrm{v} .}{ }^{32}$

Verble (1974) foi o primeiro a aplicar a espectroscopia Raman no estudo dos modos vibracionais da magnetita, porém a análise dos possíveis modos vibracionais, ativos em Raman, foi feita em 1967, por White e DeAngelis. ${ }^{34}$ Segundo White e Angelis os cinco modos vibracionais Raman previstos para essa estrutura são: $A_{1 g}, E_{g}$ e três 
modos $T_{2 g}$. Apenas os átomos de oxigênio e os sítios de simetria tetraédrica contribuem efetivamente para o espectro Raman. O modo $A_{1 g}$ é o estiramento simétrico dos átomos de oxigênio em relação aos átomos de ferro presentes no sítio tetraédrico. O modo $E_{g}$ é referente a uma flexão simétrica desses átomos de oxigênio. Nos modos $T_{2 g}$ tem-se: $T_{2 g}^{1}$, modo referente a translação dos átomosde oxigênio; $T_{2 g}^{2}$, estiramento assimétrico dos átomos de oxigênio e $T_{2 g}^{3}$ flexão assimétrico dos átomos de oxigênio.

Não existe na literatura um consenso a respeito do número de modos vibracionais observados nos espectros Raman. Enquanto Shebanova e Laser ${ }^{35}$ observaram quatro modos vibracionais, no trabalho de Verble foi relatado a presença de apenas três modos Raman. ${ }^{32}$ Por outro lado, no trabalho de Gavesetal. ${ }^{36}$ foramverificados a presença de seis picos Raman.

Como dito anteriormente, na magnetita estão presente dois estados de oxidação do ferro $\left(\mathrm{Fe}^{2+} e \mathrm{Fe}^{3+}\right)$. Na presença de somente íons $F e^{3+}$ não há momento magnético resultante, pois, os mesmos são divididos igualmente entre as posições tetraédricas e octaédricas. Já os íons $F e^{2+}$ ficam nos interstícios octaédricos e são os responsáveis pelo comportamento magnético do material, ou seja, são os responsáveis pela magnetização de saturação. ${ }^{22}$

A temperatura ambiente a magnetita apresenta uma magnetização de saturação $\left(\mathrm{M}_{\mathrm{S}}\right)$ de aproximadamente $96 \mathrm{emu} / \mathrm{g}$, a qual decresce com o aumento da temperatura, indo à zero na temperatura de Curie $\left(\mathrm{T}_{\mathrm{C}} \sim 880 \mathrm{~K}\right)$. Por outro lado, quando submetida a temperaturas abaixo de $120 \mathrm{~K}$, a magnetita apresenta um ordenamento dos íons de $\mathrm{Fe}^{2+}$ e $\mathrm{Fe}^{3+}$ na sub-rede octaédrica e a unidade de cela é ligeiramente distorcida da simetria cúbica para monoclínica. Acima de $120 \mathrm{~K}$ o ordenamento se quebra, levando a uma troca contínua de um elétron do íonFe ${ }^{2+}$ para o seu vizinho $\mathrm{Fe}^{3+}$ do sítio $\mathrm{B}$, convertendo $\mathrm{oFe}^{2+}$ para $\mathrm{Fe}^{3+} \mathrm{e}$ vice-versa. Isto é, cada sítio é ocupado metade do tempo por $\mathrm{Fe}^{2+} \mathrm{e}$ 
outra metade do tempo, por $\mathrm{Fe}^{3+}$, de tal modo que se pode associar a uma população $\mathrm{Fe}^{2,5+}$. Esta transição é denominada de Transição de Verwey $(\mathrm{TV})$ e a mobilidade eletrônica converte a magnetita de um isolante elétrico a um semicondutor.

\subsection{Vórtice Magnético}

Materiais ferromagnéticos geralmente formam estruturas de domínio para reduzir a sua energia magnetostáticos. No entanto, em sistemas ferromagnéticos muito pequenos a formação de paredes de domínio não é energeticamente favorecida, de modo em partículas de material ferromagnético com dimensões submicrométrica, uma configuração de spins orientados na forma de vórtice é formada. Esta configuração de spins é principalmente encontrada em nanodiscos, mas também podem ser encontradas em nanopilares ou partículas que tenham uma seção circular ou elíptica. No caso de nanodiscos apresentando vórtice magnético como estado fundamental, a anisotropia de forma do disco faz com que a magnetização fique contida ao plano do disco, exceto próximo ao centro da seção onde os momentos magnéticos apresentariam ângulos muito grandes entre si, o que implicaria em um custo energético muito alto. Como resultado para minimizar a energia, os momentos magnéticos próximos ao centro circulam para fora do plano, criando o denominado núcleo do vórtice, como representado na Fig. 2.6 


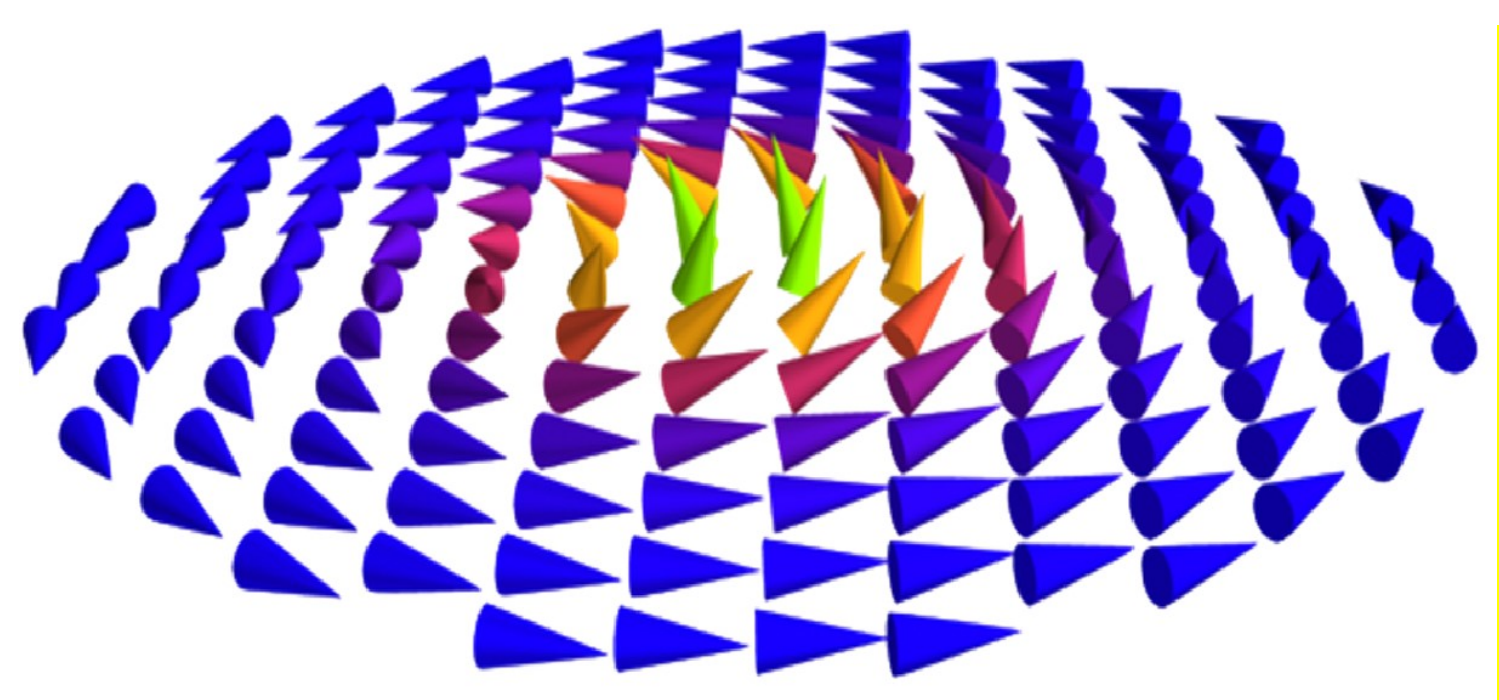

Figura 2.6 Representação dos momentos magnéticos em uma configuração de vórtice com destaque para seu núcleo. momentos ${ }^{37}$.

A curva de histerese típica de um vórtice tem uma forma bastante peculiar, conforme apresentado na Figura 2.7. Como pode ser verificado, embora este sistema não apresente remanência, as perdas histeréticas são acentuadas, sobretudo, nos lóbulos relacionados à aniquilação e nucleação do núcleo do vórtice.

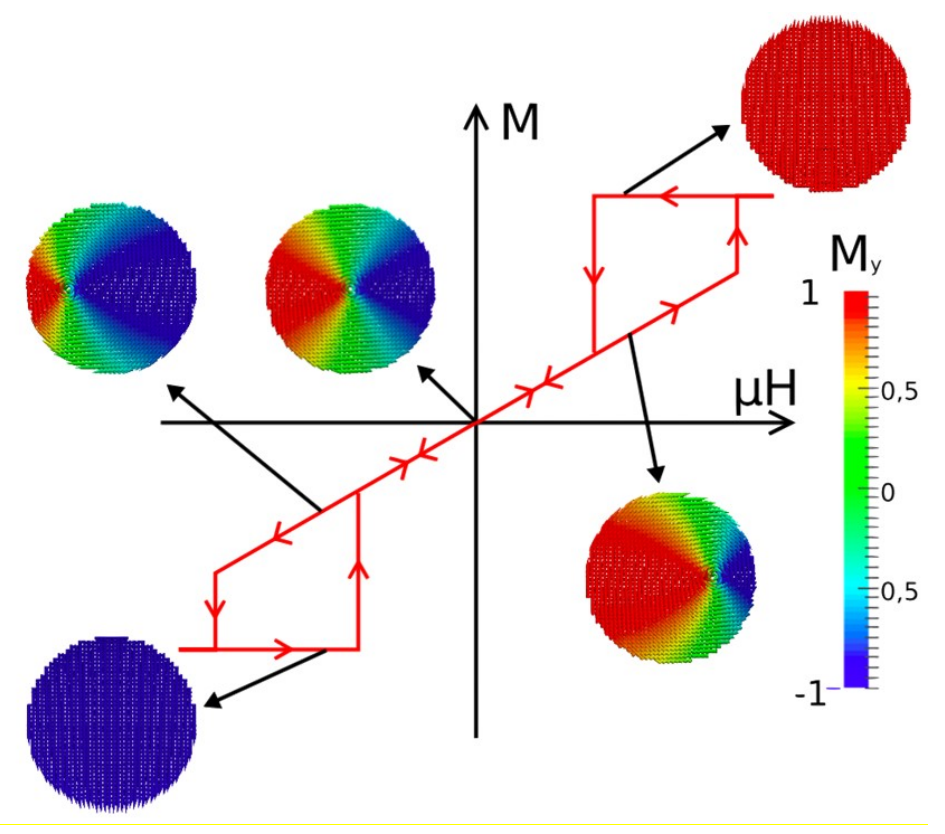

Figura 2.7 Representação da histerese medida ao longo da direção y e a distribuição dos momentos magnéticos correspondentes a diferentes regiões da histerese. ${ }^{38}$ 


\section{Capítulo 3. Técnicas de Caracterização}

\subsection{Microscopia Eletrônica}

Várias são as técnicas capazes de observar detalhes da superfície de forma ampliada. Uma das formas mais antigas e simples é o uso de uma lupa, a qual teve sua capacidade ampliada com o desenvolvimento do microscópio óptico. O microscópio óptico ilumina a amostra com luz visível ou ultravioleta e seu poder de aumento da imagem é de no máximo de 2000 vezes. ${ }^{39} \mathrm{Na}$ década de 1930 , foi desenvolvida uma nova técnica que possibilitou a análise de amostras na escala nanométrica, foi quando surgiu os primeiros microscópios eletrônicos.

A microscopia eletrônica é uma técnica de grande importância para o estudo de nanomateriais, pois esses possuem dimensões inferiores ou da ordem do comprimento de onda da luz visível. Sendo assim, efeitos de difração tornam-se críticos e impossibilitam o uso de microscópios ópticos no estudo de nanoestruturas.

Eles foram desenvolvidos por meio de métodos de visualização em que a imagem é formada a partir de feixes de elétrons, os mesmos são refratados por meio de lentes eletrônicas em um sistema de alto vácuo. Esse feixe de elétrons interage com a matéria resultando em vários fenômenos, como mostrado na Figura $3.1^{40}$ A mesma pode ser dividida em Microscopia Eletrônica de Transmissão (MET) e Microscopia Eletrônica de Varredura (MEV). 


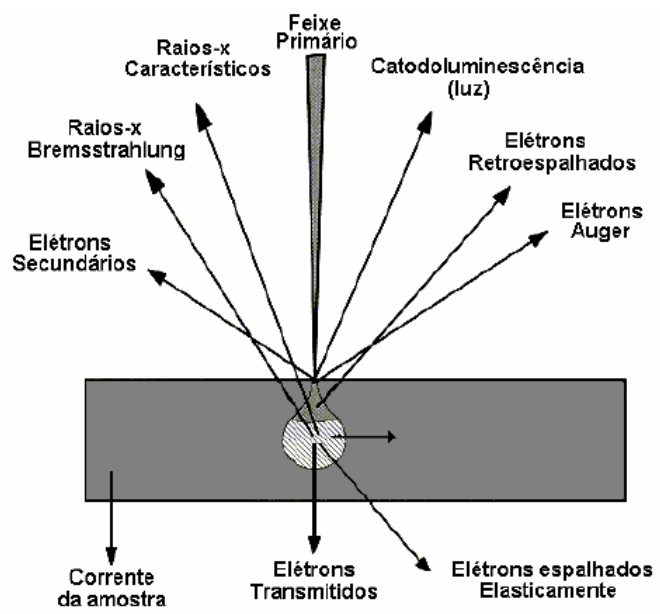

Figura 3.1 - Sinais resultantes da interação do feixe de elétrons primários com a amostra. ${ }^{41}$

Atualmente os microscópios eletrônicos, tanto o de transmissão como o de varredura, podem nos dar informações tais como, a ultraestrutura ou morfologia do objeto em estudo. Estas informações podem ser qualitativas (identificação e localização de elementos químicos) ou quantitativas ${ }^{42}$.

\subsubsection{Microscopia Eletrônica de Transmissão (MET)}

$\mathrm{Na}$ microscopia eletrônica de transmissão (MET) a imagem se forma no momento em que o feixe de elétrons atravessa a amostra. $\mathrm{O}$ padrão formado pelo feixe de elétrons é direcionada para um anteparo, com características fluorescentes, gerando uma imagem bidimensional ${ }^{43}$. $\mathrm{O}$ aumento do MET varia de 1000 a aproximadamente 200000 vezes.

No MET o fenômeno responsável por gerar o contraste é o espalhamento elástico, isso ocorre, pois parte desses elétrons são barrados pela abertura da lente objetiva. ${ }^{44}$. A partir das imagens de microscopia eletrônica é possível determinar o diâmetro médio das partículas. A contagem pode ser feita com o auxílio do software, como o Image-J. Para montar o histograma dos tamanhos das partículas usa-se o método 
Sturges ${ }^{45}$ Com os dados obtidos plota-se um histograma, que pode ser ajustado com uma distribuição log-normal $f(D)$ do tipo

$$
f(D)=\frac{A}{D \sigma \sqrt{2 \pi}} \exp \left[-\frac{\ln \left(D / D_{0}\right)}{2 \sigma^{2}}\right]
$$

onde, $\sigma$ é o desvio padrão do diâmetro (dispersão), $D_{0}$ é o diâmetro médio da distribuição e A parâmetro de normalização.

O diâmetro máximo $\left(D_{\text {máx }}\right)$ da distribuição pode ser dado por:

$$
D_{\text {máx }}=D_{0} \exp \left(-\sigma^{2}\right)
$$

sendo o valor do diâmetro médio $(\langle D\rangle)$ de

$$
\langle D\rangle=D_{0} \exp \left(\frac{\sigma^{2}}{2}\right)
$$

e o desvio padrão de

$$
\sigma_{D}=\langle D\rangle \sqrt{\exp \sigma^{2}-1}
$$

\subsection{2 - Microscopia Eletrônica de Varredura (MEV)}

O microscópio eletrônico de varredura tem poder de resolução em escala manométrica. Ele trabalha em vácuo e, geralmente, possui efeitos destrutivos para a amostra. No MEV os elétrons varrem a superfície do material a ser analisado, resultando em uma imagem topográfica, tridimensional, com grande quantidade de detalhes ${ }^{46}$. Durante a análise das amostras são produzidos raios-X, elétrons retroespalhados e elétrons secundários, todos esses sinais são detectados e analisados por diferentes técnicas (ver Figura 3.1) ${ }^{47} \mathrm{~A}$ imagem, nesse tipo de microscopia, é 
formada a partir dos elétrons secundários que saem da amostra, os mesmos são captados, passam por um amplificador e então são convertidos em imagem em um monitor. $^{48}$

A partir desse tipo de análise é possível obter imagens com aumento de até 100.000 vezes com resoluções na ordem de $20 \mathrm{~nm}$. As diferenças entre o microscópio eletrônico de varredura e o microscópio óptico, é que o MEV utiliza elétrons secundários em vez de luz para produzir uma imagem. Para focalizar o feixe é usado lentes magnéticas.

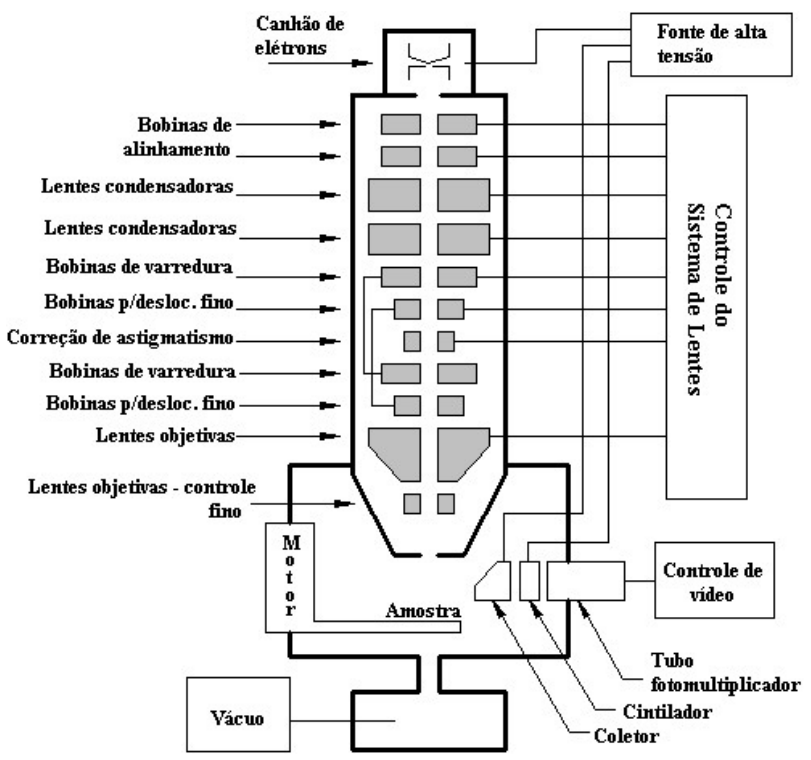

Figura 3.2 - Esquema da coluna do $M E V .^{49}$

\subsection{Difração de raios-X}

Em 1895, o físico alemão Wihelm Conrad Roentgen, realizando experimentos do comportamento de descargas elétricas em gases rarefeitos e ampolas de Crookes, descobriu os Raios X. Roentgen percebeu uma fluorescência que não era proveniente 
dos raios catódicos, pois os mesmos não atravessam o vidro do tubo. Ele percebeu que o que causava a florescência se originava na parede da ampola de Crookes, não sabendo do que se tratava chamou esses agentes de raios $\mathrm{X}^{50}$

Os raios $X$ são radiações eletromagnéticas com comprimento de onda $(\lambda)$ da ordem de $1,0 \AA$. Possuem características típicas de ondas, tais como polarização, interferência e difração. Eles são produzidos por meio de um feixe de elétrons acelerado que ao atingir um alvo, tubo de raios X, é freado, Figura 3.3. Quando os elétrons acelerados se chocam com o alvo produz dois tipos de raios X. Sendo que um deles forma o espectro contínuo, e é formado a partir da desaceleração dos elétrons durante a penetração no anodo. $\mathrm{O}$ outro tipo é o raio X característico do material do que forma o anodo. Dessa forma, cada espectro de raios $\mathrm{X}$ é a superposição de um espectro contínuo e de uma série de linhas espectrais características do anodo. ${ }^{51}$

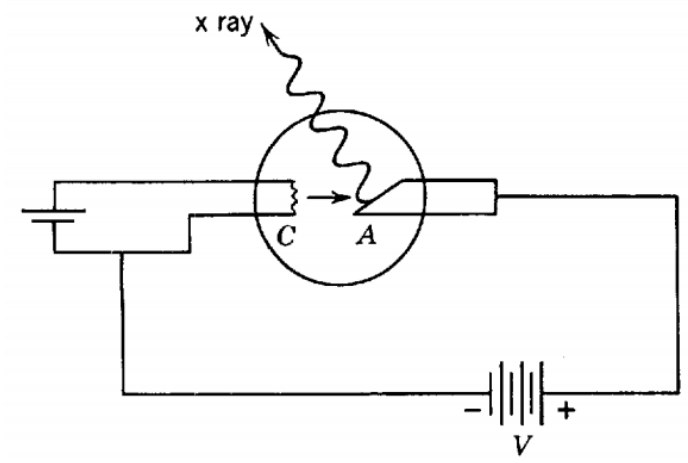

Figura 3.3 - Tubo de raios $X .{ }^{51}$

Uma das principais técnicas de caracterização microestrutural de materiais cristalinos é a difração de raios X, ela ocorre sempre que uma frente de ondas passa por fendas cuja separação é comparável ao comprimento de onda $(\lambda)$ da radiação. ${ }^{52}$

Para que ocorra a difração é necessário que o caminho percorrido pelos raios $\mathrm{X}$ e o comprimento de onda da radiação incidente sejam diferentes, isso levando em consideração dois ou mais planos de uma estrutura cristalina. Essa condição pode ser expressa pela lei de Bragg. ${ }^{53}$ 
$n . \lambda=2 d \operatorname{sen} \theta$, onde $\mathrm{n}$ é a ordem de difração

Toda vez que o ângulo de Bragg $\left(\theta_{\mathrm{B}}\right)$ for tal que a diferença de caminho ótico entre os feixes incidentes e difratados (ver Figura 3.4), a distância $\overline{M N L}$, for igual a um número inteiro $\mathrm{n}$ de comprimento de onda $\lambda$ haverá interferência construtiva. Dessa forma pode-se relacionar os espaços da rede $d_{h k l}$, (sendo h, k, 1 os índices de Miller ) com a distância $\overline{M N L}$,pela equação de Bragg. ${ }^{54}$

O diâmetro médio das nanopartículas pode ser determinado utilizando a equação de Scherrer, a mesma relaciona a dimensão dos nanocristais com a largura observada da linha difratada a meia altura do pico:

$$
p=\frac{K \lambda}{B \cos \theta_{B}}
$$

onde $p$ é o tamanho médio dos cristais, $K$ é a constante de Scherrer e B é a largura total à meia altura $^{53}$

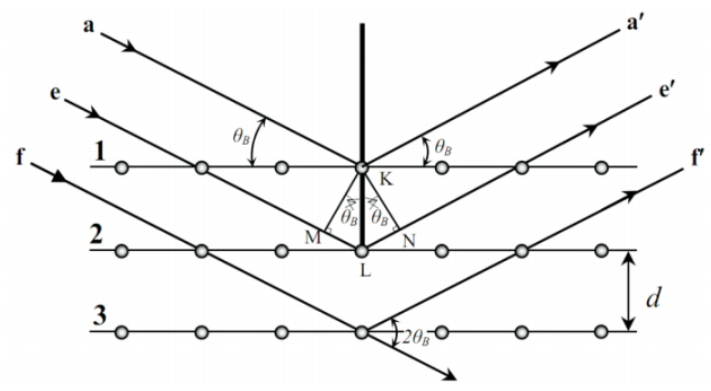

Figura 3.4 - Representação da difração de raios-X por um cristal. ${ }^{54}$

\subsection{Espectroscopia Raman}

A Espectroscopia Raman é uma técnica que utiliza uma fonte monocromática de luz que incide sobre a amostra e dessa forma ocorre uma interação e a luz é espalhada. 
Essa radiação espalhada é separada por um monocromador e a intensidade dela é medida por um detector que gera um espectro que relaciona a frequência do fóton espalhado com número de eventos em cada frequência (intensidade). ${ }^{55}$

Quando a luz possui a mesma energia que a fonte monocromática ocorre espalhamento elástico, espalhamento Rayleigh e quando a energia é diferente o espalhamento é inelástico, efeito Raman Figura 3.5. ${ }^{56}$

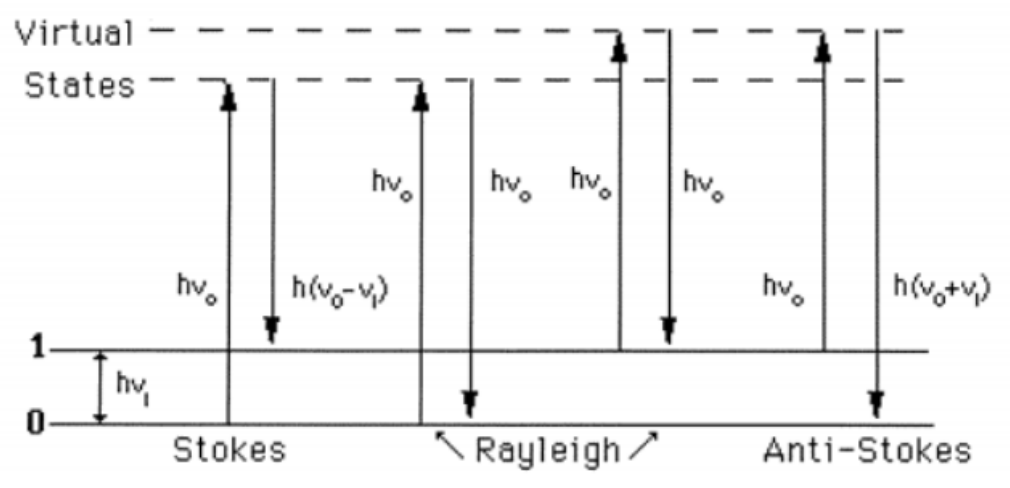

Figura 3.5-Representação do Espalhamento da radiação no Raman.

A partir do segundo tipo de espalhamento é possível obter várias informações importantes sobre a composição química do objeto por meio da diferença de energia.A diferença de energia está associada com alguma frequência de vibração da molécula que interagiu com o fóton, de acordo com a Equação 1. Quando isso ocorre, tem-se o efeito Raman vibracional, a mesma está ligada à variação do momento de dipolo induzido na molécula pelo campo elétrico da radiação incidente..$^{57}$

$$
E_{i}=E_{f} \pm h v_{\text {molec }}
$$

Sendo que, $\mathrm{E}_{i}$ é a energia do fóton incidente, $\mathrm{E}_{f}$ é a energia do fóton espalhado, $h$ é a constante de Planck e $v_{m o l e c}$ é a frequência de vibração da molécula. 


\subsection{Espectroscopia Mössbauer}

Rudolf Ludwing Mössbauer foi o primeiro a explicar o efeito Mössbauer em 1957 e recebeu o Prêmio Nobel em Física no ano de1961. ${ }^{58}$ A espectroscopia Mössbauer é uma forma de caracterização que faz a análise dos núcleos atômicos e do ambiente que o envolve por meio de um processo de absorção nuclear ressonante sem recuo. ${ }^{54}$

Ela é bastante útil, pois a partir dela é possível obter dados importantes, em relação a ligação química e a estrutura molecular. ${ }^{59}$ A mesma é bastante seletiva, pois detecta transições nucleares de energias muito baixas. ${ }^{60}$ Essa técnica não pode ser aplicada para todos elementos químicos e não pode ser utilizada em líquidos e gases, ela é utilizada principalmente para estanho e ferro.

Em qualquer tipo de espectroscopia, para detectar uma absorção, é necessário criar e destruir as condições de ressonância, então é necessário ter um dispositivo que varie a energia dos fótons emitidos. Na espectroscopia Mössbauer essa variação será feita pelo acréscimo de energia Doppler ao fóton quando se põe a fonte emissora em movimento. ${ }^{59}$

$\mathrm{Na}$ espectroscopia Mössbauer uma fonte radioativa adequada é utilizada para emitir radiação gama, que, por sua vez, pode ser absorvida por núcleos específicos presentes na amostra. No caso do ferro, por exemplo, uma fonte de ${ }^{57} \mathrm{Co}$, ao decair para ${ }^{57} \mathrm{Fe}$ emite outro fóton com energia de $14,4 \mathrm{keV}$ (Figura 3.6). Transições nucleares obtidas a partir absorção de raios $\gamma$ estão ligadas ao efeito Mössbauer, sendo a condição de ressonância entre a fonte e a amostra obtida pelo efeito Doppler. ${ }^{59,61}$ 


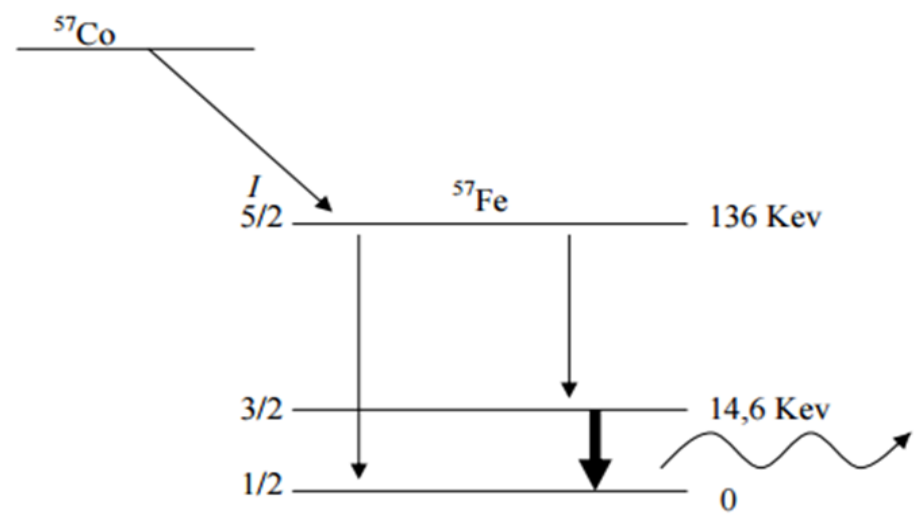

Figura 3.6 - Representação do decaimento radioativo do ${ }^{57} \mathrm{Co}$.

As principais condições para que o ocorra o efeito Mössbauersão: ${ }^{60}$

1. A amostra analisada tenha átomos do mesmo elemento, no estado fundamental.

2. Trocar o espectro de luz contínua por fótons $\gamma$, para absorção, fazer uso de núcleos idênticos aos que absorvem radiação $\gamma$, pois dessa forma é possível aumentar a detecção e a absorção.

3. A amostra que irá absorver a radiação $\gamma$ deve ter espessura pequena para ter uma quantidade de radiação emitida significativa.

4. Ter frequência $v_{0}$ e a diferença de energia entre os estados fundamental e excitado deverá ser expresso pela equação de Planck.

$$
E_{e}-E_{f}=E_{0}=\frac{h \cdot c_{0}}{\lambda}=h . v
$$

Onde $h=6,26075 \times 10^{-34} \mathrm{~J} . \mathrm{s}$ (constante de Planck), $c_{0}=299792458 \mathrm{~m} . \mathrm{s}^{-1}$ (velocidade da luz no vácuo), $\lambda$ é o comprimento de onda e $v$ é a frequência de radiação.

Quando os núcleos sonda sofrem perturbações ao interagir com os núcleos da sua vizinhança surgem as diferenças de energia entre os níveis nucleares do emissor e absorvedor. Essas interações são denominadas interações hiperfinas. ${ }^{45}$ 


\subsubsection{Interações Hiperfinas}

Existem três interações fundamentais no efeito Mössbauer, sendo elas:

A interação monopolar elétrica, responsável por gerar um deslocamento do espectro Mössbauer, o deslocamento isomérico (IS), como mostra a Figura 3.7. Tal fenômeno se manifesta como um afastamento, em relação ao zero da velocidade, do centroide do espectro de ressonância. Dessa forma esse deslocamento é resposta da diferença entre o estado excitado e o fundamental da energia de interação eletrostática entre a densidade de cargas nucleares e a distribuição de cargas eletrônica, que possuem uma probabilidade finita de serem encontradas na região nuclear. ${ }^{61}$ Por meio da medida do desvio isomérico é possível obter informações sobre a densidade eletrônica (como estados de oxidação, grau de covalência, tipo de ligação, entre outros) no núcleo em diferentes compostos químicos. ${ }^{45}$

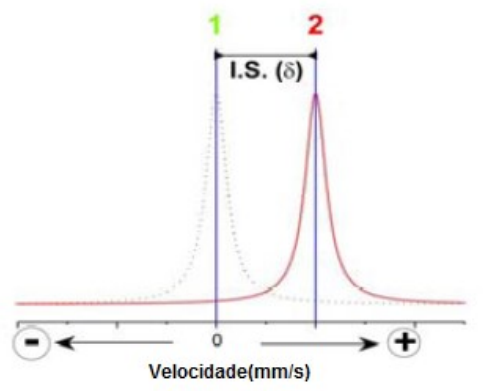

(a)

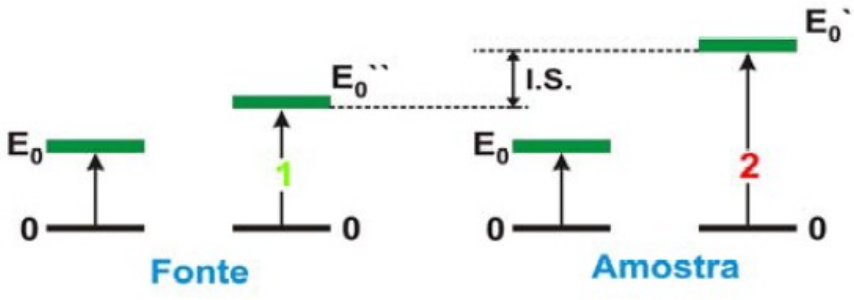

(b)

Figura 3.7- (a) Espectro com desvio isomérico e (b) esquema do deslocamento dos níveis de energia do núcleo. ${ }^{62}$

O desdobramento quadrupolar elétrico, causa divisões das linhas espectrais, como mostra a Figura 3.8. No estado excitado $\left(\mathrm{I}_{\mathrm{ex}}=3 / 2\right)$, o núcleo do ${ }^{57} \mathrm{Fe}$ possui um momento de quadrupolo nuclear (QS), sendo assim, a distribuição de cargas nucleares deste estado não é esférica. Quando este núcleo estiver em um local onde a distribuição de cargas extra nucleares não for esfericamente simétrica, ou seja, num ambiente onde 
existir um Gradiente de Campo Elétrico não nulo, surge uma interação quadrupolar de natureza eletrostática ${ }^{63}$ Essa interação gera informações sobre a simetria das primeiras esferas de coordenação do núcleo sonda que, por sua vez, é influenciada pelo tipo de ligação química, presença de vacâncias de oxigênio, e outros tipos de desordem estrutural.

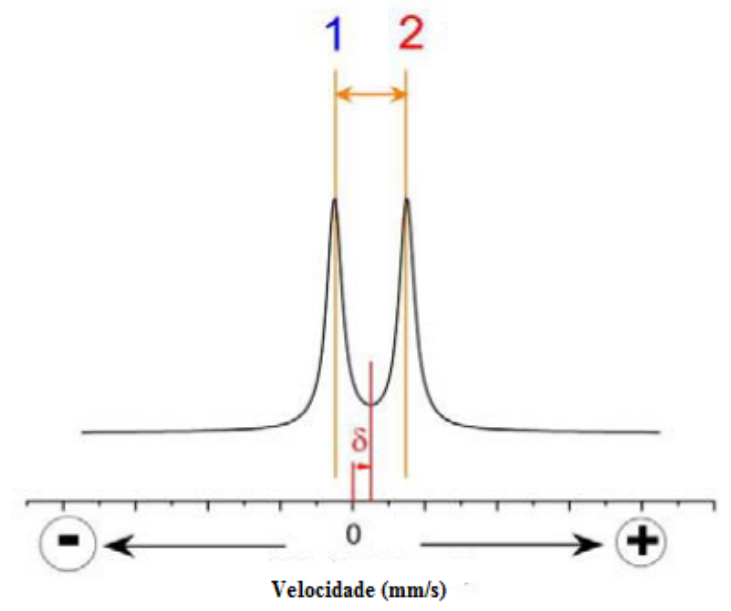

(a)

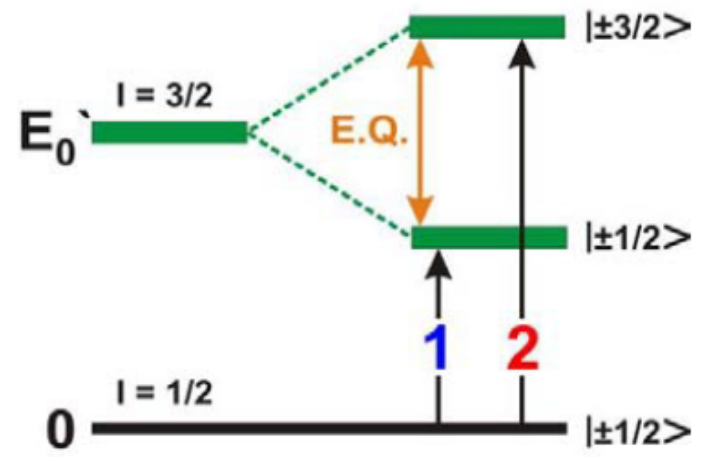

(b)

Figura 3.8 - (a) Espectro com desdobramento quadrupolar e (b) esquema do desdobramento quadrupolar. ${ }^{62}$

Campo Magnético Hiperfino, a interação hiperfina magnética ocorre entre o núcleo e os elétrons da vizinhança através do momento de dipolo magnético nuclear e o campo magnético no núcleo, quando há a presença de um campo magnético externo, ocorre a quebra de degenerescência dos níveis de energia, fenômeno chamado de efeito Zeeman. O núcleo absorvedor, que possui momento dipolar magnético nuclear, interage com o campo magnético da vizinhança (do núcleo da amostra), na posição por ela ocupada. Essa interação dá origem ao sexteto, devido o desdobramento dos níveis envolvidos em seus subníveis e consequentes transições que são permitidas pelas regras de seleção, como mostrado na Figura 3.9. Esse efeito remove completamente a degeneração dos níveis de energia nuclear. Essa interação levanta a degenerescência do nível de energia de um núcleo de spin I e se desdobrando em (2I+1) subníveis. ${ }^{62,64}$ 


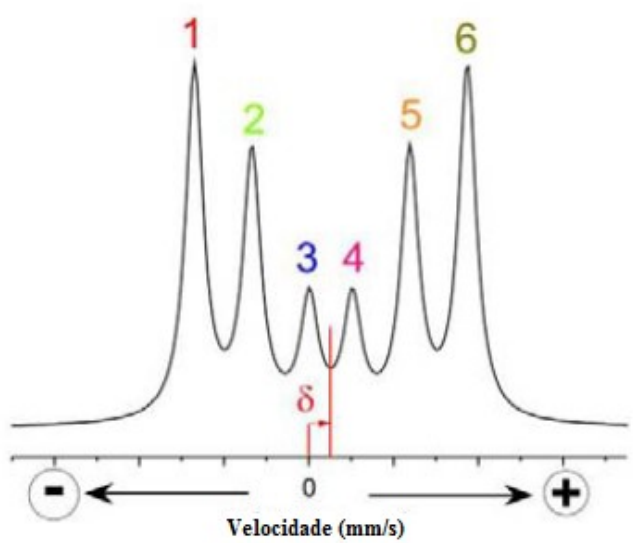

(a)

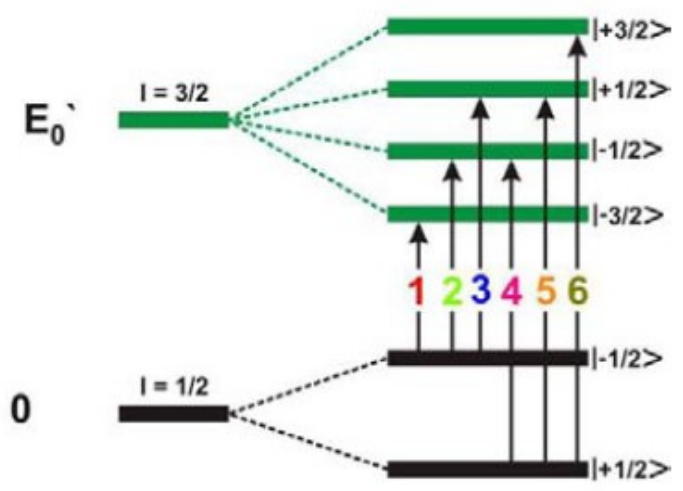

(b)

Figura 3.9 - (a) Espectro com desdobramento magnético e (b) esquema do desdobramento magnético. ${ }^{62}$

\section{5 - Medidas de Magnetização}

A forma com que se comporta magneticamente, um determinado composto nanopartículado, depende basicamente das propriedades físicas de cada partícula e do ambiente em que ela se encontra. De acordo com a resposta de um material a um campo magnético aplicado é possível classifica-lo. Essa classificação pode ser dada pela razão entre a magnetização do meio $(\mathrm{M})$ e campo magnético $(\mathrm{H})$, sendo assim a mesma será denominada de susceptibilidade $(\chi)$ :

$$
\chi=\frac{M}{H}
$$

A relação entre a indução magnética $(B)$ e $H$, também indica a resposta do material ao campo magnético é chamada de permeabilidade $(\mu)$ :

$$
\mu=\frac{B}{\boldsymbol{H}}
$$

Curvas de $\mathrm{M}$ ou $\mathrm{B}$ versus $\mathrm{H}$ são denominadas curvas de magnetização e são características do tipo de material. Utiliza-se uma curva de magnetização $(\mathrm{M})$ versus 
campo magnético $(\mathrm{H})$ para o estudo de materiais magnéticos, a partir dela obtém-se um ciclo denominado de curva de histerese. A magnetização do material varia em função da intensidade do campo magnético aplicado. O valor máximo de magnetização atingido é denominado de magnetização de saturação $\left(\mathrm{M}_{\mathrm{S}}\right)$. Se o campo magnético for reduzido, os momentos magnéticos efetivos tendem as se desalinharem e, consequentemente, a magnetização total do material diminui. ${ }^{65}$

Em materiais ferro e ferrimagnéticos, inicialmente, o campo induzido é nulo e aumenta gradativamente, até que a amostra atinja a saturação. Após esse processo, o campo induzido é novamente reduzido até atingir o valor nulo. Para o campo igual a zero, o valor da magnetização não é nulo, o que é chamada de magnetização remanescente $\left(\mathrm{M}_{\mathrm{r}}\right)$ Em seguida, o sentido do campo é invertido para fazer com que a magnetização caia para zero, dessa forma é obtido o campo coercivo ou coercividade $\left(\mathrm{H}_{\mathrm{C}}\right)$. O campo é aumentado novamente, até o material alcançar a saturação no sentido oposto. O campo é posteriormente reduzido e invertido novamente, até fechar o ciclo, formando assim a curva de histerese, mostrado na Figura 3.10. O ciclo de histerese mostra a magnetização de um determinado material sob a influência de um campo magnético e o quanto de magnetização permanece nele depois que esse campo é removido. ${ }^{66}$

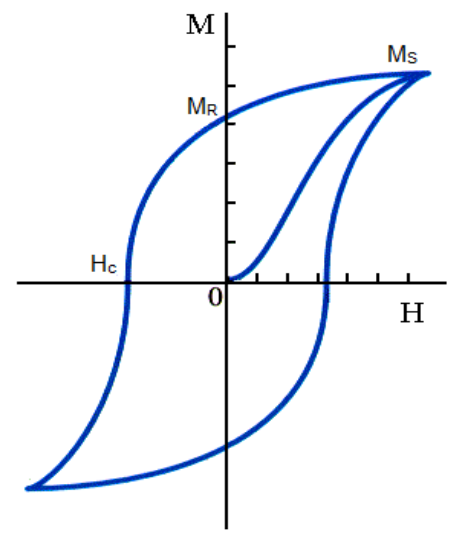

Figura 3.10 - Curva de histerese. ${ }^{67}$ 


\section{Capítulo 4. Procedimentos Experimentais}

\subsection{Materiais}

Os materiais utilizados para todas as sínteses foram:

- Sulfato de sódio Anidro P.A. - ACS, $\mathrm{Na}_{2} \mathrm{SO}_{4}$, VETEC - Química Fina LTDA, Teor: 99,0\%;

- Fosfato de sódio monobásico Anidro P.A. , $\mathrm{NaH}_{2} \mathrm{PO}_{4}$, Cromoline Química Fina, Teor: 99,0\%

- Fosfato de sódio dibásicoheptahidratado P.A., $\mathrm{Na}_{2} \mathrm{HPO}_{4} .7 \mathrm{H}_{2} \mathrm{O}$,VETEC - Química Fina LTDA, Teor: 98,0\% - 102,0\%;

- Cloreto férrico hexahidratado P.A., $\mathrm{FeCl}_{3} .6 \mathrm{H}_{2} \mathrm{O}$, Synth, Teor: 97,0\% $102,0 \%$;

- Água destilada;

- Gás comprimido: Hidrogênio e Argônio $\left(H_{2}\right.$ e $\left.A r\right)$, na proporção 4\% / $96 \%$, respectivamente.

\subsection{Metodologia}

A metodologia empregada nesse trabalho foi:

- A síntese de nanoanéis magnéticos pelo método hidrotermal.

- A caracterização dos nanoanéis: a morfologia e a distribuição de tamanho dos mesmos foram realizadas a partir da 
MicroscopiasEletrônica de Varredura (MEV), Microscopias Eletrônica Transmissão (MET) e Microscopia Eletrônica de Transmissão de Alta Resolução (HRTEM)

- A estrutura e a fase cristalográfica foram realizadas por meio das técnicas de Difração de raios-X (DRX) e Espectroscopias Raman

- As propriedades magnéticas foram determinadas por meio da Espectroscopia Mössbauer e medidas de Magnetização

\subsubsection{Síntese das Nanopartículas}

\subsubsection{Síntese da Hematita}

As nanopartículas de hematita $\left(\alpha-\mathrm{Fe}_{2} \mathrm{O}_{3}\right)$ foram preparadas a partir da adaptação da rota de síntese descrita no trabalho de Liang e colaboradores ${ }^{68}$, conforme descrito a seguir.

Foi dissolvido em $400 \mathrm{mLde}$ água destilada 216,24mg de $\mathrm{FeCl}_{3} \cdot 6 \mathrm{H}_{2} \mathrm{O}$ em seguida foi adicionado $1,07 \mathrm{mg}$ de $\mathrm{Na}_{2} . \mathrm{HPO}_{4} \cdot 7 \mathrm{H}_{2} \mathrm{O}$ e $3,13 \mathrm{mg}$ de $\mathrm{Na}_{2} \mathrm{SO}_{4}$. A solução foi colocada no ultrassom por 10 minutos. Foi transferido60mL dessa solução para uma autoclave de inox com recipiente para amostra de teflon, a mesma foi levada para a estufa à $210^{\circ} \mathrm{C}$, por $48 \mathrm{~h}$.

Depois da autoclave a solução foi resfriada à temperatura ambiente, e em seguida o precipitado foi separado por centrifugação, lavado com água destilada e etanol absoluto e seco sob vácuo, a temperatura ambiente. Com este procedimento foram obtidos osnanoanéis hematita. Estas amostras foram denominadas $\mathrm{NA}-\left(\alpha-\mathrm{Fe}_{2} \mathrm{O}_{3}\right)$. 


\subsubsection{Redução dos nanoanéis de $\alpha-\mathrm{Fe}_{2} \mathrm{O}_{3}$ para $\mathrm{Fe}_{3} \mathrm{O}_{4}$}

Para a preparação dos nanoanéis de $\mathrm{Fe}_{3} \mathrm{O}_{4}$, foi realizado a redução dos nanoanéis de $\alpha-\mathrm{Fe}_{2} \mathrm{O}_{3}$. Para esse processo o pó seco de $\alpha-\mathrm{Fe}_{2} \mathrm{O}_{3}$ foi aquecido em forno tubular a $500^{\circ} \mathrm{C}$ sob um ambiente misto de $\mathrm{H}_{2}(5 \%)$ e $\mathrm{Ar}(95 \%)$ durante $3 \mathrm{~h}$. Em seguida, o forno foi resfriado até à temperatura ambiente ainda sob um contínuo fluxo do gás hidrogênio e do gás argônio. ${ }^{69}$ Estas amostras foram denominadas NA- $\left(\mathrm{Fe}_{3} \mathrm{O}_{4}\right)$.

\subsubsection{Preparo da amostra de magnetita bulk - Amostra de referência}

Para comparação dos resultados de difração de raios-X e de magnetização, foi utilizada uma amostra de referência, constituída por partículas micrométricas de um cristal de magnetita natural previamente macerado. Esta amostra foi denominada de $\mathrm{Fe}_{3} \mathrm{O}_{4}-$ bulk.

\subsubsection{Caracterização dos Materiais}

\subsubsection{Espectroscopia Raman}

Para a aquisição dos espectros Raman foi utilizado um espectrômetro triplo Jobin Yvon, modelo T64000 equipado com grades de 1800 linhas por milímetro e uma CCD (Charge-Coupled Device) de 2048 x 512 pixels resfriada a nitrogênio. O sistema permite realizar medidas em macro-Raman e em micro-Raman, sendo que para as medidas em micro-Raman podem ser utilizadas objetivas de 10,50 e 100 vezes. Como fonte de excitação, podem-se utilizar lasers de Argônio sintonizado na linha $514 \mathrm{~nm}$. 
As amostras usadas para obter os espectros Raman foram preparadas das seguintes formas:

- A hematita foi seca em dessecadora, sob vácuo. O pó seco foi depositado sobre uma lamínula de vidro e a mesma foi analisada.

- O pó seco de magnetita foi colocado sobre a lamínula de vidro e então analisado.

\subsubsection{Difração de raios $X$}

As medidas de difração de raios X foram realizadas no Laboratório de Difração de Raios-X do Instituto de Geociências da Universidade de Brasília. Foi utilizado um difratrômetro modelo Rigaku (Ultima IV) na configuração $\theta-2 \theta$.

A fonte de radiação utilizada foi um tubo de cobre, $K_{\alpha}($ médio $)=1,5418 \AA$. As medidas foram realizadas geralmente no intervalo de $20^{\circ}$ a $120^{\circ}$, com um passo de $0,05^{\circ}$ e com uma velocidade de varredura de $0,5^{\circ}$ por minuto.

\subsubsection{Medidas de Magnetização}

As medidas de magnetização (curvas de histerese e medidas de FC e ZFC) foram realizadas no Magnetômetro SQUID da Quantum Design. As medidas foram realizadas no intervalo de temperatura de 4 a $300 \mathrm{~K}$ e campos magnéticos variando de 0 a 5 T. As medidas de ZFC e FC foram realizadas sob campo magnético de 100 Oe 


\subsubsection{Espectroscopia Mössbauer}

As medidas de espectroscopia Mössbauer foram realizadas no Laboratório de Espectroscopia Mössbauer do Instituto de Física da Universidade de Brasília.

Os espectros foram obtidos a partir da geometria de transmissão, usando uma fonte de ${ }^{57}$ Co numa matriz de Ródio (Rh), a temperatura ambiente e a $77 \mathrm{~K}$.

Ciências Biológicas da Universidade de Brasília, no departamento de Biologia Celular.

As amostras foram examinadas e fotografadas com um microscópio eletrônico de transmissão JOEL, modelo 1011, operando em 80kV.

\subsubsection{Microscopia Eletrônica de Varredura}

As imagens de microscopia Eletrônica de Varredura foram obtidas no Laboratório de Microscopia do Instituto de Ciências Biológicas da Universidade de Brasília, no departamento de Biologia Celular.

As amostras foram examinadas e fotografadas através do Microscópio de Varredura JEOL, modelo JSM-7001F, em condições de vácuo de 3,6 x $10^{-4} \mathrm{~Pa}$.

Para o preparo das amostras de nanoanéis aqui estudadas, aproximadamente 1 mg das mesmas foi dispersa em água destilada que em seguida foi agitada com ultrasom por cerca de 15 minutos. Após esse procedimento, uma alíquota da dispersão final foi depositada sobre um porta amostra ('stub' metálico). A amostra secou à temperatura ambiente. Finalmente, as imagens de MEV foram obtidas. 


\subsubsection{Microscopia Eletrônica de Transmissão de Alta Resolução}

As imagens de Microscopia Eletrônica de Transmissão de Alta Resolução foram obtidas no Laboratório Multiusuário de Microscopia de Alta Resolução, no departamento de Física da Universidade Federal de Goiás.

As amostras foram analisadas através do Microscópio Eletrônico de Transmissão (MET), Jeol, modelo JEM-2100, equipado com EDS, Thermo Scientific.

Para o preparo das amostras de nanoanéis aqui estudadas, aproximadamente 1 mg das mesmas foi dispersa em água destilada que em seguida foi agitada com ultrasom por cerca de 15 minutos. Após esse procedimento, uma alíquota da dispersão final foi depositada sobre filme de formvar suportado por uma grade de cobre de 100 mesh. A tela secou à temperatura ambiente. Finalmente, as imagens de TEM foram obtidas. 


\section{Capítulo 5. Resultados e Discussões}

\subsection{Microscopia Eletrônica de transmissão}

Como o objetivo verificar a morfologia das nanoetruturas como sintetizadas e tratadas termicamente em atmosfera rica de hidrogênio, micrografias de Microscopia Eletrônica de Varredura (MEV), Microscopia Eletrônica de Transmissão (MET) e de Microscopia Eletrônica de Transmissão de Alta Resolução (HRTEM) foram obtidas. Nas Figuras. 5.1 e 5.2 são exibidas as micrografias de MEV ((a) e (b)), MET ((c) e (d)e HRTEM (e) e (f) das amostras NA- $\left(\alpha-\mathrm{Fe}_{2} \mathrm{O}_{3}\right)$ e NA- $\left(\mathrm{Fe}_{3} \mathrm{O}_{4}\right)$, respectivamente. Das micrografias pode-se claramente observar que estruturas com morfologias de nanoanéis com tamanhos uniformes são produzidas em larga escala para ambas as fases cristalográficas. Como observado nas Figuras. 5.1 e 5.2 (d) os nanoanéis são monocristais que exibem morfologias dodecaédrica com um buraco central. Por último, são mostrados nas Fig. 5.1 e 5.2 (e) e (f) as micrografias de HRTEM, evidenciando a presenças dos planos (-210) e (110) da amostra NA- $\left(\alpha-\mathrm{Fe}_{2} \mathrm{O}_{3}\right)$ e dos planos (322) e (221) da amostra NA-( $\left.\mathrm{Fe}_{3} \mathrm{O}_{4}\right)$, respectivamente.

Histogramas obtidos a partir das micrografias de MET são mostrados na Fig. 5.3. Nos painéis (a), (b) e (c) são mostrados os dados referentes aos valores dos diâmetros externos e internos e das espessuras dos nanoanéis da amostra da amostra NA- $\left(\alpha-\mathrm{Fe}_{2} \mathrm{O}_{3}\right)$, enquanto os painéis (d), (e) e (f) mostram os mesmos dados para os nanoanéis da amostra NA-( $\left.\mathrm{Fe}_{3} \mathrm{O}_{4}\right)$. Note que ambas as amostras apresentam nanoanéis com diâmetros externos da ordem de $140 \mathrm{~nm}$, com baixa dispersão de tamanho $(\sigma=$ 0.12). Em completo, o diâmetro interno dos nanoanéis de ambas as fases é da ordem de $70 \mathrm{~nm}$, com dispersão de tamanho bem mais elevada $(\sigma \sim 0.30)$. Por último, a maior 
dispersão de tamanho é verificada para a espessura dos nanoanéis $(\sigma \sim 0.4)$, os quais são da ordem $95 \mathrm{~nm}$.

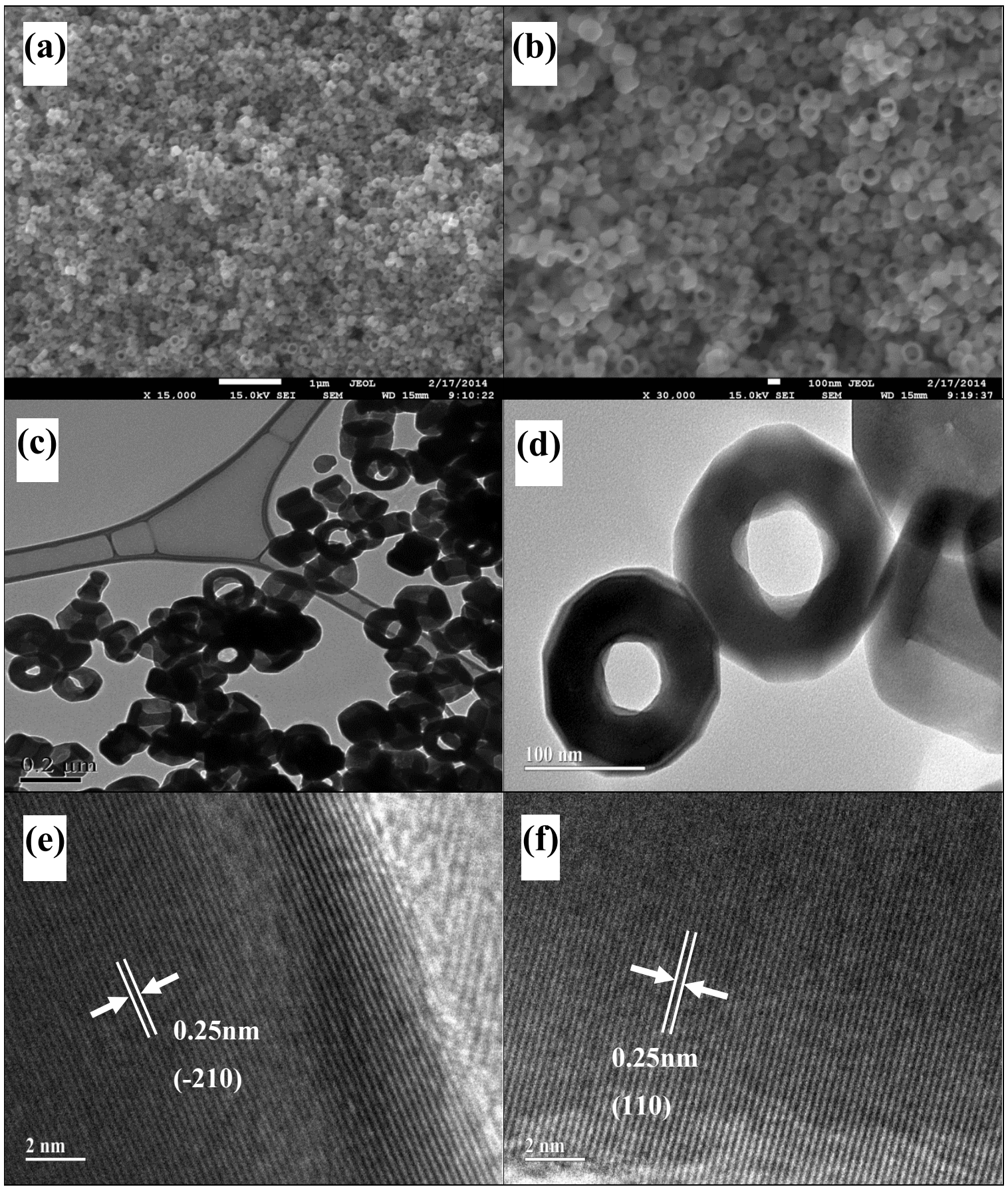

Figura 5.1 - Micrografias de MEV (a, b), MET (c, d) eHRTEM (e, f) da amostra NA-( $\left.\alpha-\mathrm{Fe}_{2} \mathrm{O}_{3}\right)$. 


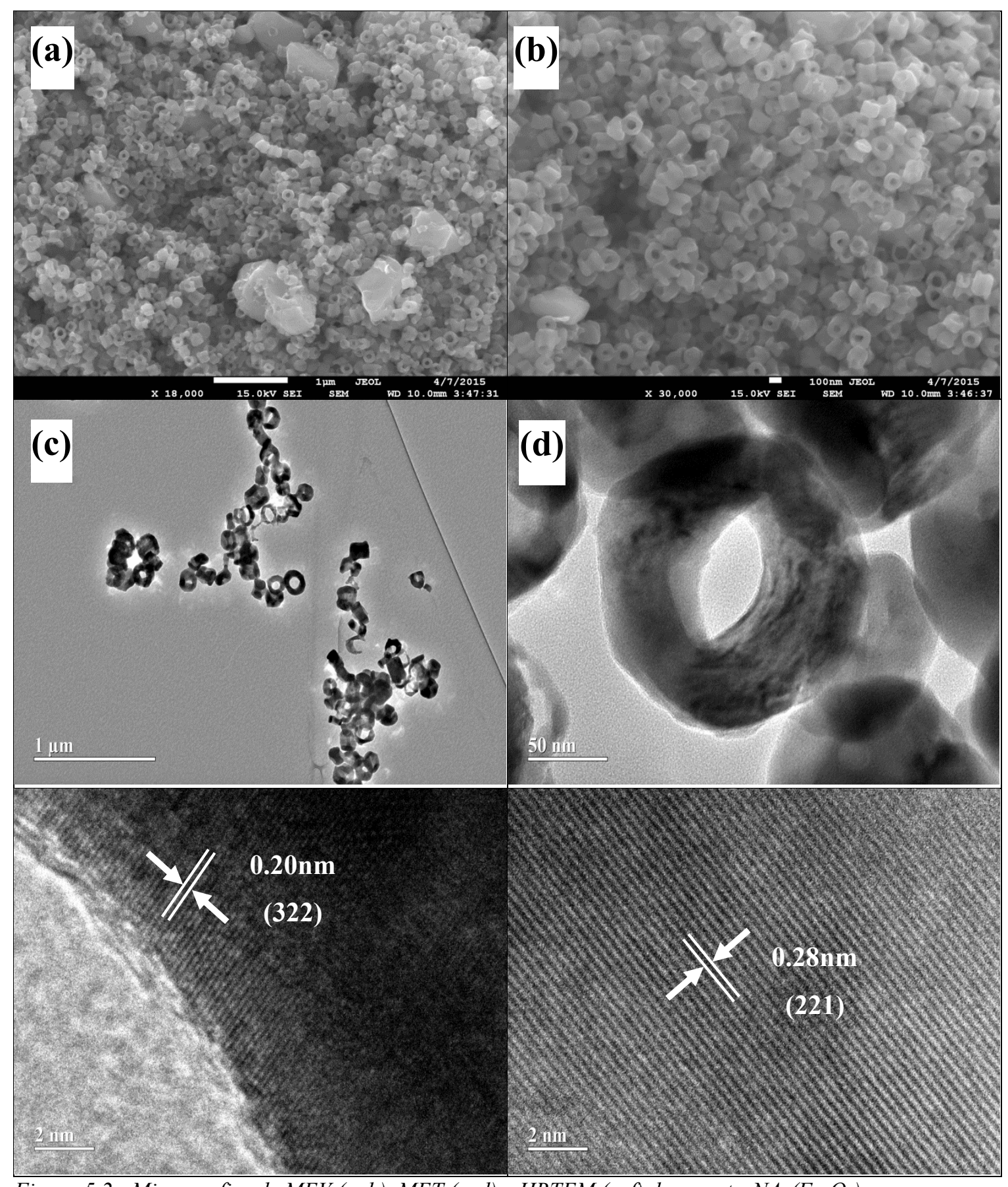

Figura 5.2 - Micrografias de MEV (a, b), MET (c, d) e HRTEM (e, f) da amostraNA-(Fe $\mathrm{O}_{4}$ ). 


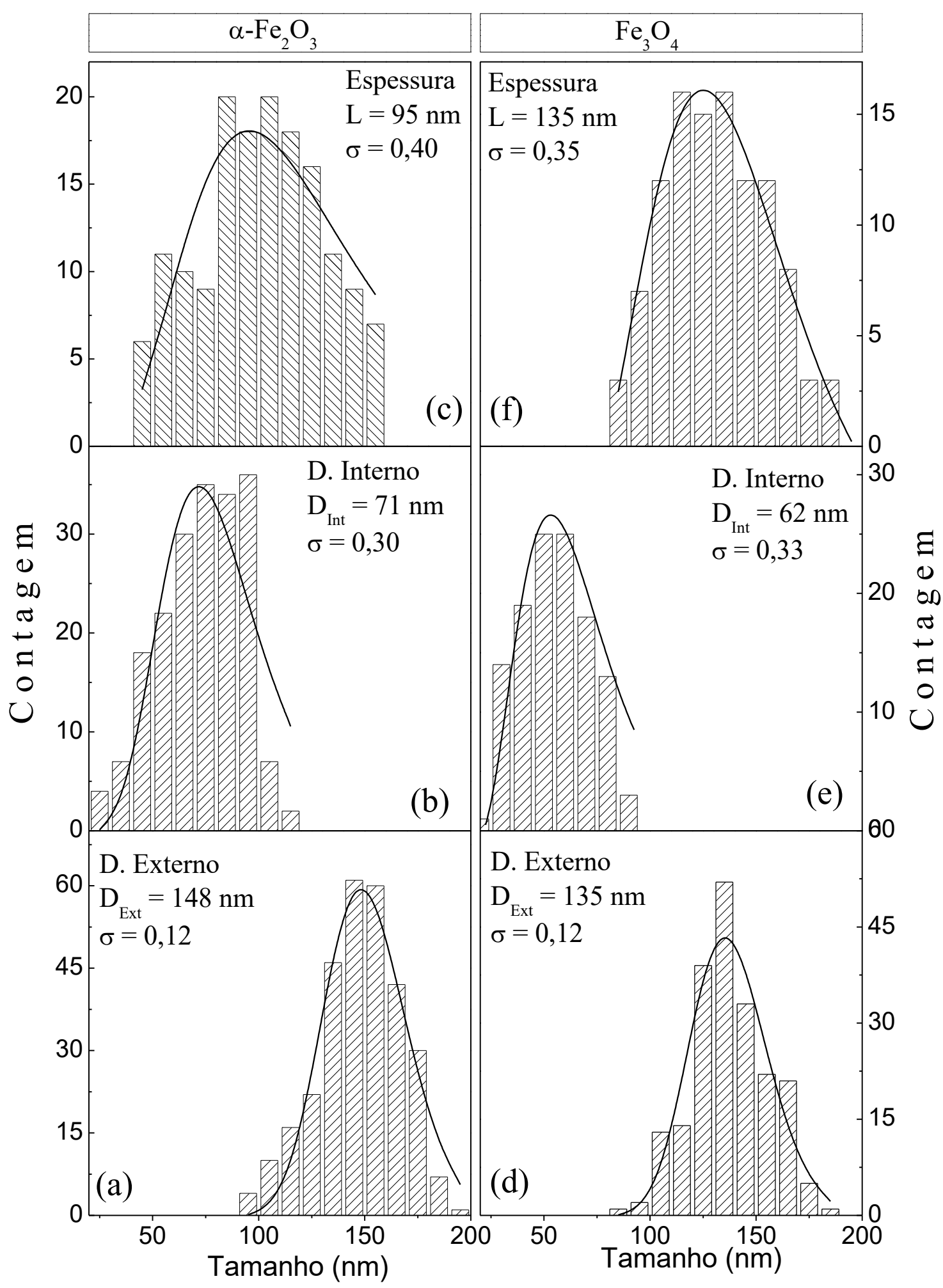

Figura 5.3 - Histogramas obtidas a partir das imagens de MET das amostras $\mathrm{NA}-\left(\alpha-\mathrm{Fe}_{2} \mathrm{O}_{3}\right)$ e $\mathrm{NA}$ $\left(\mathrm{Fe}_{3} \mathrm{O}_{4}\right)$. Nos painéis (a), (b) e (c) são mostrados os dados referentes aos valores dos diâmetros externos e internos e da espessura dos nanoanéis da amostra $\mathrm{NA}-\left(\alpha-\mathrm{Fe}_{2} \mathrm{O}_{3}\right)$, enquanto os painéis (d), (e) e (f) mostram os mesmos dados para a amostra $\mathrm{NA}-\left(\mathrm{Fe}_{3} \mathrm{O}_{4}\right)$. 


\subsection{Difração de raios-X}

Como o objetivo de determinar as fases cristalográficas das nanoestruturas aqui preparadas, medidas de difração de raios-X (DRX) foram realizadas. Os difratogramas obtidos para as amostras NA- $\left(\alpha-\mathrm{Fe}_{2} \mathrm{O}_{3}\right)$ e NA-( $\left.\mathrm{Fe}_{3} \mathrm{O}_{4}\right)$ são mostrados na Fig. 5.4 (i) e (ii), respectivamente. Para comparação, um difratograma de uma amostra de magnetita natural (denominada bulk) foi obtido (Fig. 5-4 (iii)). Para obter os parâmetros de rede e verificar a presença de fases extras todos os difratogramas foram refinados pelo método de Rietveld, para isto foi utilizado o Programa $\mathrm{GSAS}^{70} \mathrm{e}$ a interface gráfica EXPGUI. ${ }^{71}$ Os picos de difração foram ajustados com a função de perfil de pseudoVoigt de Thompson-Cox-Hastings. ${ }^{72} \mathrm{O}$ difratograma apresentado na Fig.4 (i) mostra, como esperado, linhas características da fase hematita, com parâmetros de rede $a_{\mathrm{o}}=$ $5.0359 \AA$ e $c_{0}=13.762 \AA$, em concordância com os dados padrão (JCPDS 33-0664 - $a_{\mathrm{o}}$ $=5.0356 \AA$ eco $=13.7489 \AA$ ). Não foi verificada a presença de outras fases cristalográficas.

Na comparação entre os difratogramas mostrados na Fig. 5.4 (ii) e (iii), é verificado que o tratamento térmico em atmosfera rica de hidrogênio da fase hematita, induziu, como desejado, a formação da fase espinélio cúbica, caracterizados pelos picos de difração principais em $2 \theta=30,0,35,5,43,1,57,0,62,6$, e $89,7^{\circ}$ indexados aos planos cristalográficos (220), (311), (400), (333), (440) e (731), respectivamente. 


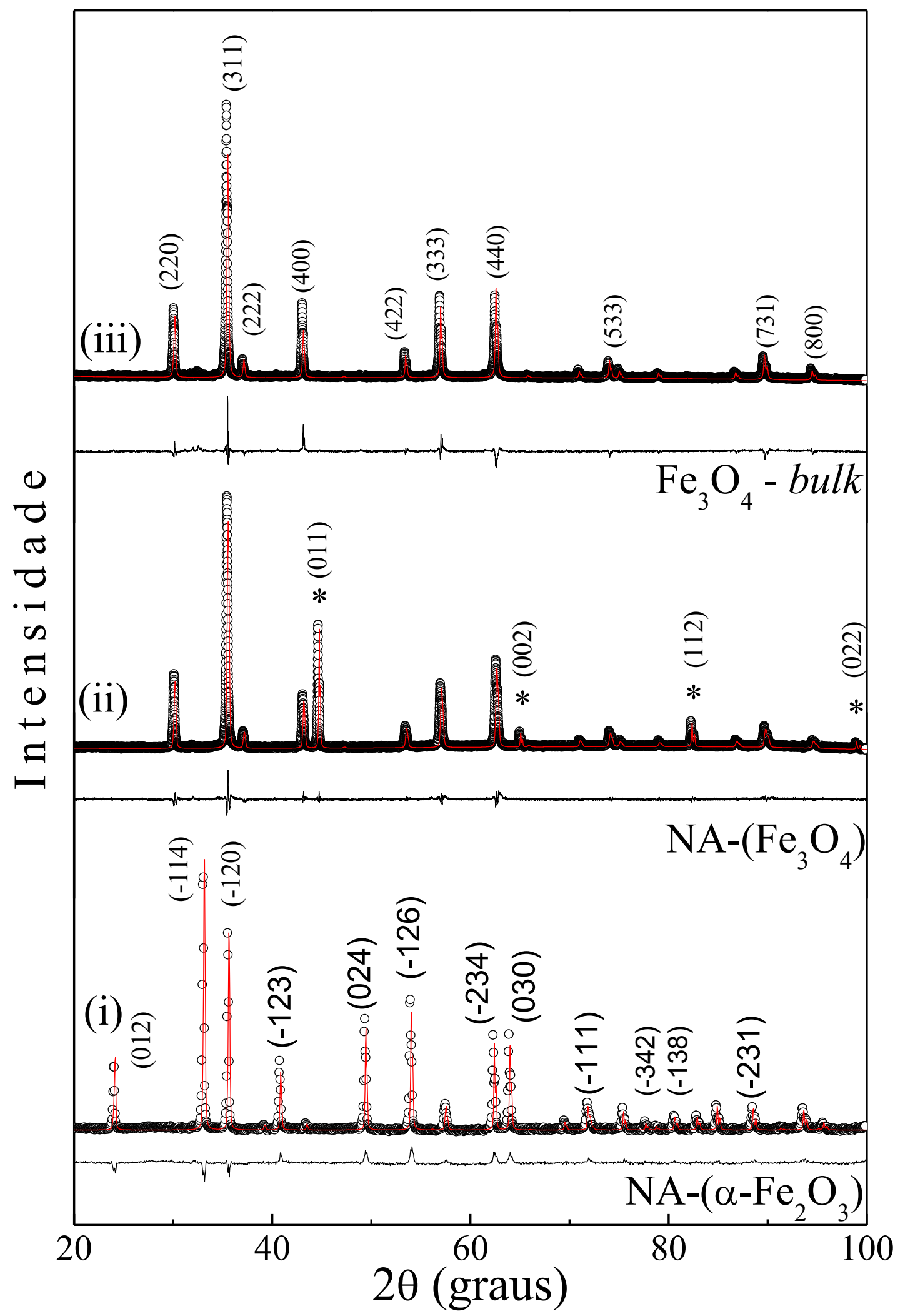

Figura 5.4 - Refinamento Rietveld dos padrões de DRX das amostras $\mathrm{NA}-\left(\alpha-\mathrm{Fe}_{2} \mathrm{O}_{3}\right)$ (i) e $\mathrm{NA}-\left(\mathrm{Fe}_{3} \mathrm{O}_{4}\right)(\mathrm{ii})$. Em (iii) é mostrado um padrão de DRX de uma amostra de magnetita bulk. 
Foi encontrado que o parâmetro de rede da fase espinélio cúbica é de $8.396 \AA$, em concordância com a carta cristalográfica da magnetita, JCPDS 79-0417 onde $a_{\mathrm{o}}=$ 8.394Å. Contudo, além dos picos de difração típicos da magnetita é também verificado a presença de picos de difrações extras, em torno de $2 \theta=44,8,65,0$ 82,5 e 98,8 ${ }^{\circ}$. Estes picos de difração estão associados aos planos (011), (002), (112) e (022), característicos da fase cristalográfica do $\alpha$-Fe, com parâmetro de rede de $a_{o}=2.867 \AA$. Também em concordância coma carta cristalográfica referente ao $\alpha$-Fe (JCPDS 03-065-4899, com $a_{o}$ $=2.867 \AA$ ). Em complemento, o refinamento de Rietvield mostrou que as frações de massa das fases cristalográficas espinélio cúbica e $\alpha$-Fe são de $88 \%$ e $\quad 12 \%$ respectivamente.
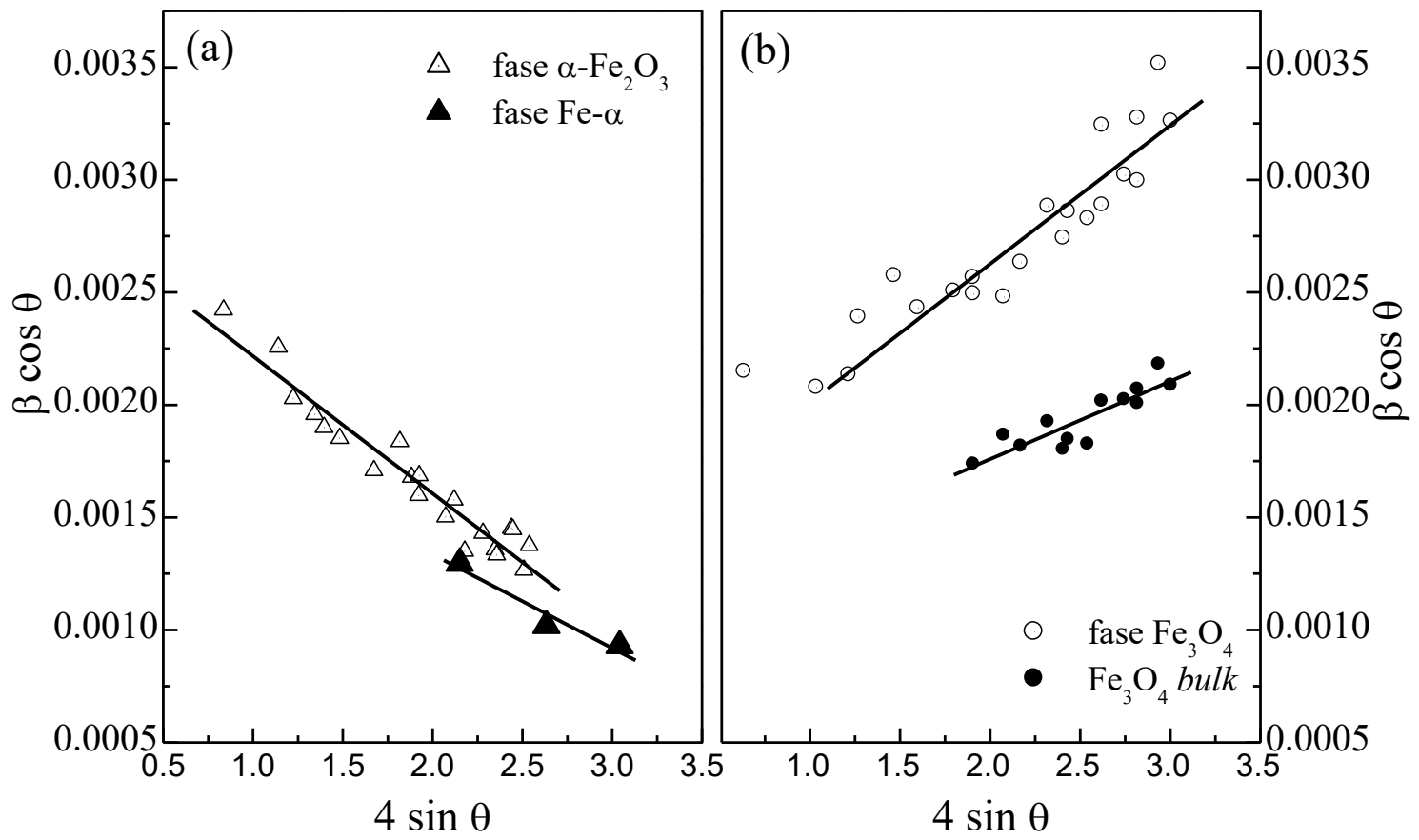

Figura 5.5- Gráficos de Williamson-Hall obtidos para as amostras NA-(a-Fe2O3) (a) e NA-(Fe3O4) (b). No painel (a) são mostrados os dados das fases $\alpha-F e 2 O 3$ (triângulos abertos) e $\alpha-F e$ (triângulos fechados), provenientes da amostra $N A-(\alpha-F e 2 O 3)$. Em (b) são mostrados os dados referentes a fase Fe3O4 da amostra NA-(Fe3O4) (círculos abertos) e da magnetita bulk (círculos fechados). 
As Figuras. 5.5 (a) e (b) mostram os gráficos de Williamson-Hall para as fases $\alpha$-Fe (triângulos fechados) e $\alpha-\mathrm{Fe}_{2} \mathrm{O}_{3}$ (triângulos abertos) presentes na amostra $\mathrm{NA}-\left(\alpha-\mathrm{Fe}_{2} \mathrm{O}_{3}\right)$ e NA- $\left(\mathrm{Fe}_{3} \mathrm{O}_{4}\right)$ e para as fases de magnetita bulk (círculos fechados) e magnetita sintetizada (círculos abertos), presentes na amostra NA- $\left(\mathrm{Fe}_{3} \mathrm{O}_{4}\right)$, respectivamente. Os dados referentes à largura a meia altura $(\beta)$ foram obtidos por meio do método de Rietveld. Para uma melhor comparação os gráficos estão apresentados nas mesmas escalas. Da Fig. 5.5 foram verificados que os diâmetros cristalográficos médios dos cristalitos das fases $\alpha-\mathrm{Fe}_{2} \mathrm{O}_{3} \mathrm{e}$ $\mathrm{Fe}_{3} \mathrm{O}_{4}$ são 55 e $70 \mathrm{~nm}$ respectivamente. Um diâmetro médio de $64 \mathrm{~nm}$ foi encontrado para os cristalitos de $\alpha$-Fe. Este valor sugere que nanocristais, como um todo, da fase $\alpha$ $\mathrm{Fe}_{2} \mathrm{O}_{3}$ foram transformadas em nanocristais de $\alpha-\mathrm{Fe}$, e que provavelmente estas nanopartículas apresentam morfologia de nanoanéis. Este resultado sugere que um controle mais rigoroso do tratamento térmico poderá levar a produção de nanoanéis, com fase única, de $\mathrm{Fe}_{3} \mathrm{O}_{4}$ ou de $\alpha$-Fe.

As inclinações das curvas apresentadas na Fig. 5.5 (a) mostram que as deformações da rede cristalográfica $(\varepsilon)$ das fases de $\mathrm{Fe}_{3} \mathrm{O}_{4}$ - bulk e sintetizada são de $4 \times 10^{-4}$ e $6 \times 10^{-4}$, respectivamente. Ao mesmo tempo, verifica-se que as inclinações das curvas referentes às fases $\alpha-\mathrm{Fe}$ e $\alpha-\mathrm{Fe}_{2} \mathrm{O}_{3}$ são de $-4 \times 10^{-4} \mathrm{e}-6 \times 10^{-4}$. Os sinais negativos indicam contração da rede cristalina.

\subsection{Espectroscopia Raman}

Como discutido no Capítulo 2, a hematita $\left(\alpha-\mathrm{Fe}_{2} \mathrm{O}_{3}\right)$ e a maguemita $\left(\gamma-\mathrm{Fe}_{2} \mathrm{O}_{3}\right)$ se apresentam na mesma fórmula química, contudo se cristalizam em diferentes estruturas e, portanto, facilmente diferenciadas por DRX. Por outro lado, a magnetita $\left(\mathrm{Fe}_{3} \mathrm{O}_{4}\right)$ possui a mesma estrutura cristalina da maghemita $\left(\gamma-\mathrm{Fe}_{2} \mathrm{O}_{3}\right)$ de modo a não ser possível diferenciálas por difração de raios X. A espectroscopia Raman, por sua vez, é altamente sensível tanto 
aos aspectos químicos quanto aos estruturais, de modo que ela é muito utilizada na identificação de estruturas polimórficas. ${ }^{73}$ Assim, com o objetivo de comprovar a real formação da fase magnetita em vez da fase maghemita a espectroscopia Raman foi usada.

A Fig. 5.6 mostra os espectros Raman das amostras NA- $\left(\alpha-\mathrm{Fe}_{2} \mathrm{O}_{3}\right)$ e NA- $\left(\mathrm{Fe}_{3} \mathrm{O}_{4}\right)$, realizados a temperatura ambiente. Note que o espectro Raman da amostra NA- $(\alpha-$ $\mathrm{Fe}_{2} \mathrm{O}_{3}$ ), na região de 200 a $800 \mathrm{~cm}^{-1}$ apresenta 8 modos vibracionais situados em 224 , 246, 287, 300, 406, 497, 607 e $657 \mathrm{~cm}^{-1}$. Os modos localizados em 224 e $497 \mathrm{~cm}^{-1}$ são atribuídos às vibrações com simetrias $\mathrm{A}_{1 \mathrm{~g}}$, enquanto os demais modos vibracionais, com exceção do modo em $657 \mathrm{~cm}^{-1}$, apresentam simetria $\mathrm{E}_{\mathrm{g}}$, todos característicos da hematita. A banda em $657 \mathrm{~cm}^{-1}$, é muitas vezes atribuída a presença de unidades $\mathrm{OH}$ aprisionados nos canais da estrutura da hematita formada (hidrohematita), que leva a um abaixamento da simetria estrutural e um consequente aparecimento de modos vibracionais proibidos. A presença desta banda é comum em hematitas naturais. ${ }^{27}$

$\mathrm{O}$ espectro Raman da amostra NA-( $\left.\mathrm{Fe}_{3} \mathrm{O}_{4}\right)$ apresenta características totalmente diferentes das observadas para a amostra NA- $\left(\alpha-\mathrm{Fe}_{2} \mathrm{O}_{3}\right)$, evidenciado que uma nova fase cristalográfica foi alcançada com o tratamento térmico em atmosfera rica em hidrogênio. Resultado já comprovado por DRX. Como abordado anteriormente, a maghemita possui a mesma estrutura cristalina da magnetita, mas com vacâncias nos sítios octaédricos. A distribuição dessas vacâncias não é ordenada (quebra da ordem a longo alcance) o que torna a maguemita um material com ordem cristalina menor que a magnetita. 


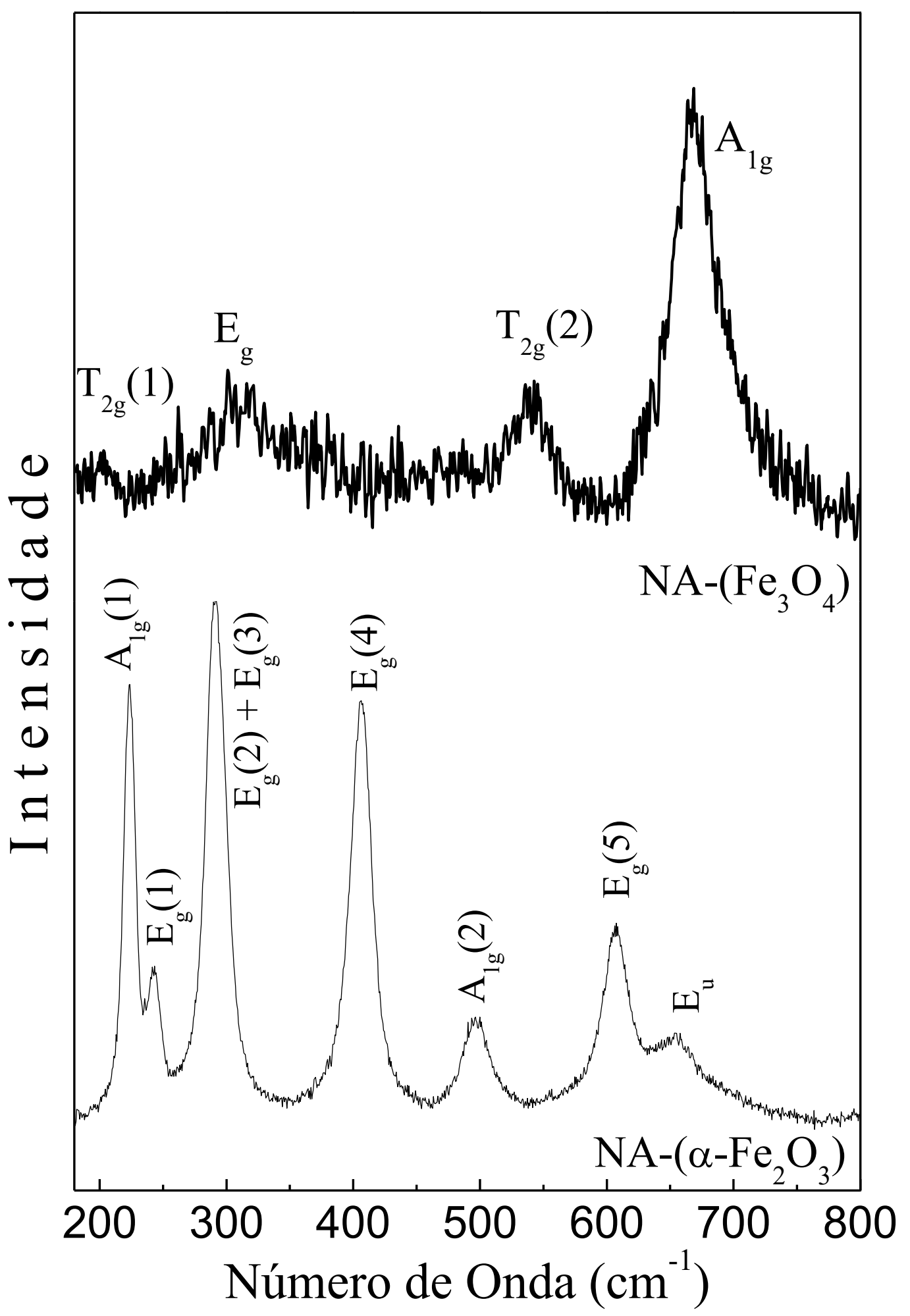

Figura 5.6 - Espectros Raman das amostras $\mathrm{NA}-\left(\mathrm{Fe}_{3} \mathrm{O}_{4}\right)\left(\right.$ a) e $\mathrm{NA}-\left(\alpha-\mathrm{Fe}_{2} \mathrm{O}_{3}\right)$ (b). 
Isso afeta claramente seu espectro Raman que é caracterizado pela presença de estruturas largas e assimétricas. Além do mais, é verificado que o espectro Raman da maghemita possui uma banda em torno de $715 \mathrm{~cm}^{-1} \cdot{ }^{25}$ Como pode ser visto claramente na Fig. 5.6, o espectro Raman da amostra NA- $\left(\mathrm{Fe}_{3} \mathrm{O}_{4}\right)$ apresenta picos Raman relativamente estreitos e bem definidos. Contudo, diferentemente dos 5 modos vibracionais esperados para a magnetita $\left(\mathrm{A}_{1 \mathrm{~g}}, \mathrm{E}_{\mathrm{g}}\right.$ e $\left.3 \mathrm{~T}_{\mathrm{g}}\right)$, o espectro Raman da amostra NA-( $\left.\mathrm{Fe}_{3} \mathrm{O}_{4}\right)$ apenas 4 modos vibracionais, situados em 203, 310, 545 e $669 \mathrm{~cm}^{-1}$. Este resultado está de acordo com o trabalho de Shebanova e Lazer. ${ }^{35}$ Ainda de acordo com este trabalho estes modos apresentam simetrias $T_{2 g}$ (1), $E_{g}, T_{2 g}$ (2) e $A_{1 g}$, respectivamente. Uma quinta banda é esperada em torno de $490 \mathrm{~cm}^{-1}$, contudo, não é clara a presença desta banda no espectro mostrado na Fig. 5.6. De qualquer forma, as características espectrais mostradas pela amostra NA- $\left(\mathrm{Fe}_{3} \mathrm{O}_{4}\right)$ revela sem dúvida que a fase cristalográfica formada é a da magnetita e não a da maghemita.

\subsection{Espectroscopia Mössbauer}

A Figura 5.7 mostra os espectros Mössbauer das amostras NA- $\left(\alpha-\mathrm{Fe}_{2} \mathrm{O}_{3}\right)$ e NA(Fe3O4), obtidos a $300 \mathrm{~K}$ (inferior no painel) e a $77 \mathrm{~K}$ (superior no painel). Os espectros Mössbauer da amostra NA- $\left(\alpha-\mathrm{Fe}_{2} \mathrm{O}_{3}\right)$, obtidos em ambas as temperaturas (ver Fig. 5.7 (a)) apresentam perfis totalmente simétricos, podendo ser ajustados com um único sexteto, com campo hiperfino $\left(\mathrm{H}_{\mathrm{f}}\right)$, desvio isomérico (IS) e desdobramento quadrupolar (QS) iguais a 511 kOe, $-0.22 \mathrm{~mm} / \mathrm{s}$ e $0.37 \mathrm{~mm} / \mathrm{s}$, respectivamente. Estes valores são consistentes com os valores encontrados para a fase hematita e são idênticos aos relatados no trabalho de Gotic e colaboradores ao estudarem nanoanéis de hematita dopados com diferentes metais de transição. ${ }^{74}$ Além de demostrar que os nanoanéis aqui obtidos são constituídos por apenas uma fase cristalográfica, a presença de um único sexteto, evidência a ausência de relaxação 
paramagnética a $300 \mathrm{~K}$, em concordância com o fato de que o tamanho médio das nanopartículas obtidos por DRX e MET está acima do tamanho crítico de um monodomínio $(\sim 30 \mathrm{~nm}) \cdot{ }^{75}$ Os parâmetros hiperfinos obtidos a partir dos ajustes, para as duas amostras e para as temperaturas de 77 e $300 \mathrm{~K}$ são mostrados na Tabela 5.1.
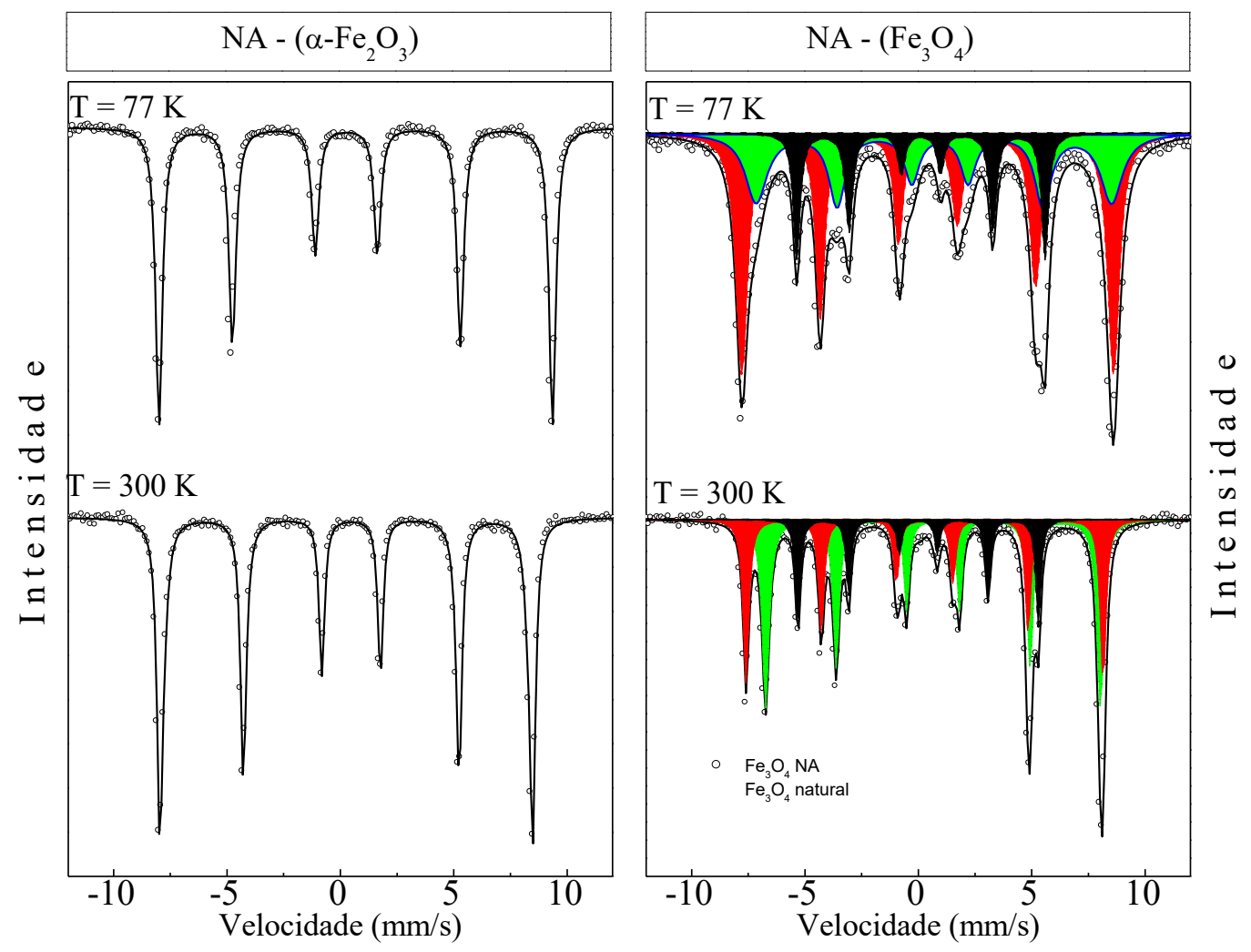

Figura 5.7 - Espectros Mössbauer nas temperaturas ambiente (inferior) e a $77 \mathrm{~K}$ (superior) das amostras $\mathrm{NA}-\left(\alpha-\mathrm{Fe}_{2} \mathrm{O}_{3}\right)(\mathrm{a})$ e $\mathrm{NA}-\left(\mathrm{Fe}_{3} \mathrm{O}_{4}\right)(b)$.

Tabela 5.1 - Parâmetros obtidos dos ajustes dos espectros Mössbauer a 300 e 77 K, das amostras NA-( $\alpha$ $\left.\mathrm{Fe}_{2} \mathrm{O}_{3}\right)$ e $\mathrm{NA}-\left(\mathrm{Fe}_{3} \mathrm{O}_{4}\right)$.

\begin{tabular}{|c|c|c|c|c|c|c|c|}
\hline Amostras & $\begin{array}{c}\mathrm{T} \\
(\mathrm{K})\end{array}$ & Comp & $\begin{array}{c}\text { IS } \\
(\mathrm{mm} / \mathrm{s})\end{array}$ & $\begin{array}{c}\mathrm{QS} \\
(\mathrm{mm} / \mathrm{s})\end{array}$ & $\begin{array}{c}\mathrm{H}_{\mathrm{f}} \\
(\mathrm{KOe})\end{array}$ & $\begin{array}{c}\text { A } \\
(\%)\end{array}$ & Atribuição \\
\hline \multirow{2}{*}{$\mathrm{NA}-\left(\alpha-\mathrm{Fe}_{2} \mathrm{O}_{3}\right)$} & 300 & -- & 0.37 & -0.22 & 511 & 100 & $\alpha-\mathrm{Fe}_{2} \mathrm{O}_{3}$ \\
\hline & 77 & -- & 0.47 & 0.41 & 539 & 100 & $\alpha-\mathrm{Fe}_{2} \mathrm{O}_{3}$ \\
\hline \multirow{6}{*}{$\mathrm{NA}-\left(\mathrm{Fe}_{3} \mathrm{O}_{4}\right)$} & \multirow{3}{*}{300} & -- & 0,00 & $-0,01$ & 330 & 18,5 & $\alpha-\mathrm{Fe}$ \\
\hline & & $\mathrm{Fe}^{2+, 3+}(\mathrm{B})$ & 0,65 & 0,00 & 459 & 32,0 & $\mathrm{Fe}_{3} \mathrm{O}_{4}$ \\
\hline & & $\mathrm{Fe}^{3+}(\mathrm{A})$ & 0,27 & 0,00 & 490 & 49,5 & $\mathrm{Fe}_{3} \mathrm{O}_{4}$ \\
\hline & \multirow{3}{*}{77} & -- & 0.11 & 0,00 & 340 & 17.4 & $\alpha-\mathrm{Fe}$ \\
\hline & & $\mathrm{Fe}^{2+}(\mathrm{B})$ & 0.80 & -0.27 & 487 & 31,5 & $\mathrm{Fe}_{3} \mathrm{O}_{4}$ \\
\hline & & $\mathrm{Fe}^{3+}(\mathrm{A})$ & 0,40 & 0,00 & 509 & 51.1 & $\mathrm{Fe}_{3} \mathrm{O}_{4}$ \\
\hline
\end{tabular}


IS - desvio isomérico, QS - interação quadrupolar elétrica, HF - campo hiperfino.

Os espectros Mössbauer da amostra NA-( $\left.\mathrm{Fe}_{3} \mathrm{O}_{4}\right)$ mostrados na Fig. 5.7 (b), para a temperatura de 77 e $300 \mathrm{~K}$ foram ajustados com 3 sextetos bem definidos, portanto sem evidencias de relaxação paramagnética a $300 \mathrm{~K}$. Foi encontrado que, para a temperatura de $300 \mathrm{~K}$, os parâmetros hiperfinos do primeiro sexteto, cuja área espectral é de 18,5 \%, são $\mathrm{H}_{\mathrm{hf}}=330 \mathrm{kOe}, \mathrm{IS}=0,0 \mathrm{~mm} / \mathrm{s}$ e QS = -0,01. Estes parâmetros estão em boa concordância com obtidos para nanopartículas de $\alpha-F e{ }^{76}$ Uma vez que a área espectral relativa pode estar correlacionada ao teor de íons de ferro cristalizados em uma determinada fase cristalográfica, é simples supor que esse sexteto descreve a fase cristalográfica do $\alpha$-Fe. Considerando que a célula unitária da magnetita é composta por 32 íons de oxigênio e 24 ions de ferro $\left(8 \mathrm{Fe}^{3+}\right.$ no sítio tetraédrico e $8\left(\mathrm{Fe}^{3+}+\mathrm{Fe}^{2+}\right)$ no sítio octaédrico) enquanto a célula unitária do $\alpha$-Fe é de apenas um íon de Fe e de um íon de O é fácil verificar que o teor de massa da fase $\alpha$-Fe com a relação ao teor de massa da fase $\mathrm{Fe}_{3} \mathrm{O}_{4}$ está em boa concordância com os $12 \%$ determinados por difração de raios-X, como relatado anteriormente.

As demais componentes, que a $300 \mathrm{~K}$, apresentam valores de $\mathrm{H}_{\mathrm{f}}=459$ e $490 \mathrm{kOe}$, IS $=0,65$ e $0,27 \mathrm{~mm} / \mathrm{s}$ e $\mathrm{QS}=0,0$ e $0,0 \mathrm{~mm} / \mathrm{s}$ estão relacionadas à ocupação de $\mathrm{Fe}^{2+}+$ $\mathrm{Fe}^{3+}$ no sítio octaedro e $\mathrm{Fe}^{3+}$ no sítio tetraédrico, respectivamente. Os valores de $\mathrm{H}_{\mathrm{f}}$ aqui encontrados são levemente inferiores aos valores encontrados para a magnetita bulk, que de acordo com o trabalho de Evans e Hafner são, respectivamente, iguais a 460 e 493 kOe. ${ }^{77}$ Por outro lado, os valores de $\mathrm{H}_{\mathrm{f}}$ obtidos para a amostra NA- $\left(\mathrm{Fe}_{3} \mathrm{O}_{4}\right)$ são exatamente iguais aos valores de $\mathrm{H}_{\mathrm{f}}$ encontrados para uma amostra de magnetita com deficiência de cátion, denominada Kenotetrahedral. ${ }^{77}$ Reduções nos valores de $\mathrm{H}_{\mathrm{f}}$ em razão do aumento do número de vacâncias de cátions, na estrutura cristalina da magnetita também foi verificado na Ref. $\left[{ }^{78}\right]$. As pequenas variações nos valores de $\mathrm{H}_{\mathrm{f}}$, por si só, não são suficientes para assegurar a presença de vacâncias de cátions na estrutura cristalina dos nanoanéis aqui sintetizados. Contudo, esta hipótese é reforça ao se verificar que a razão entre as áreas espectrais 
relativas aos sítios tetraédricos e octaédricos $(\mathrm{A} / \mathrm{B})$ é de $\sim 0.64$, valor superior 0.5 esperado para uma magnetita estequiométrica. No trabalho de Evans e Hafner foi encontrado que $\mathrm{A} / \mathrm{B}=0.59$ para a estrutura Kenotetrahedral.

\section{Medidas Magnéticas}

A Fig. 5.8 mostra as curvas de magnetização em função do campo aplicado (M vs H) para a amostra NA- $\left(\alpha-\mathrm{Fe}_{2} \mathrm{O}_{3}\right)$, realizadas nas temperaturas de $300 \mathrm{~K}$ (a) (círculos fechados e $5 \mathrm{~K}$ (b) (círculos abertos). A existência do ciclo de histerese, à temperatura ambiente, bem como a ausência de magnetização de saturação deve ser notada na Fig. 5.8 (a). Observe que, em campos mais altos, a curva $\mathrm{M}$ vsH, mostra uma dependência quase linear da magnetização com o campo magnético aplicado. Os valores de magnetização remanescente e coercividade são $\mathrm{M}_{\mathrm{r}}=0,11 \mathrm{emu} / \mathrm{g}$ e $\mathrm{H}_{\mathrm{C}}=260$ Oe, respectivamente. Os parâmetros magnéticos estão listados na Tabela 5.2. A existência da histerese evidencia um estado ferromagnético fraco da amostra à temperatura ambiente. Note que o valor de $\mathrm{H}_{\mathrm{C}}$, aqui encontrado, é muito menor que valor obtido para a hematita bulk $\left(\mathrm{H}_{\mathrm{C}}=1670\right.$ Oe).$^{30}$ Contudo, estes valores estão próximos dos valores de $M_{r}$ e $H_{C}$ encontrados para nanoanéis de hematita $\left(0,14 \mathrm{emu} / \mathrm{g}\right.$ e 200 Oe, respectivamente) obtidos na Ref. $\left[{ }^{79}\right]$. Uma vez que a coercividade de uma determinada amostra é determinada tanto pela coercividade do nanocristal individual quanto pela interação entre os nanocristais, o fato de que $\mathrm{H}_{\mathrm{C}}$ ser pequeno sugere que a interação magnética entre os nanoanéis é pequena.

A curva de $\mathrm{M}$ vs $\mathrm{H}$, obtida a 5K, é mostrada na Fig. 5.8 (b). Um pequeno ciclo de histerese (inserção na Fig. 5.8 (b)) com a magnetização remanente $\mathrm{M}_{\mathrm{r}}=0,01 \mathrm{emu} / \mathrm{g}$ e coercividade $\mathrm{H}_{\mathrm{C}}=390 \mathrm{Oe}$, pode ser observado. Estes valores são menores que os correspondentes valores à temperatura ambiente (ver Tabela 5.2). A existência do ciclo de histerese abaixo $T_{M}$ (temperatura Morin) indica que existem spins não compensados na 
superfície dos nanoanéis de hematita. A coercividade diferente de zero abaixo da temperatura de Morin não é uma característica da hematita bulk e está relacionada ao tamanho e a forma das nanopartículas. Vários estudos a este respeito têm sido reportados. ${ }^{80}$, 81,23

Tabela 5.2- Parâmetros Magnéticos obtidos para as amostras $\mathrm{NA}\left(\mathrm{\alpha}_{-}-\mathrm{Fe}_{2} \mathrm{O}_{3}\right)$ e $\mathrm{NA}-\mathrm{Fe}_{3} \mathrm{O}_{4}$. Para comparação também são mostrados dados referentes a amostras de $\alpha-\mathrm{Fe}_{2} \mathrm{O}_{3}-$ bulk* (ref. ${ }^{30}$ ) e $\mathrm{Fe}_{3} \mathrm{O}_{4}$ bulk (deste trabalho).

\begin{tabular}{ccccc}
\hline Amostras & $\begin{array}{c}\mathrm{T} \\
(\mathrm{K})\end{array}$ & $\begin{array}{c}\mathrm{M}_{\mathrm{r}} \\
(\mathrm{emu} / \mathrm{g})\end{array}$ & $\begin{array}{c}\mathrm{M}_{\mathrm{s}} \\
(\mathrm{meu} / \mathrm{g})\end{array}$ & $\begin{array}{c}\mathrm{H}_{\mathrm{C}} \\
(\mathrm{Oe})\end{array}$ \\
\hline$\alpha-\mathrm{Fe}_{2} \mathrm{O}_{3}-$ bulk & 300 & 0.29 & 2.35 & 1670 \\
$\mathrm{NA}-\left(\alpha-\mathrm{Fe}_{2} \mathrm{O}_{3}\right)$ & 300 & 0.11 & 2.85 & 261 \\
& 5 & 0.01 & 3.24 & 367 \\
$\mathrm{Fe}_{3} \mathrm{O}_{4}$ bulk & 300 & 6,8 & 89 & 119 \\
$\mathrm{NA}-\mathrm{Fe}_{3} \mathrm{O}_{4}$ & 5 & 11,5 & 99 & 217 \\
& 5 & 11,0 & 110 & 266 \\
\hline
\end{tabular}

*Valores retirados da Ref. $\left[{ }^{30}\right]$ 


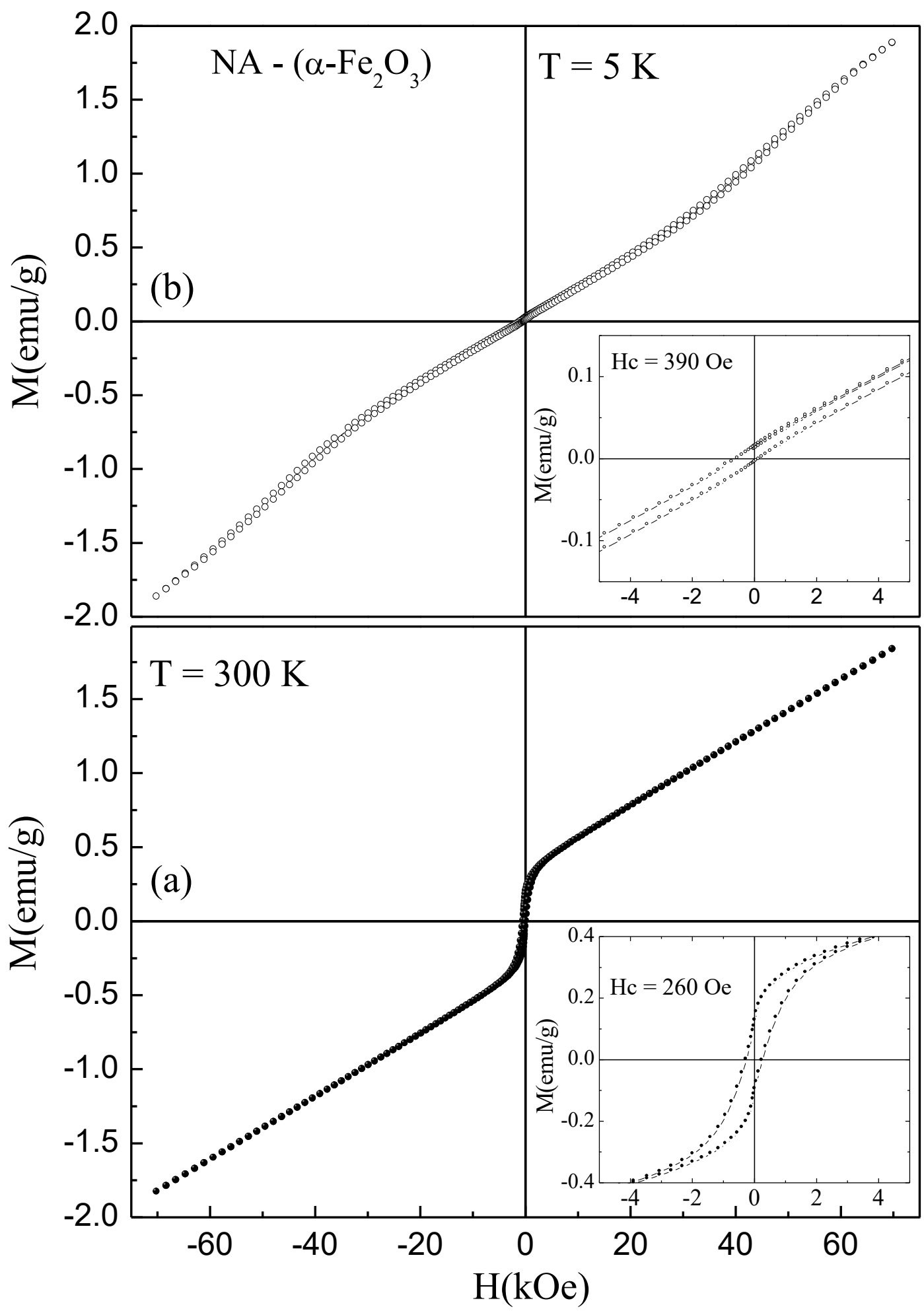

Figura 5.8 - Curvas de histerese, magnetização vs campo magnético aplicado, nas temperaturas de 300 (a) e $5 \mathrm{~K}(b)$, para a amostras $\mathrm{NA}-\left(\alpha-\mathrm{Fe}_{2} \mathrm{O}_{3}\right)$. 
As curvas de magnetização em função do campo aplicado ( $\mathrm{M}$ vs $\mathrm{H}$ ), obtidas para a amostra $\mathrm{NA}-\mathrm{Fe}_{3} \mathrm{O}_{4}$, (curvas em preto) nas temperaturas de $300 \mathrm{~K}$ (a) e $5 \mathrm{~K}$ (b), são mostradas na Fig. 5.9. Para comparação, também são apresentados na Fig. 5.9 as curvas M vs $\mathrm{H}$ obtido para uma amostra de magnetita bulk em ambas as temperaturas(curvas em vermelho). Os parâmetros magnéticos estão resumidos na Tabela 5.2. Observe que todos os parâmetros magnéticos são superiores aos observados para a amostra NA- $(\alpha-$ $\mathrm{Fe}_{2} \mathrm{O}_{3}$ ) e para a amostra de $\mathrm{Fe}_{3} \mathrm{O}_{4}$ bulk. Por exemplo, a magnetização de saturação da amostra NA- $\left(\alpha-\mathrm{Fe}_{2} \mathrm{O}_{3}\right)$, em $5 \mathrm{~K}$, é de $116 \mathrm{emu} / \mathrm{g}$ enquanto que a da magnetita bulk é de $99 \mathrm{emu} / \mathrm{g}$. Os valores de $\mathrm{M}_{\mathrm{S}}$ foram determinados a partir da extrapolação das curvas de Magnetização em altos campos magnéticos versus o recíproco do campo magnético aplicado ( $\mathrm{M}$ vs $1 / \mathrm{H}$ quando $\mathrm{H} \rightarrow \infty$ ). Em complemento, os valores de $\mathrm{M}_{\mathrm{r}}$ e $\mathrm{H}_{\mathrm{C}}$ observados para a amostra $\mathrm{NA}$ - $\mathrm{Fe}_{3} \mathrm{O}_{4} \mathrm{são}$ duas vezes maiores que os observados para a magnetita bulk. Esta discrepância pode estar associada à forma anisotrópica dos nanoanéis que por sua vez pode levar a uma anisotropia magnética das nanopartículas. Este assunto será abordado posteriormente. 


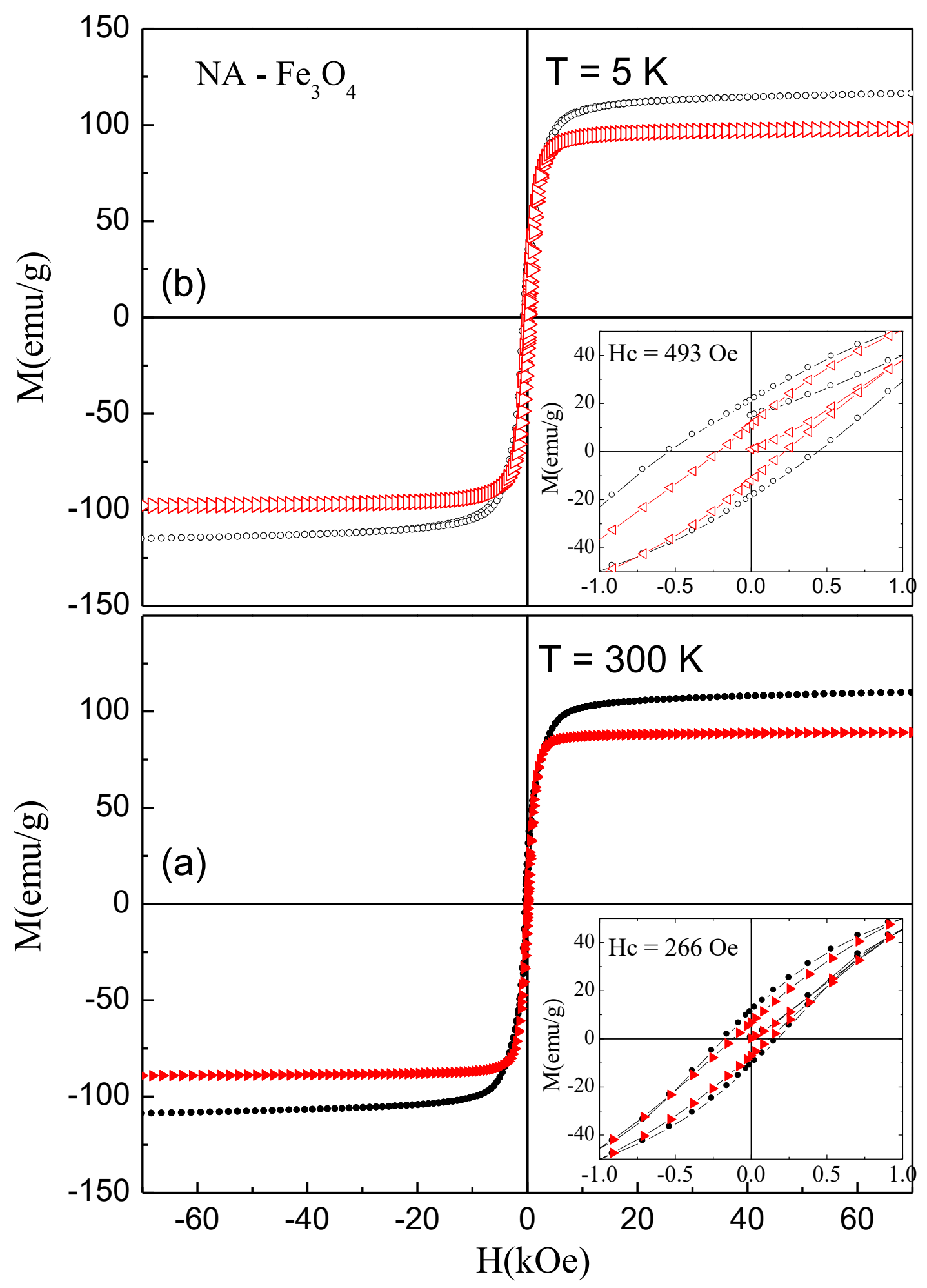

Figura 5.9 - Curvas de histerese, magnetização vs campo magnético aplicado obtido para a amostra NA$\left(\mathrm{Fe}_{3} \mathrm{O}_{4}\right.$ ) (símbolos em preto) nas temperaturas de $300 \mathrm{~K}(\mathrm{a})$ e $5 \mathrm{~K}$ (b). As curvas em vermelho mostram $M$ contra $\mathrm{H}$ obtido para uma amostra $\mathrm{Fe}_{3} \mathrm{O}_{4}$ - bulk. 
Curvas de magnetização zero-field-cooled (ZFC) e field-cooled (FC) das amostras NA- $\left(\alpha-\mathrm{Fe}_{2} \mathrm{O}_{3}\right)$ e NA- $\left(\mathrm{Fe}_{3} \mathrm{O}_{4}\right)$ (símbolos fechados) são mostradas na Fig. 5.10 e 5.11. Para comparação curas ZFC e FC de uma amostra e $\mathrm{Fe}_{3} \mathrm{O}_{4}$ bulk (símbolos abertos) também são mostradas na Fig. 5.11. Nas medidas de ZFC, as amostras foram resfriadas a campo zero até a temperatura de $5 \mathrm{~K}$. Em baixa temperatura um campo magnético externo de 100 Oe é aplicado e a magnetização é obtida em função do aumento da temperatura. Depois de alcançar $300 \mathrm{~K}$, a amostra é resfriada com campo de 100 Oe, até a temperatura de $5 \mathrm{~K}$, em seguida a amostra foi aquecida e as medidas FC foram realizadas.

Com pode ser visto na Fig. 5.10 a magnetização da amostra NA- $\left(\alpha-\mathrm{Fe}_{2} \mathrm{O}_{3}\right)$ é quase constante até a temperatura de $200 \mathrm{~K}$ e então começa a crescer com o aumento da temperatura. Esta transição é conhecida como Transição de Morin $\left(\mathrm{T}_{\mathrm{M}}\right)$, que é explicada levando-se em conta a reorientação dos spins em $\mathrm{T}_{\mathrm{M}}$. Esta reorientação é devido à competição entre dois tipos de anisotropia; a anisotropia magnetocristalina (dominante abaixo de $\mathrm{T}_{\mathrm{M}}$ ), que tende a alinhar os momentos magnéticos ao longo do eixo $c$, e a anisotropia de forma (longo alcance) (dominante acima de $T_{M}$ ) que faz com que os spins se alinhem ao longo do plano $a-b$. Note que as curvas FC e ZFC apresentam comportamentos interessantes. Por exemplo, é verificado que em baixas temperaturas há uma superposição entre as curvas FC e ZFC. Esta superposição está ausente para $\mathrm{T}>\mathrm{T}_{\mathrm{M}}$. Este comportamento é característico do antiferromagnetismo a temperaturas baixas e do fraco ferromagnetismo a temperaturas mais altas. É bem conhecido que abaixo de $\mathrm{T}_{\mathrm{M}}$, o spin está orientado em direção antiparalela ao longo do eixo c, mostrando propriedades antiferromagnéticas, enquanto que acima de $\mathrm{T}_{\mathrm{M}}$, os spins estão levemente inclinados e o fraco termomagnetismo se manifesta. ${ }^{80}$ Outro comportamento interessante a ser observado, é o que ocorre em aproximadamente $243 \mathrm{~K}$ (ver Fig 5.10). Uma explicação para este comportamento não é clara. Contudo, é conhecido da literatura que $\mathrm{T}_{\mathrm{M}}$ depende fortemente do tamanho das nanopartículas, decrescendo com o decréscimo do diâmetro das mesmas. De modo que a 
Transição de Morin tende a desaparecer para sistemas com diâmetro de aproximadamente 8 nm. ${ }^{82}$ Assim, tal comportamento pode estar relacionado a efeitos de superfície devido à morfologia das nanopartículas. Contudo para maiores esclarecimentos mais estudos se fazem necessários.

A Fig. 5.11 mostras as curvas de ZFC e FC para as amostras NA - $\mathrm{Fe}_{3} \mathrm{O}_{4}$ (símbolos fechados) e $\mathrm{Fe}_{3} \mathrm{O}_{4}-$ bulk (símbolos abertos). Observe que a curva ZFC da amostra NA $\mathrm{Fe}_{3} \mathrm{O}_{4}$ é caracterizada por um largo platô típico de nanopartículas que apresentam temperaturas de relaxação superiores a $300 \mathrm{~K}$. Pode ser visto que todas as curvas ZFC mostram duas temperaturas de transição: uma em torno de $120 \mathrm{~K}$, correspondendo a temperatura de Verwey, acima da qual os elétrons saltam rapidamente entres os íons de $\mathrm{Fe}^{2+}$ e $\mathrm{Fe}^{3+}$ do sítio octaedro, e outra em torno de $50 \mathrm{~K}$, que pode estar associado a uma reorientação dos momentos magnéticos dos íons de Fe. Este comportamento foi observado em nanoanéis de magnética sintetizadas por um método semelhante ao aqui utilizado. ${ }^{83}$ Também deve ser notado que a curva $\mathrm{FC}$ da amostra $\mathrm{NA}-\mathrm{Fe}_{3} \mathrm{O}_{4}$ difere da curva FC da $\mathrm{Fe}_{3} \mathrm{O}_{4}$ - bulk. Este comportamento está consistente com outros estudos envolvendo magnetita nanoestruturada e está associada a uma anisotropia magnética adicional induzida pela superfície das nanoestruturas o que pode explicar a discrepância entre os parâmetros magnéticos observados na Tabela 5.2. ${ }^{84}$ 


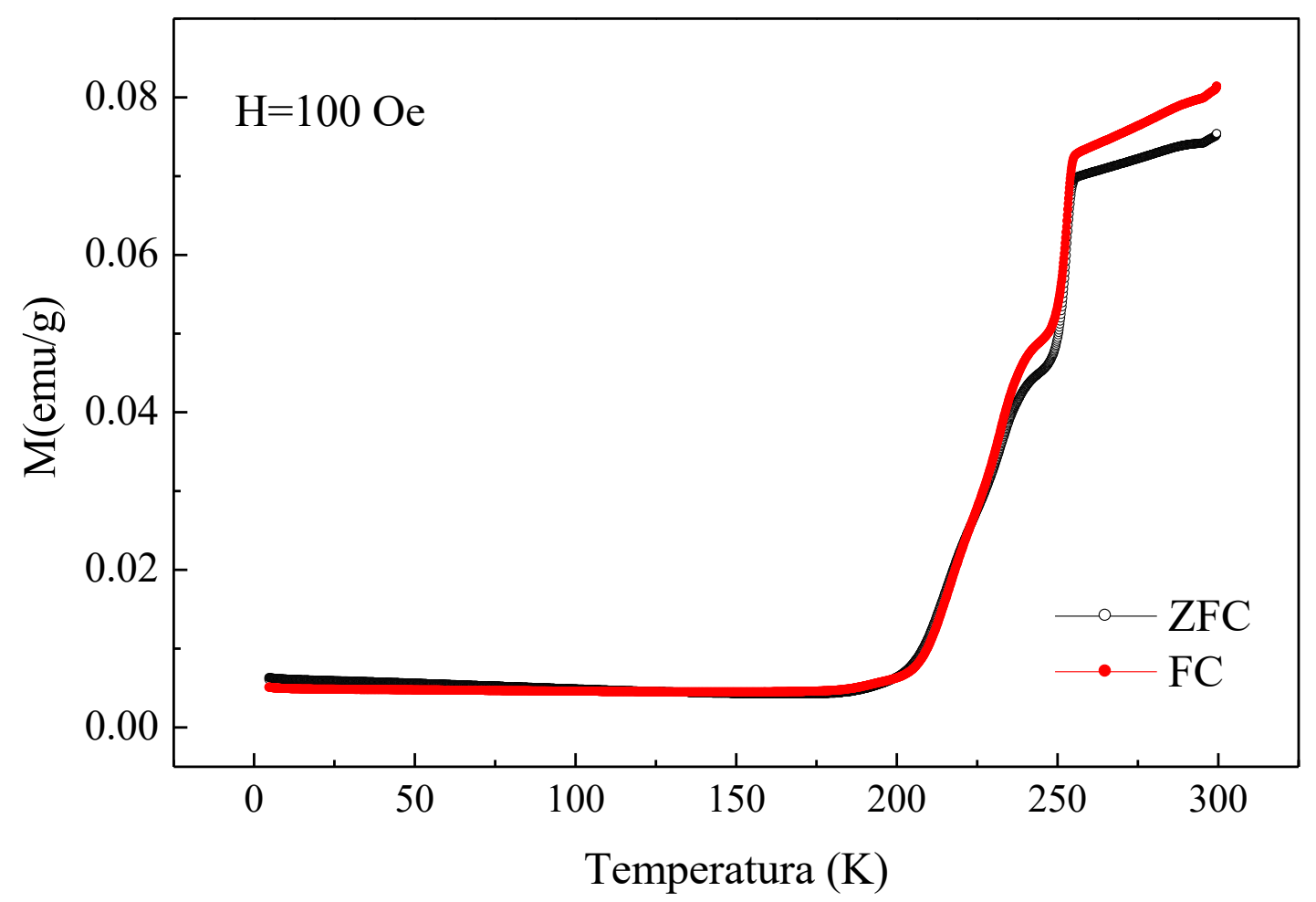

Figura 5.10 - Curvas de magnetização zero-field-cooled (ZFC) (símbolos pretos) e field-cooled (FC) (símbolo vermelho) da amostra $\mathrm{NA}-\left(\alpha-\mathrm{Fe}_{2} \mathrm{O}_{3}\right)$.

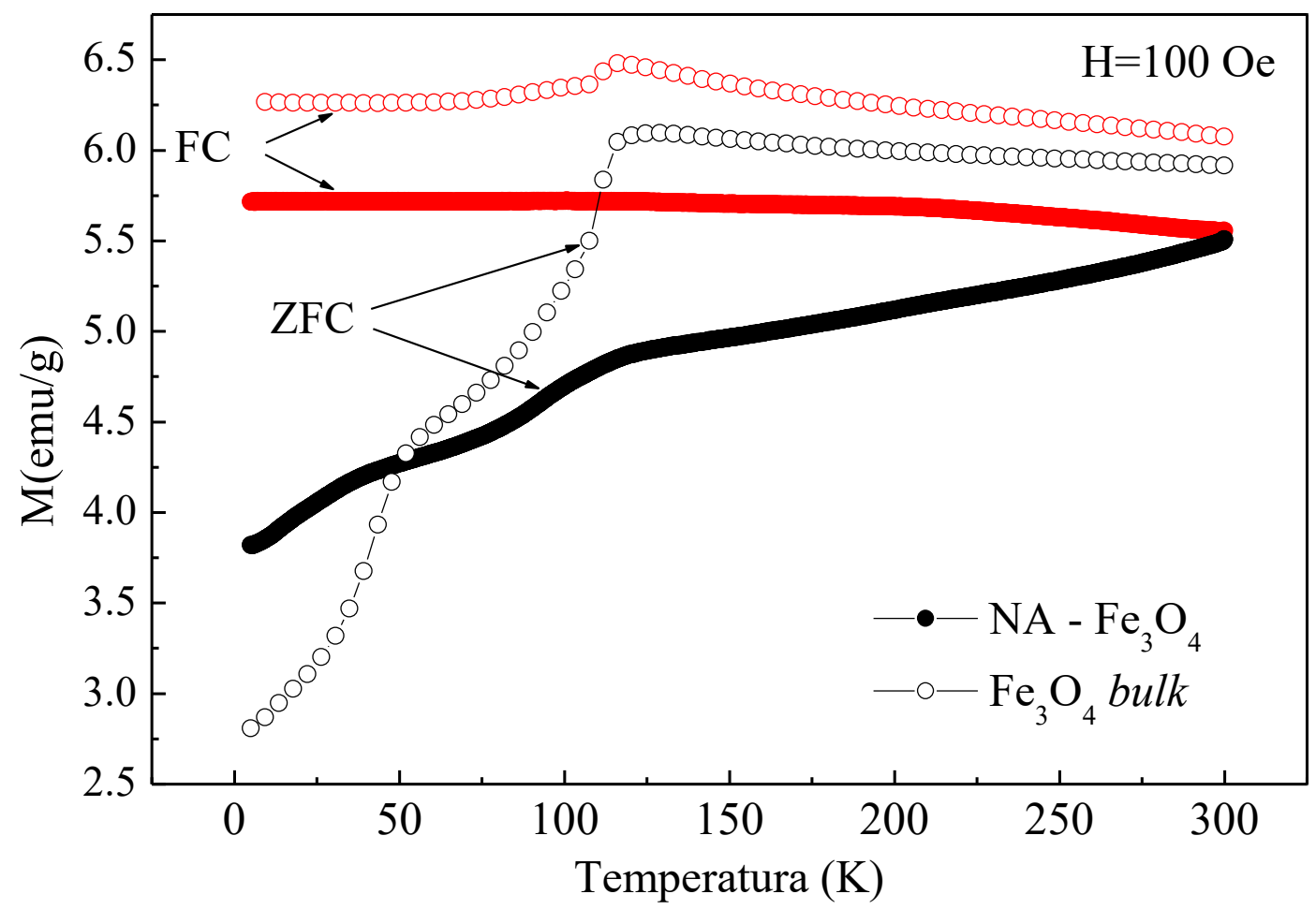

Figura 5.11 - Curvas de magnetização zero-field-cooled (ZFC) (símbolos pretos) e field-cooled (FC) (simbolo vermelho) da amostraNA- $\left(\mathrm{Fe}_{3} \mathrm{O}_{4}\right)$. 
Uma forma de estimar o valor da anisotropia magnética das amostras de magnetita (NA - $\mathrm{Fe}_{3} \mathrm{O}_{4} \mathrm{e} \mathrm{Fe}_{3} \mathrm{O}_{4}$-bulk) é utilizar a lei de aproximação à saturação. Esta lei é expressa pela relação: ${ }^{85}$

$$
M(H)=M_{S}\left[1-\frac{b}{H^{2}}\right]+\chi_{h f} H
$$

onde, $M_{S}$ corresponde à magnetização de saturação, $b$ é uma constante associada a anisotropia magnetocristalina cujo valor é dado por $b=\frac{4 K_{e f f}^{2}}{15 M_{S}^{2}}$ para um sistema com simetria cúbica, $K_{\text {eff }}$ corresponde a constante de anisotropia efetiva, $H$ é o valor do campo magnético aplicado e $\chi_{h f}$ é a susceptibilidade a altos campos. O termo e $\chi_{h f}$ é muito pequeno em temperaturas muito abaixo da temperatura de Curie e pode ser desprezado ${ }^{86}$

Usando a Equação 5.1 para ajustar os dados de $\mathrm{M}$ vs $\mathrm{H}$, no intervalo de campos magnéticos altos (ver Fig. 5.12) e os valores de Ms obtidos anteriormente, foi possível estimar os valores da anisotropia magnéticas como sendo $K_{\text {eff }}=1,5 \times 10^{5} \mathrm{erg} / \mathrm{cm}^{3}$ para a magnetita bulk e $K_{\text {eff }}=8,0 \times 10^{5} \mathrm{erg} / \mathrm{cm}^{3}$ para a amostra NA $-\mathrm{Fe} 3 \mathrm{O} 4$. O valor de $K_{\text {eff }}$ encontrado para a magnetita bulk está consistente com a literatura. ${ }^{87}$ 


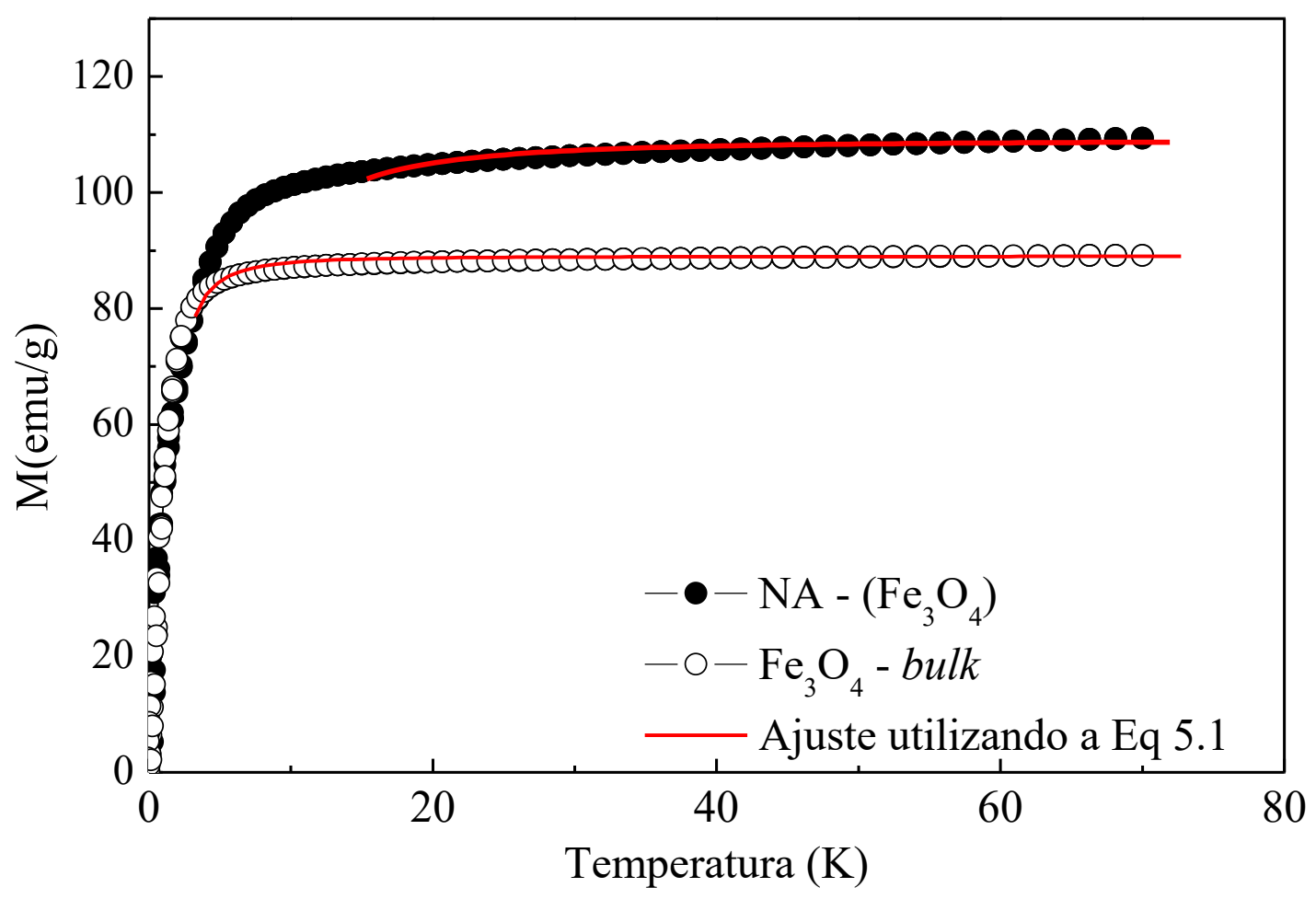

Figura 5.12 - Ajuste da curva de M vsH usando a lei de aproximação à saturação (Eq. 5.1) para as amostras $\mathrm{NA}-\left(\mathrm{Fe}_{3} \mathrm{O}_{4}\right)$ e $\mathrm{Fe}_{3} \mathrm{O}_{4}-$ bulk. 


\section{Capítulo 6. Conclusões e Perspectivas futuras}

\subsection{Conclusões}

Neste trabalho, nanopartículas magnéticas a base de óxidos de ferro, produzidos com sucesso por meio do processo hidrotermal, foram investigados por Microscopias Eletrônica de Varredura (MEV) e Transmissão (MET), Microscopia Eletrônica de Transmissão de Alta Resolução (HRTEM), Difração de raios-X (DRX), Espectroscopias Raman e Mössbauer e medidas de Magnetização.

Inicialmente, mostrou-se que nanopartículas de hematita $\left(\alpha-\mathrm{Fe}_{2} \mathrm{O}_{3}\right)$ com morfologias de nanoanéis podem ser sintetizadas, por vias hidrotérmicas, por meio a adição de sais contendo fosfato $\left(\mathrm{PO}_{4}^{3-}\right)$ e sulfato $\left(\mathrm{SO}_{2}^{4-}\right)$, à reação hidrotérmica. Em seguida estas partículas foram reduzidas, passando de hematita para magnetita $\left(\mathrm{Fe}_{3} \mathrm{O}_{4}\right)$, sem comprometer sua morfologia inicial.

Análises realizadas por MEV, MET e HRTEM, mostraram que as nanopartículas aqui produzidas são constituídas por monocristais dos óxidos de ferro com morfologias de nanoanéis com espessuras, diâmetros externos e internos médios de 95, 140 e 65 nm, respectivamente. Os dados de DRX, por meio da análise de Rietveld, demonstraram que os nanoanéis, como sintetizados (NA- $\left(\alpha-\mathrm{Fe}_{2} \mathrm{O}_{3}\right)$ ), apresentam fase única de hematita, com parâmetros de rede compatíveis com os da hematita bulk. Foi também verificado que o tratamento térmico, em atmosfera rica de hidrogênio, dos nanoanéis de hematita, induz a formação da fase espinélio cúbico, com parâmetro de rede próprios da fase magnetita. Contudo, além da fase espinélio, verificou-se a presença de picos de difração extras, característicos da fase $\alpha$-Fe. Em complemento, os dados de Rietveld 
revelaram que $12 \%$ da massa total da amostra de NA- $\left(\alpha-\mathrm{Fe}_{2} \mathrm{O}_{3}\right)$ está cristalizada na fase $\alpha-F e$, e que provavelmente estas nanopartículas apresentam morfologia de nanoanéis. Este resultado sugere que um controle mais rigoroso do tratamento térmico poderá levar a produção de nanoanéis, com fase única, de $\mathrm{Fe}_{3} \mathrm{O}_{4}$ ou de $\alpha-\mathrm{Fe}$.

A confirmação da formação de nanoanéis de $\mathrm{Fe}_{3} \mathrm{O}_{4}$ e não de $\gamma$-Fe2O3 foi realizada por meio das técnicas de espectroscopia Raman e espectroscopia Mössbauer. Os espectros Raman mostraram a presença de 4 modos vibracionais, situados 203, 310, 545 e 669 cm-1, em concordância com o espectro Raman de um monocristal de magnetita bulk. Em complemento, os espectros Mössbauer da amostra NA-( $\left.\mathrm{Fe}_{3} \mathrm{O}_{4}\right)$ mostraram a presença de duas fases cristalográficas de ferro, com parâmetros hiperfinos típicos da magnetita e do $\alpha$-Fe. Os dados ainda mostraram que o teor de ferro cristalizado na fase $\alpha$-Fe $(18 \%)$ está em concordância com o teor de massa total desta fase $(12 \%)$, revelado por DRX. Por último, não foram encontradas relaxação paramagnética a $300 \mathrm{~K}$, em nenhuma das amostras.

A curva de $\mathrm{M}$ vs $\mathrm{H}$, realizada a $300 \mathrm{~K}$, para a amostra NA- $\left(\alpha-\mathrm{Fe}_{2} \mathrm{O}_{3}\right)$ mostrou que o valor do campo coersivo desta amostra é muito menor que valor obtido para a hematita bulk. Contudo, os valores de $\mathrm{M}_{\mathrm{r}}$ e $\mathrm{H}_{\mathrm{C}}$, aqui encontrados, são consistentes com valores da literatura, ao estudarem nanoanéis de hematita produzidos de forma semelhante. Além do mais, a constatação da existência de ciclo de histerese em temperaturas abaixo da transição de Morin, evidencia a existência de spins não compensados na superfície dos nanoanéis de hematita, de modo que este comportamento está relacionado ao tamanho e a forma das nanopartículas.

Foi verificado que os valores magnetização de saturação, bem como os valores de $\mathrm{M}_{\mathrm{r}}$ e $\mathrm{H}_{\mathrm{C}}$ obtidos para amostra NA- $\left(\alpha-\mathrm{Fe}_{2} \mathrm{O}_{3}\right)$ (a 5 e $300 \mathrm{~K}$ ), são superiores aos valores encontrados para a magnetita bulk. Esta discrepância pode estar associada à forma 
anisotrópica dos nanoanéis que por sua vez leva a um aumento da anisotropia magnética das nanopartículas. Foi encontrado que a anisotropia magnética da amostra NA- $(\alpha-$ $\mathrm{Fe}_{2} \mathrm{O}_{3}$ ) é 5 vezes maior que a da magnetita bulk. 


\subsection{Perspectivas Futuras}

- Sintetizar amostras de nanoanéis dopados com diferentes metais de transição (Co, Mn, $\mathrm{Zn}$, etc) de forma a obter nanoanéis com novas características magnéticas.

- Produzir fluídos magnéticos a partir dos nanoanéis sintetizados e disponibilizalos para testes em Magnetohipertemia. 


\section{Referências Bibliográficas}

1. Ferreira, H. S.; Rangel, M. D., NANOTECHNOLOGY: GENERAL ASPECTS AND POTENTIAL APPLICATIONS IN CATALYSIS. Quimica Nova 2009, 32 (7), 1860-1870.

2. Foundation, N. S. Nanotechnology definition. http://www.nsf.gov/crssprgm/nano/reports/omb nifty50.jsp (accessed 17 de novembro).

3. JUNIOR, M. Â. S. Obtenção e caracterização de nanopartículas magnéticas inseridas em materiais carbonosos porosos a partir da decomposição do pentacarbonil ferro Universidade Federal do Espírito Santo Vitória, Espírtio Santo., 2009.

4. LesliePelecky, D. L.; Rieke, R. D., Magnetic properties of nanostructured materials. Chemistry of Materials 1996, 8 (8), 1770-1783.

5. $\quad$ Miranda-Vilela, A. L.; Peixoto, R. C. A.; Longo, J. P. F.; e Cintra, D. d. O. S.; Portilho, F. A.; Miranda, K. L. C.; Sartoratto, P. P. C.; Báo, S. N.; de Azevedo, R. B.; Lacava, Z. G. M., Dextran-Functionalized Magnetic Fluid Mediating Magnetohyperthermia Combined with Preventive Antioxidant Pequi-Oil Supplementation: Potential Use Against Cancer. Journal of Biomedica Nanotechnology 2013, pp 1261-1271.

6. Kumar, C. S. S. R.; Mohammad, F., Magnetic nanomaterials for hyperthermiabased therapy and controlled drug delivery. Advanced Drug Delivery Reviews 2011, 63 (9), 789-808.

7. Huang, C.; Tang, Z.; Zhou, Y.; Zhou, X.; Jin, Y.; Li, D.; Yang, Y.; Zhou, S., Magnetic micelles as a potential platform for dual targeted drug delivery in cancer therapy. International Journal of Pharmaceutics 2012, 429 (1-2), 113-122.

8. Kim, D.-H.; Rozhkova, E. A.; Ulasov, I. V.; Bader, S. D.; Rajh, T.; Lesniak, M. S.; Novosad, V., Biofunctionalized magnetic-vortex microdiscs for targeted cancer-cell destruction. Nature Materials 2010, 9 (2), 165-171.

9. Laurent, S.; Forge, D.; Port, M.; Roch, A.; Robic, C.; Elst, L. V.; Muller, R. N., Magnetic iron oxice nanoparticles: synthesis, stabilization, vectorization, physicochemical characterizations and biological applications. Chemical Review 2008, pp 2064-2110.

10. Fortin, J.-P.; Wilhelm, C.; Servais, J.; Menager, C.; Bacri, J.-C.; Gazeau, F., Size-sorted anionic iron oxide nanomagnets as colloidal mediators for magnetic hyperthermia. Journal of the American Chemical Society 2007, 129 (9), 2628-2635.

11. Shinio, T.; Okuno, T.; Hassdorf, R.; Shigeto, K.; Ono, T., Magnetic Vortex Core Observation in Circular Dots of Permaloy. Science 2000, pp 930-932.

12. Berry, C. C.; Curtis, A. S. G., Functionalisation of magnetic nanoparticles for applications in biomedicine. Journal of Physics D-Applied Physics 2003, 36 (13), R198R206.

13. Sinnecker, J. P., Revista Brasileira de Ensino de Física 2000, pp 396-405.

14. Kittel, C., Introduction to Solid State Physics. 2005.

15. Teles, L. K. Notas de Aula - FIS 32:Eletricidade e Magnetismo. http://www.fis.ita.br/fis32/notas/fis32-notas aula.pdf.

16. Santos, C. M. B. Efeito da Variação do Processo de Síntese nas Propriedades Estruturais de Nanopartículas de CoFe2O4. Universidade de Brasília, Brasília, 2008.

17. Ribeiro, G. A. P., As Propriedades Magnéticas da Matéria: um Primeiro Contato. Revista Brasileira de Ensino de Física 2000, pp 299-305. 
18. Knobel, M., Partículas Finas: Superparamagnetismo e Magnetoresistência Gigante. Revista Brasileira de Ensino de Física 2000, 22, 387-395.

19. Morris, R. V.; Golden, D. C.; Shelfer, T. D.; Lauer, H. V., Lepidocrocite to maghemite to hematite: A pathway to magnetic and hematitic Martian Soil. Meteoritics \& Planetary Science 1998, 33 (4), 743-751.

20. Vayssieres, L.; Beermann, N.; Lindquist, S. E.; Hagfeldt, A., Controlled aqueous chemical growth of oriented three-dimensional crystalline nanorod arrays: Application to iron(III) oxides. Chemistry of Materials 2001, 13 (2), 233-235.

21. Cornell, R. M.; Schwertmann, U., The Iron Oxides: Structure, Properties, Reactions, Occurrences and Uses. Wiley: 2003.

22. Oliveira, L. C. A.; Fabris, J. D.; Pereira, M. C., IRON OXIDES AND THEIR APPLICATIONS IN CATALYTIC PROCESSES: A REVIEW. Quimica Nova 2013, $36(1), 123-130$.

23. Tadic, M.; Citakovic, N.; Panjan, M.; Stojanovic, Z.; Markovic, D.; Spasojevic, V., Synthesis, morphology, microstructure and magnetic properties of hematite submicron particles. Journal of Alloys and Compounds 2011, 509 (28), 7639-7644.

24. Teja, A. S.; Koh, P.-Y., Synthesis, properties, and applications of magnetic iron oxide nanoparticles. Progress in Crystal Growth and Characterization of Materials 2009, 55 (1-2), 22-45; Machala, L.; Zboril, R.; Gedanken, A., Amorphous iron(III) Oxide - A review. Journal of Physical Chemistry B 2007, 111 (16), 4003-4018.

25. de Faria, D. L. A.; Venâncio Silva, S.; de Oliveira, M. T., Raman microspectroscopy of some iron oxides and oxyhydroxides. Journal of Raman Spectroscopy 1997, 28 (11), 873-878.

26. Bersani, D.; Lottici, P. P.; Montenero, A., Micro-Raman investigation of iron oxide films and powders produced by sol-gel syntheses. Journal of Raman Spectroscopy 1999, 30 (5), 355-360.

27. Kustova, G. N.; Burgina, E. B.; Sadykov, V. A.; Poryvaev, S. G., Vibrational spectroscopic investigation of the goethite thermal decomposition products. Physics and Chemistry of Minerals 18 (6), 379-382.

28. Moriya, T., Anisotropic Superexchange Interaction and Weak Ferromagnetism. Physical Review 1960, 120 (1), 91-98; Dzyaloshinsky, I., A thermodynamic theory of "weak" ferromagnetism of antiferromagnetics. Journal of Physics and Chemistry of Solids 1958, 4 (4), 241-255.

29. Morin, F. J., Magnetic Susceptibility of \$lensuremath $\left\{\right.$ alpha $\left\{\{\text { mathrm }\{\mathrm{Fe}\}\}_{-}\{2\}\{\backslash \text { mathrm }\{\mathrm{O}\}\}_{-}\{3\} \$\right.$ and \$lensuremath $\{\backslash$ alpha $\}\{\backslash$ mathrm $\{\mathrm{Fe}\}\}$ _ $\{2\}\{\backslash \text { mathrm }\{\mathrm{O}\}\}_{-}\{3\} \$$ with Added Titanium. Physical Review 1950, 78 (6), 819-820.

30. Hill, A. H.; Jiao, F.; Bruce, P. G.; Harrison, A.; Kockelmann, W.; Ritter, C., Neutron Diffraction Study of Mesoporous and Bulk Hematite, $\alpha-\mathrm{Fe} 2 \mathrm{O} 3$. Chemistry of Materials 2008, 20 (15), 4891-4899.

31. Machado, F. B.; Moreira, C. A.; Andre, A. C.; Godoy, A. M.; Ferreira, J. A.; Galembeck, T.; Nardy, A. J. R.; Artur, A. C.; Oliveira, M. A. F. d. Encicloédia Multimídia de Minerais [on-line]. http://www.rc.unesp.br/museudpm.

32. Verble, J. L., Temperature-dependent light-scattering studies of the Verwey transition and electronic disorder in magnetite. Physical Review B 1974, 9 (12), 52365248.

33. Magalhães, F. Síntese e Caracterização de Óxidos de Ferro e Compósitos para Aplicações no Tratamento Redox de Efluentes Aquosos. Universidade Federal de Minas Gerais, Belo Horizonte, Minas Gerais, 2008. 
34. White, W. B.; DeAngelis, B. A., Interpretation of the vibrational spectra of spinels. Spectrochimica Acta Part A: Molecular Spectroscopy 1967, 23 (4), 985-995.

35. Shebanova, O. N.; Lazor, P., Raman spectroscopic study of magnetite (FeFe2O4): a new assignment for the vibrational spectrum. Journal of Solid State Chemistry 2003, 174 (2), 424-430.

36. Graves, P. R.; Johnston, C.; Campaniello, J. J., Raman scattering in spinel structure ferrites. Materials Research Bulletin 1988, 23 (11), 1651-1660.

37. Fangohr

http://www.southampton.ac.uk/ fangohr/gallery/smalldiskwithvortex fuzzy.png.

38. Dias, C. S. B. Estudo de vórtice magnético em nanopartícula para aplicações em hipertermia magnética. Universidade Estadual de Campinas, 2014.

39. Dedavid, B. A.; Gomes, C. I.; Machado, G., Microscopia eletrônica de varredura: aplicações e preparação de amostras: materiais poliméricos, metálicos e semicondutores. EDIPUCRS: Porto Alegre, 2007; p 60.

40. Haddad, A. S. A.; Attias, M.; Farina, M.; Meirelles, M.; Silveira, M., Técnicas Básicas de Microscopia Eletrônica Aplicadas às Ciências Biológicas. Departamento de Editoração Eletrônica da Universidade Estadual do Norte Fluminense., 1998.

41. Mansur, H. S. Caracterização de Materiais e Interfaces. http://docplayer.com.br/3984094-Copyright-prof-dr-herman-s-mansur-2011-

caracterizacao-de-materiais-e-interfaces.html.

42. Farina, M., Fundamento de Microscopia Analítica para Biólogos. In Técnicas básicas de microscopia eletrônica aplicadas às ciências biológicas, Souza, W. d., Ed. Sociedade Brasileira de Microscopia: Rio de Janeiro, 1998; pp 161-177.

43. Galleti, S. R., Introdução a Microscopia Eletrônica. O Biológico 2003, pp 33-35.

44. Haddad, A. S., A.; Attias, M.; Farina, M.; Meirelles, M.; Silveira, M., Técnicas Básicas de Microscopia Eletrônica Aplicadas às Ciências Biológicas. Departamento de Editoração Eletrônica da Universidade Estadual do Norte Fluminense., 1998.

45. Félix, L. L. Síntese e caracterização de nanopartículas de Fe3O4 recobertas com ouro. Universidade de Brasília, 2013.

46. Marchi, E. C. S.; Castro, D. M. Revisão de Microscopia. http://www.if.ufrj.br/ micha/arquivos/apresentacoes/micgeral.PDF (accessed $18 \mathrm{de}$ dezembro).

47. Callister, W. D., Materials Science And Engineering: An Introduction. John Wiley \& Sons: 2007.

48. Melo, R. C. N., Células e Microscopia: princípios básicos e práticas. UFJF: Juiz de Fora, MG, 2002; p 144.

49. Teixeira, F. S. Microscopia Eletrônica de Varredura: Conceitos Básicos. http://fap.if.usp.br/ nandast/mev.html (accessed 21 de maio).

50. Salmeron, R. A. Raios X. http://efisica.if.usp.br/moderna/raios-x/raios-X/ (accessed 27 de novembro).

51. Eisberg, R.; Resnick, R., Física Quântica: Átomos, Moléculas, Sólidos. Núcleos e Partículas. Elsevier: Rio de Janeiro, 1979.

52. Kahn, H. Difração de Raios X. http://www.ciul.ul.pt/ luisa/PLDTR/DIFRACCAO.pdf (accessed 26 de novembro).

53. Cullity, B. D., Elements of X-ray diffraction. Addison-Wesley Publishing Company: Massachusetts, 1978.

54. JUNIOR, M. Â. S. Obtenção e caracterização de nanopartículas magnéticas inseridas em materiais carbonosos porosos a partir da decomposição do pentacarbonil ferro. Universidade Federal do Espírito Santo Vitória, Espírtio Santo., 2009. 
55. Rodrigues, F. Espectroscopia Raman de Líquidos Iônicos Imidazólicos: Interações Interiônicas, Organização Estrutural e Efeitos de Micro-Ambiente. Universidade de São Paulo, São Paulo, 2010.

56. Faria, D. L. A. d. Entenda o que é espectroscopia Raman. http://crq4.org.br/sms/files/file/Espectroscopia_Raman_4.pdf $\quad$ (accessed 24 de novembro).

57. Sala, O., Fundamentos de espectroscopia Raman e no infravermelho. 2.ed. ed.; UNESP: São Paulo, SP, 2008.

58. R. H, H., The Mössbauer Effect and Its Application in Chemistry. In The Mössbauer Effect and Its Application in Chemistry, AMERICAN CHEMICAL SOCIETY: 1967; Vol. 68, pp 1-20.

59. Muraoka, T. K.; Zutin, K.; Ananias, S. R.; Mauro, A. E.; Nogueira, V. M.; Rechenberg, H. R., Investigação por espectroscopia Mössbauer de compostos de ferro(0) contendo dissulfeto de carbono. Eclética Química 2004, pp 27-32.

60. Nascimento, C. K.; Oliveira, J. M.; Braga, J. P.; Fabris, J. D., Máxima absorção ressonante em espectroscopia Mössbauer. Revista Brasileira de Ensino de Física 2013, pp 4308-4314.

61. Drago, V. Uma Introdução à Espectroscopia Mössbauer para Químicos. http://moderna.paginas.ufsc.br/files/2012/12/MOSSBAUER.pdf $\quad$ (accessed 26 de novembro).

62. Campos, M. Investigação por Espectroscopia Mössbauer das fases formadas e sua influência na resistência à corrosão do aço inoxidável austenítico AISI 316L Nitretado. Universidade Federal de São Carlos, São Carlos, 2009.

63. Drago, V. Uma Introdução à Espectroscopia Mössbauer para Químicos. http://moderna.paginas.ufsc.br/files/2012/12/MOSSBAUER.pdf $\quad$ accessed 26 de novembro).

64. Dyar, M. D.; Agresti, D. G.; Schaefer, M. W.; Grant, C. A.; Sklute, E. C., Mossbauer Spectroscopy of Earth and Planetary Materials. Annual Review of Earth and Planetary Sciences 2006, pp 83-125.

65. Mathew, D. S.; Juang, R. S., An overview of the structure and magnetism of spinel ferritenanoparticles and their synthesis in microemulsions. Chemical Engineering Journal 2007, pp 51-65.

66. Letti, C. J. Estudo de Nanocompósitos formados por partícula de óxidos de ferro e polímeros por meio da Espectroscopia Raman. Universidade de Brasília, 2013.

67. Mundim, K. C. Histerese Magnética. (accessed 20 de Janeiro de 2016).

68. Liang, H. F.; Jiang, X. D.; Chen, W.; Wang, S. Q.; Xu, B. B.; Wang, Z. C., alpha-Fe2O3/Pt hybrid nanorings and their enhanced photocatalytic activities. Ceramics International 2014, 40 (4), 5653-5658.

69. Lv, B.; Xu, Y.; Gao, Q.; Wu, D.; Sun, Y., Controllable Synthesis and Magnetism of Iron Oxides Nanorings. Journal of Nanoscience and Nanotechnology 2010, 10 (4), 2348-2359.

70. Larson, A. C.; Dreele, R. B. V. General Structure Analysis System (GSAS); Los Alamos National Laboratory: 2000.

71. Toby, B. H., EXPGUI, a graphical user interface for GSAS. Journal of Applied Crystallography 2001, 34 (2), 210-213.

72. Finger, L. W.; Cox, D. E.; Jephcoat, A. P., A correction for powder diffraction peak asymmetry due to axial divergence. Journal of Applied Crystallography 1994, 27 (6), 892-900. 
73. Fondell, M.; Johansson, F.; Gorgoi, M.; von Fieandt, L.; Boman, M.; Lindblad, A., Phase control of iron oxides grown in nano-scale structures on FTO and $\mathrm{Si}(100)$ : Hematite, maghemite and magnetite. Vacuum 2015, 117, 85-90.

74. Gotic, M.; Drazic, G.; Music, S., Hydrothermal synthesis of alpha-Fe2O3 nanorings with the help of divalent metal cations, $\mathrm{Mn} 2+, \mathrm{Cu} 2+, \mathrm{Zn} 2+$ and $\mathrm{Ni} 2+$. Journal of Molecular Structure 2011, 993 (1-3), 167-176.

75. Goya, G. F.; Veith, M.; Rapalavicuite, R.; Shen, H.; Mathur, S., Thermal hysteresis of spin reorientation at Morin transition in alkoxide derived hematite nanoparticles. Applied Physics A 2004, 80 (7), 1523-1526.

76. Nunes, E. d. S.; Viali, W. R.; da Silva, S. W.; Coaquira, J. A. H.; Garg, V. K.; de Oliveira, A. C.; Morais, P. C.; Jafelicci Júnior, M., Characterization of tetraethylene glycol passivated iron nanoparticles. Applied Surface Science 2014, 315, 337-345.

77. Evans, B. J.; Hafner, S. S., 57Fe Hyperfine Fields in Magnetite (Fe3O4). Journal of Applied Physics 1969, 40 (3), 1411-1413.

78. Yang, J. B.; Zhou, X. D.; Yelon, W. B.; James, W. J.; Cai, Q.; Gopalakrishnan, K. V.; Malik, S. K.; Sun, X. C.; Nikles, D. E., Magnetic and structural studies of the Verwey transition in Fe3-SO4 nanoparticles. Journal of Applied Physics 2004, 95 (11), 7540-7542.

79. Tao, B.; Zhang, Q.; Liu, Z. Z.; Geng, B. Y., Cooperative effect of $\mathrm{pH}$ value and anions on single-crystalline hexagonal and circular alpha-Fe2O3 nanorings. Materials Chemistry and Physics 2012, 136 (2-3), 604-612.

80. Gupta, R. K.; Ghosh, K.; Dong, L.; Kahol, P. K., Structural and magnetic properties of phase controlled iron oxide rods. Materials Letters 2011, 65 (2), 225-228.

81. Kim, C. H.; Chun, H. J.; Kim, D. S.; Kim, S. Y.; Park, J.; Moon, J. Y.; Lee, G.; Yoon, J.; Jo, Y.; Jung, M.-H.; Jung, S. I.; Lee, C. J., Magnetic anisotropy of vertically aligned $\alpha-\mathrm{Fe} 2 \mathrm{O} 3$ nanowire array. Applied Physics Letters 2006, 89 (22), 223103.

82. Zysler, R. D.; Fiorani, D.; Testa, A. M.; Suber, L.; Agostinelli, E.; Godinho, M., Size dependence of the spin-flop transition in hematite nanoparticles. Physical Review $B$ 2003, 68 (21), 212408.

83. Jia, C. J.; Sun, L. D.; Luo, F.; Han, X. D.; Heyderman, L. J.; Yan, Z. G.; Yan, C. H.; Zheng, K.; Zhang, Z.; Takano, M.; Hayashi, N.; Eltschka, M.; Klaui, M.; Rudiger, U.; Kasama, T.; Cervera-Gontard, L.; Dunin-Borkowski, R. E.; Tzvetkov, G.; Raabe, J., Large-Scale Synthesis of Single-Crystalline Iron Oxide Magnetic Nanorings. Journal of the American Chemical Society 2008, 130 (50), 16968-16977.

84. Tang, J.; Wang, K.-Y.; Zhou, W., Magnetic properties of nanocrystalline Fe3O4 films. Journal of Applied Physics 2001, 89 (11), 7690-7692.

85. Andreev, S. V.; Bartashevich, M. I.; Pushkarsky, V. I.; Maltsev, V. N.; Pamyatnykh, L. A.; Tarasov, E. N.; Kudrevatykh, N. V.; Goto, T., Law of approach to saturation in highly anisotropic ferromagnets Application to $\mathrm{Nd} \cdot \mathrm{Fe} \cdot \mathrm{B}$ melt-spun ribbons. Journal of Alloys and Compounds 1997, 260 (1-2), 196-200; VázquezVázquez, C.; López-Quintela, M. A.; Buján-Núñez, M. C.; Rivas, J., Finite size and surface effects on the magnetic properties of cobalt ferrite nanoparticles. Journal of Nanoparticle Research 2010, 13 (4), 1663-1676.

86. Cullity, B. D.; D, G. C., Introduction to magnetic materials. 2nd ed. ed.; IEEE Press, John Wiley \& Sons: Hoboken, New Jersey, 2009.

87. Aragón, R., Cubic magnetic anisotropy of nonstoichiometric magnetite. Physical Review B 1992, 46 (9), 5334-5338. 